\title{
A Conspicuous Clay Ovoid in Nakhla: Evidence for Subsurface Hydrothermal Alteration on Mars with Implications for Astrobiology
}

\author{
Elias Chatzitheodoridis, Sarah Haigh, ${ }^{2}$ and Ian Lyon ${ }^{3}$
}

\begin{abstract}
A conspicuous biomorphic ovoid structure has been discovered in the Nakhla martian meteorite, made of nanocrystalline iron-rich saponitic clay and amorphous material. The ovoid is indigenous to Nakhla and occurs within a late-formed amorphous mesostasis region of rhyolitic composition that is interstitial to two clinopyroxene grains with Al-rich rims, and contains acicular apatite crystals, olivine, sulfides, Ti-rich magnetite, and a new mineral of the rhoenite group. To infer the origin of the ovoid, a large set of analytical tools was employed, including scanning electron microscopy and backscattered electron imaging, wavelength-dispersive X-ray analysis, X-ray mapping, Raman spectroscopy, time-of-flight secondary ion mass spectrometry analysis, high-resolution transmission electron microscope imaging, and atomic force microscope topographic mapping. The concentric wall of the ovoid surrounds an originally hollow volume and exhibits internal layering of contrasting nanotextures but uniform chemical composition, and likely inherited its overall shape from a preexisting vesicle in the mesostasis glass. A final fibrous layer of Fe-rich phases blankets the interior surfaces of the ovoid wall structure. There is evidence that the parent rock of Nakhla has undergone a shock event from a nearby bolide impact that melted the rims of pyroxene and the interstitial matter and initiated an igneous hydrothermal system of rapidly cooling fluids, which were progressively mixed with fluids from the melted permafrost. Sharp temperature gradients were responsible for the crystallization of Al-rich clinopyroxene rims, rhoenite, acicular apatites, and the quenching of the mesostasis glass and the vesicle. During the formation of the ovoid structure, episodic fluid infiltration events resulted in the precipitation of saponite rinds around the vesicle walls, altered pyrrhotite to marcasite, and then isolated the ovoid wall structure from the rest of the system by depositing a layer of iron oxides/hydroxides. Carbonates, halite, and sulfates were deposited last within interstitial spaces and along fractures. Among three plausible competing hypotheses here, this particular abiotic scenario is considered to be the most reasonable explanation for the formation of the ovoid structure in Nakhla, and although compelling evidence for a biotic origin is lacking, it is evident that the martian subsurface contains niche environments where life could develop. Key Words: Biomorph-Clays-Search for life (biosignatures)—Martian meteorites-Hydrothermal systems. Astrobiology 14, 651-693.
\end{abstract}

\section{Introduction}

$\mathbf{O}$ VER THE LAST several decades, the composition, morphology, and history of the martian surface have been characterized to a large extent at both the macro- and mesoscopic scales. Remote sensing of the martian surface by orbiting spacecraft and in situ investigations conducted by landers and rovers has contributed to these investigations and improved our understanding of the planet (e.g., Bibring et al., 2006, 2007; Bish et al., 2013; Blake et al., 2013). The first major aim was to discover evidence of past or present water on the surface of Mars and then, more importantly, to search for the presence of life. Water has already been detected on Mars (Bibring et al., 2004; Arvidson et al., 2005; Bellucci et al., 2007), and there is strong evidence that liquid water was a major component of the martian surface in the past

\footnotetext{
${ }^{1}$ Department of Geological Sciences, School of Mining and Metallurgical Engineering, National Technical University of Athens, Athens, Greece.

${ }^{2}$ School of Materials, The University of Manchester, Manchester, UK.

${ }^{3}$ School of Earth, Atmospheric and Environmental Sciences, The University of Manchester, Manchester, UK.
} 
(e.g., Malin and Edgett, 2003; Perron et al., 2007; Dohm et al., 2009). Direct evidence of water has also recently been detected by the Phoenix lander (Smith et al., 2009) in the form of permafrost, as also reported earlier by Boynton et al. (2002) based on evidence from remote sensing studies. Fluvial conglomerates have also been identified in Gale Crater with the Mast Camera (Mastcam) of the Mars Science Laboratory (MSL) Curiosity rover, indicating that extended aqueous flows once took place on the surface of the planet in that region (Williams et al., 2013). Furthermore, the Sample Analysis at Mars (SAM) instrument on board the MSL Curiosity rover recently measured significant quantities (1.53 wt \%) of an $\mathrm{H}_{2} \mathrm{O}$ component released from the amorphous fines of the Rocknest eolian deposit of Gale Crater (Leshin et al., 2013), among other volatiles such as $\mathrm{CO}_{2}, \mathrm{SO}_{2}$, and $\mathrm{O}_{2}$.

The abundance and distribution of water on the martian surface throughout its history has also been inferred from the mapping of phyllosilicates (Bibring et al., 2005; Poulet et al., 2005, 2008a, 2008b; Loizeau et al., 2007; Bishop et al., 2008; Combe et al., 2008; Ehlmann et al., 2008a, 2009; Mustard et al., 2008; Marzo et al., 2009; Wray et al., 2009a, 2009b; Carter et al., 2010; Fairén et al., 2010); serpentines (Ehlmann et al., 2010); opaline silica-rich deposits (Bandfield, 2008; Milliken et al., 2008; Squyres et al., 2008; Rice et al., 2010), such as the recent discovery of extensive hydrated and poorly crystalline silica materials in the western Hellas Basin (Bandfield et al., 2013); carbonates (Ehlmann et al., 2008b; Boynton et al., 2009; Michalski and Niles, 2010; Morris et al., 2010); and other minerals characteristic of evaporites, such as sulfates (Gendrin et al., 2005; Langevin et al., 2005; Fishbaugh et al., 2007; Mangold et al., 2008). Clay minerals are found almost exclusively in Noachian and early Hesperian terrains and are exposed to our view due to cratering in ejecta or within gullies found on the interior slopes of the crater walls, and in some cases within the sediments of craters (Wray et al., 2009a). The presence of clay minerals has also been detected in crustal outcrops of the northern plains of Mars, demonstrating the presence of water in both hemispheres (Carter et al., 2010). In one particular instance-in a paleolake system within Jezero Crater-the clays are reported to be smectite-rich, although these materials (along with coexisting iron oxides or hydroxides) are considered to be allochthonous sediments (Ehlmann et al., 2008a). Furthermore, clay minerals (particularly trioctahedral smectites) have now been detected in martian sedimentary rocks at Yellowknife Bay (Gale Crater) by the MSL Curiosity rover (Vaniman et al., 2014), and a significant component of amorphous material has been identified in Gale Crater (Bish et al., 2013; Blake et al., 2013; Meslin et al., 2013). Consequently, the potential for discovering that clay minerals might also have been widespread in the subsurface of early Mars (Ehlmann et al., 2011) is now higher, and this is important from the standpoint of understanding subsurface/ subaqueous processes on Mars and providing clues to the origin of such clays.

Overall, the clay minerals detected in the martian sediments mentioned in the previous paragraph are primarily $\mathrm{Fe}$ Mg-rich chlorites, although other clay minerals may also be present, such as Fe-Mg smectites, vermiculites, mixed clays, and in rare instances aluminum phyllosilicates. Extended associations of phyllosilicates and evaporitic minerals, such as chlorides and sulfates, were also documented by Wray et al. (2009a), which suggests that localized and complex hydrous environments were involved in the formation of diverse mineral suites, which were ultimately linked with variations in water/rock ratios, salinity, $\mathrm{pH}$ conditions, and temperatures. Clay minerals have also been found to occur with carbonate minerals at Nili Fossae, based on remote sensing data (Brown et al., 2010), and possibly within fluviallacustrine sediments at the Spirit landing site near Gusev Crater (Carter and Poulet, 2012), all of which has helped to advance our understanding of the history of water on Mars and consider the possibility of locating ancient habitable environments that could have supported microbial life.

Methane in the martian atmosphere can provide another indirect indicator of the presence of water in the martian subsurface because this gas can be produced during serpentinization reactions that involve water (Mumma et al., 2009). Evidentially, methane has been detected in the martian atmosphere at scattered locations on Mars (Formisano et al., 2004; Krasnopolsky et al., 2004), although disputes over this finding do exist (Zahnle et al., 2011). More recently, the MSL Curiosity rover on the martian surface did not detect methane (Webster et al., 2013).

It is therefore evident that remote sensing observations made by orbiting spacecraft and the scientific instruments on robotic landers and rovers have already provided strong evidence of secondary alteration processes on the martian surface, which suggests that habitable environments may once have existed on Mars in its distant past or possibly even today. Some of the most compelling evidence for this is provided by the occurrence of clay minerals.

Clays constitute an important mineral group of which the formation conditions give significant clues not only to the presence of water, since clays are hydrous minerals, but also to the source, type, and volume of fluids, in addition to the timescales involved and the conditions of primary mineral alteration. Even more important (and relevant to Mars astrobiology) is the notion that clay minerals may also provide clues that pertain to some of the geological processes that are potentially associated with biological activity (Banfield et al., 2001; Orofino et al., 2010), ultimately facilitating the search for both textural and chemical biosignatures (McKay et al., 1996, 2009; Gibson et al., 2001).

As highlighted above, clay minerals on Mars are primarily associated with the oldest geological terrains, which formed in the Noachian era $(>3.82 \mathrm{Ga}$ ) (Bibring et al., 2006) when neutral-to-alkaline conditions most likely persisted on the planet and the primary basaltic crust was weathered by existing liquid water. After a period of surface volcanic activity, Mars appears to have entered an acidic aqueous alteration phase in the Hesperian era that left behind sulfate minerals. According to a reinterpretation of Mars Exploration Rover mission results, acidic aqueous alteration continued until much later into the Amazonian period of martian history, although only at local scales (Fairén et al., 2009) and probably due to hydrous magmatism as suggested by the high water content of Chassigny (McCubbin et al., 2010). Most of the Amazonian period was characterized by oxidation that formed oxide minerals of iron. Until recently, certain key mineral groups were not seen on the surface of Mars in close association with one another, but now we know that sulfates and ferric oxides (Bibring et al., 2007), sulfates and clay 
minerals (Wray et al., 2009a), and finally clay minerals and carbonates (Brown et al., 2010; Carter and Poulet, 2012) do coexist, probably very locally but nevertheless indicating an associated origin. Some of these mineral associations have now also been documented at Yellowknife Bay (Gale Crater) by the MSL Curiosity rover, which has detected (along with the above-mentioned smectites) Ca sulfates, Fe oxides/ hydroxides, and Fe sulfides within sedimentary materials from that site (Vaniman et al., 2014).

It is evident that the surface and subsurface conditions on Mars have changed through time, and minerals record this history. Unraveling the details of these geological events cannot be done by remote sensing alone and will require hands-on studies of the nature, distribution, and origin of these minerals that occur at, or near, the surface of Mars. Definitive mineralogical investigations of the martian surface are currently being conducted with the Chemistry and Mineralogy (CheMin) X-ray diffraction instrument on the MSL Curiosity rover (Bish et al., 2013; Blake et al., 2013; Vaniman et al., 2014), but until deep drilling and preferably a Mars sample return mission takes place, quantitative mineralogical studies of the martian subsurface can only be provided by martian meteorites (McSween and Treiman, 1998; Treiman, 2005). Martian meteorites are rocks that were ejected from the surface of Mars through large impacts, which subsequently fell to Earth after a journey through interplanetary space. All presently known examples of martian meteorites are igneous rocks, but they also contain secondary minerals that formed by the alteration of the primary igneous minerals by reaction with the hydrosphere and atmosphere of Mars. Here, we study one such meteorite (Nakhla), which belongs to a larger subgroup of other martian meteorites called nakhlites (Treiman, 2005) and contains new evidence for martian clay minerals.

Nakhla is classified as a cumulus clinopyroxenite that crystallized at about 1.3-1.4 Ga (Ganapathy and Anders, 1969; Cassata et al., 2010; Korochantseva et al., 2011) as part of a differentiated shallow intrusion (Lentz et al., 1999). A first shock event occurred at $913 \pm 9 \mathrm{Ma}$, which resulted in a brief and localized heating of Nakhla at temperatures above the melting point of pyroxene in isolated locations (Cassata et al., 2010). The secondary aqueous alteration that affected Nakhla is estimated to have taken place on Mars at about $620 \mathrm{Ma}$ (Treiman, 2005, and references therein). Similar ages are also reported for iddingsite in the Lafayette nakhlite (Swindle et al., 2000). This alteration probably occurred rapidly, due to circulation through the Nakhla parent rock of low-temperature hydrothermal fluids, which probably originated from the melted permafrost. Hydrothermal circulation was initiated by the impact of a meteor that opened a crater at least $\sim 2 \mathrm{~km}$ in diameter (Changela and Bridges, 2011). Nakhla is thought to have been situated at a very shallow depth of about $10-20 \mathrm{~m}$ from the martian surface (Lentz et al., 1999) and, therefore, more likely to have been exposed to surface alteration. Between 10 and $11 \mathrm{Ma}$, a second impact event ejected Nakhla from the martian surface (Ganapathy and Anders, 1969; Eugster et al., 2002), after which it traveled through space and fell to Earth in 1911 at a location situated in northern Egypt, where it was immediately collected (Bunch and Reid, 1975; Reid and Bunch, 1975). Consequently, Nakhla contains minimal terrestrial contamination (Bridges and Grady, 1999; Jull et al., 2000); therefore, almost all the observed alteration in this rock took place on Mars.

Further evidence for a past wet history of Mars came with the discovery of evaporitic mineral assemblages in Nakhla, such as sulfates, halides, and carbonates (Chatzitheodoridis and Turner, 1990; Gooding et al., 1991; Bridges and Grady, 1999, 2000; Bailey et al., 2003), along with isotopic evidence that suggests a low temperature of formation for these minerals (Grady et al., 1994, for the ALH84001 carbonates; Leshin et al., 1996; Saxton et al., 2000, for Nakhla carbonates) and the involvement of near-surface processes on Mars (Bridges et al., 2001). The formation of these evaporitic mineral assemblages in Nakhla is directly related to the formation of clays, iron oxides, and oxyhydroxides. In addition, all these mineral phases exhibit a close spatial association with amorphous silica gel-mostly present in the mesostasis of Nakhla-which, collectively, is interpreted as evidence for a hydrothermal alteration event involving diluted brines (Schwenzer and Bridges, 2011), followed by rapid cooling (Bridges and Hicks, 2011) that resulted in the precipitation of semi-crystallized clay minerals bearing a similar chemical composition to the amorphous silica gel. At higher spatial resolution, textural observations made from pristine Nakhla samples reveal very fine (nanometerscale) spatial relationships between fibrous sulfates and carbonates and the amorphous silica gel, collectively indicating that the fluids from which the silica gel was deposited had been injected into preexisting saline fluids (Tomkinson et al., 2011). In addition to evaporitic minerals, coherent carbonaceous structures are also observed in association with the amorphous silica gel and probably consist of a kerogen-like material as suggested by micro-Raman analyses (McKay et al., 2011).

It is evident that some of the alteration products of Nakhla hint at the possibility of subsurface ecological niches that may be found in the shallow subsurface of Mars, which could potentially have harbored microbial life. As such, the detailed chemical and structural investigations of Nakhla alteration in the present study are carried out with the aim to further our understanding of processes that may be pertinent to the astrobiological exploration of Mars (Gooding, 1992). In particular, we investigate here the nature and origin of an intriguing ovoid structure (identified in a thin section of the Nakhla meteorite: Fig. 1), which has a conspicuously biomorphic appearance and appears to be partly amorphous and partly composed of clay. This is the first documented case of an extensive clay occurrence in Nakhla, especially for a mesostasis area, and complements early studies in which a few clay crystallites were located in the so-called "rust" along cracks in olivine (e.g., Gooding et al., 1991), as well as more recent studies in which crystallites of clay in other nakhlites were identified but not within Nakhla itself (e.g., Changela and Bridges, 2011). The discovery of a new mineral of the rhoenite group is also reported here, along with evidence for the low-temperature alteration of pyrrhotite to marcasite within Nakhla. Clinopyroxene phenocrysts having distinctive Al-rich rims were also observed in this study, which could represent evidence of melting due to a bolide shock event prior to the formation of the ovoid structure. The discovery of the ovoid structure and its peculiar nanoscale textures, together with the new mineral phase of rhoenite and the Al-rich clinopyroxene, are what 

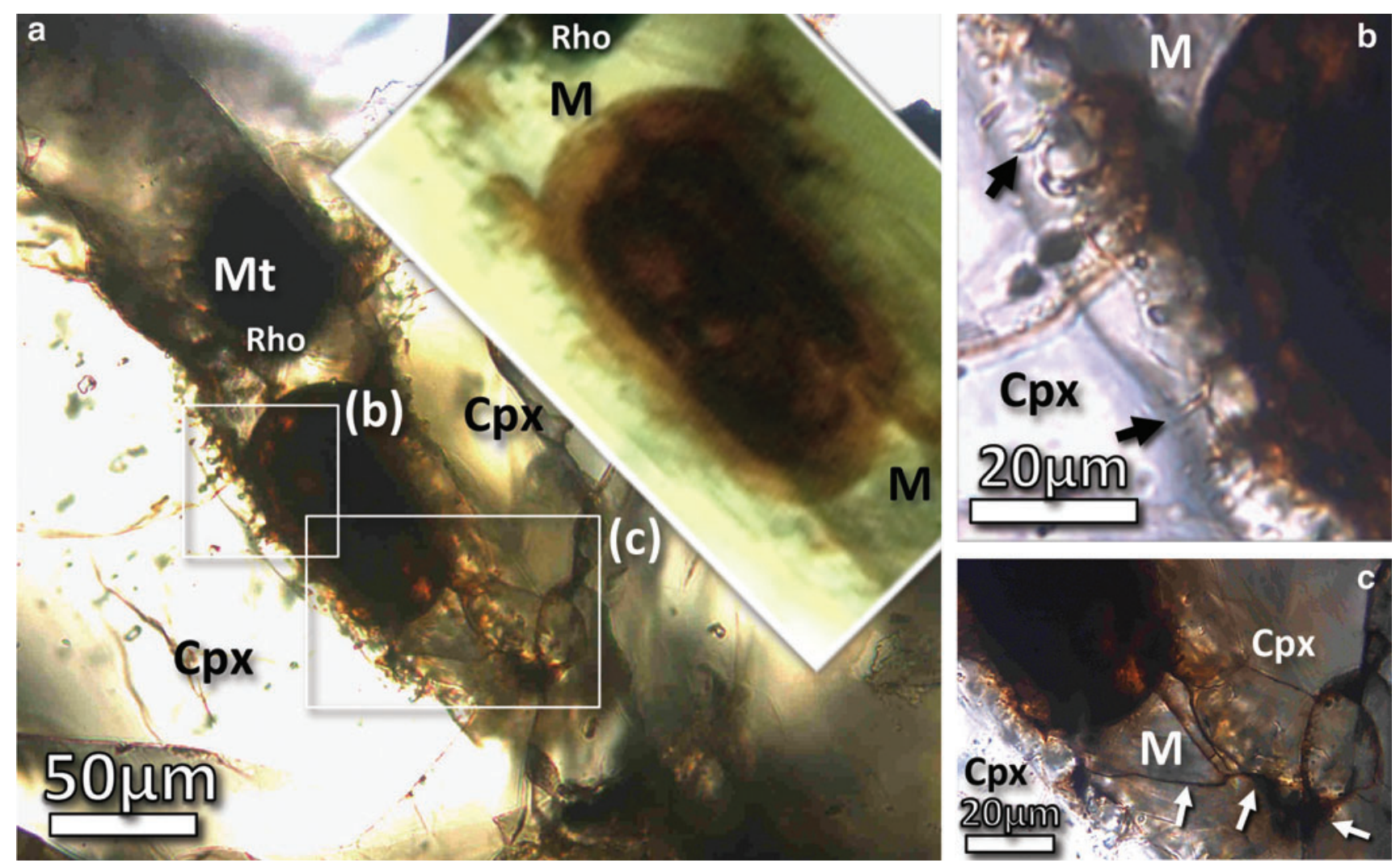

FIG. 1. Transmitted light photomicrographs taken in plane polarized light (uncrossed Nicols) of the ovoid structure in Nakhla, highlighting its petrographic context and its distinctive dark reddish-orange to brownish color (inset image is slightly magnified). (a) Overview photomicrograph. The ovoid structure is situated inside a small late-forming pocket of mesostasis materials that is interstitial to two clinopyroxene crystals (Cpx). In detail, the ovoid exhibits a sharp contact with the adjacent amorphous mesostasis phase [see $\mathrm{M}$ in inset and in (b) and (c)], which is identified as rhyolitic glass. The opaque phases are Ti magnetite (Mt) and rhoenite (Rho). (b, c) Close-up photomicrographs from (a). Black arrows in photomicrograph (b) indicate conspicuous, orange-stained microchannel features in clinopyroxene rims. White arrows in photomicrograph (c) indicate fractures in the mesostasis $M$ that are stained with iron oxide/hydroxide material (orange to yellow hues) and that extend up to the ovoid structure.

initiated this study, the aim of which was to provide important new insights into processes that initiated micro- and nanoscale alteration in the martian subsurface and to possibly uncover new clues to facilitate the search for past or present microbial life on Mars. The approach we have taken is a multiscale, multitechnique study of the ovoid structure and its chemical and mineralogical environment, using a variety of high spatial resolution instruments and analytical techniques, including scanning electron microscopy, transmission electron microscopy, backscattered electron imaging, wavelength-dispersive X-ray analysis, time-of-flight secondary ion mass spectrometry, Raman spectroscopy, and atomic force microscopy (see Section 2). We evaluate the origin of the ovoid structure in Nakhla from the standpoint of multiple competing hypotheses, considering several different abiotic scenarios, and also address questions on possible biogenic processes in void spaces within the parent rock of Nakhla. Since this is the first time that such a complicated ovoid structure has been discovered in a martian meteorite, it is expected that our findings will have significant implications for understanding the origin of similar structures that may be found during robotic or manned exploration of the planet Mars or other Solar System bodies.

\section{Materials, Methods, and Analytical Techniques}

\subsection{Sample description}

The clay ovoid structure investigated here was identified in a polished petrographic thin section of Nakhla that was prepared by the Natural History Museum of London from a rock chip sample with the identification number BM1911, 369, p.7963. During fabrication, the thin section was polished with $\mathrm{Al}_{2} \mathrm{O}_{3}$ powder from both sides and carefully prepared by using nonpolar solvents in an effort to reduce contamination or dissolution of any soluble material of the meteorite; this is similar to the preparation procedure described by Bridges and Grady (1999). Prior to electron microscopy, the surface of the thin section was carboncoated. This thin section of Nakhla is optically transparent but significantly thicker than the standard optimum thickness of $30 \mu \mathrm{m}$ that is typically used in petrographic studies of rock samples. The ovoid structure was first discovered by optical microscopy and initially identified on account of its conspicuous oval shape and distinct reddish hue when compared to the surrounding igneous material. Inside an associated clinopyroxene grain, a number of peculiar microchannel features were identified, often exceeding $5 \mu \mathrm{m}$ in length, which are also partly stained with orange-colored 
material (Fig. 1b). The ovoid structure is juxtaposed with igneous material that includes hydrous mesostasis glass of rhyolitic composition, which is locally stained with the same reddish hue along a few cracks (Fig. 1c). Both the ovoid structure and the mesostasis glass are located between two large clinopyroxene crystals (Figs. 1 and 2) that are distinguished from one another by going extinct at different angles when viewed under petrographic microscope with crossed polarizers.

The studied petrographic thin section of Nakhla is rich in clay alteration materials, hematite, and Fe-Mn carbonates. These minerals occur both in the mesostasis regions and along the distinctive orange-red-colored margins of olivine. A few sulfate crystals are also present, as well as a significantly larger number of halite crystals. Three large olivine crystals in this sample were found to contain several rounded melt inclusions, along with a variety of mineral inclusions and a network of cracks filled with serpentines, sulfates, halite, and carbonates. The main cores of the clinopyroxene crystals observed in this study are typical of Nakhla pyroxene grains with respect to their chemistry and texture, showing extensive internal chemical zonation and containing a large number of small glass melt inclusions. Several acicular apatite crystals were also identified in the mesostasis glass surrounding the ovoid structure and occur as highly elongate needles or with equant shapes often exhibiting a hollow skeletal form (marked as Ap in Fig. 2b).
FIG. 2. BSE SEM images of the surface of a polished thin section of Nakhla, highlighting the petrographic context of the ovoid structure, which is juxtaposed with two large clinopyroxene crystals and is also in contact with an amorphous mesostasis phase of a rhyolitic composition. (a) Overview BSE image. (b) Close-up image from (a), highlighting the ovoid structure and some of the surrounding phases. Abbreviations: Ap, apatite; Cpx, clinopyroxene, separated from the Al-rich Cpx with a dotted line; M, amorphous mesostasis phase (rhyolitic glass); Ol, olivine; Rho, rhoenite; $\mathrm{S}$, sulfide. The two fragments of clinopyroxene in the interior of the ovoid are interpreted as fragments of surrounding minerals incorporated into the ovoid during sample preparation. Points marked with stars indicate where electron microprobe WDX chemical analyses were made, and the corresponding data for these spot analyses are presented in Tables 1 and 2 .
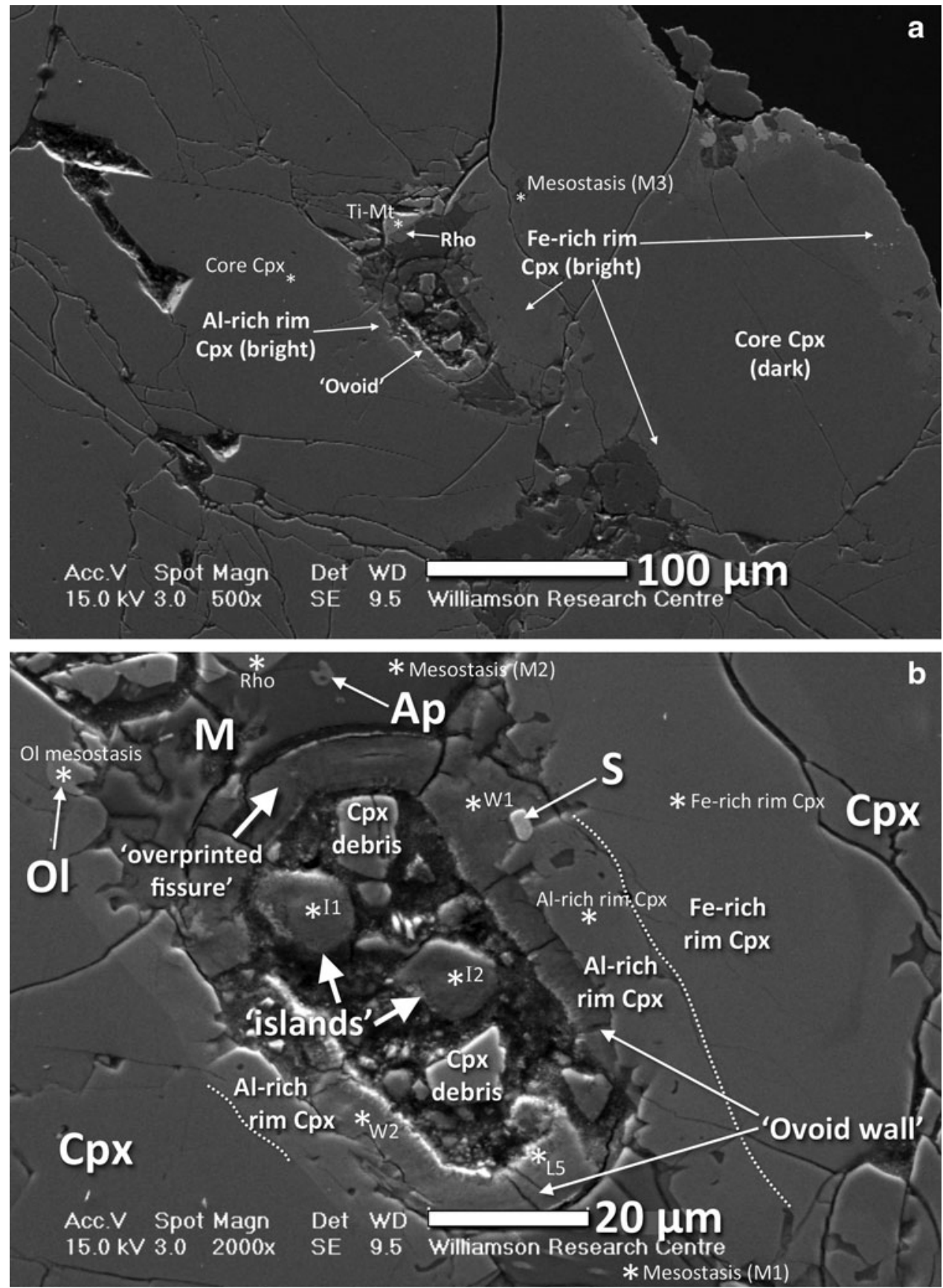


\subsection{Electron imaging and electron probe wavelength-dispersive $X$-ray analysis}

Backscattered electron (BSE) images were acquired with a Philips XL30 environmental field emission gun scanning electron microscope (SEM) equipped with an energydispersive X-ray (EDX) spectroscopy system that was used for preliminary (qualitative) chemical analysis. Quantitative chemical analysis and elemental mapping carried out in this study were performed with a Cameca SX100 electron microprobe equipped with five wavelength-dispersive X-ray (WDX) detectors, calibrated for silicates. Both of these instruments are part of the Williamson Research Centre at the University of Manchester. When analyzing silicate minerals, the beam size of the electron microprobe in typical operating conditions was $1 \mu \mathrm{m}$, with an accelerating voltage of $15 \mathrm{kV}$ and probe current of $20 \mathrm{nA}$. For the analysis of clay minerals and the amorphous mesostasis, this was deliberately defocused to $8 \mu \mathrm{m}$, and the probe current was reduced to $10 \mathrm{nA}$ to prevent beam damage of these materials. Some additional quantitative and qualitative investigations were conducted with a JEOL JSM-6380 LV SEM, equipped with an EDX system from Oxford Instruments, at the National Technical University of Athens. Prior to quantitative analyses, both instruments were calibrated with mineral reference standards.

\subsection{Transmission electron microscopy analysis}

To produce an electron-transparent specimen suitable for transmission electron microscopy analysis, a thin slice was extracted from the polished petrographic thin section of Nakhla by using a FEI Nova 200 dual focused ion beam (FIB) SEM system with a $\mathrm{Ga}^{+}$beam, at Glasgow University. Before ion milling, platinum $(\mathrm{Pt})$ was deposited onto the surface of the thin section to protect the area of interest. The slice was chosen to obtain a cross section passing through the wall of the ovoid structure. The slice had a length of about $10 \mu \mathrm{m}$, a depth of about $5 \mu \mathrm{m}$, and a thickness before final thinning of about $1 \mu \mathrm{m}$. After attaching this slice to an Omniprobe copper TEM grid by using Pt deposition, a further Pt layer was deposited on the bottom surface of the slice to enhance stability, and the sample was thinned further with low energy and reduced currents to achieve a polished surface with minimal detectable ion damage. The final sample thickness was estimated to be a relatively uniform $\sim 100 \mathrm{~nm}$ by energy-filtered transmission electron microscopy.

Preliminary transmission electron microscope (TEM) and high-resolution transmission electron microscope (HRTEM) images were taken at the Kelvin Nanocharacterization Centre, Glasgow University, with a FEI Tecnai F20 instrument, equipped with a field emission gun electron source and an acceleration voltage of $200 \mathrm{kV}$. Additional images were acquired in the School of Materials, University of Manchester, on a FEI Tecnai F30 with an accelerating voltage of $300 \mathrm{kV}$. Final TEM characterization and energyfiltered transmission electron microscope (EFTEM) imaging was performed at Liverpool University with a JEOL 2100FS at $200 \mathrm{kV}$ with a Gatan Quantum Imaging filter. A slit width of $15 \mathrm{eV}$ was used for zero-loss filtered imaging, and elemental mapping was performed by using the three-window technique and a slit width of between 15 and $60 \mathrm{eV}$. Complementary selected area electron diffraction (SAED) im- aging was performed both at Liverpool University with the JEOL 2100FS and at Manchester with the FEI Tecnai F30 and the use of selected area apertures with diameters of between $100 \mathrm{~nm}$ and $1 \mu \mathrm{m}$. To analyze the repeat distances present within our HRTEM data, the images were Fourier transformed in a standard manner (James, 2011). Regular lattice spacings in the images then appear as discrete spots or rings in the Fourier transforms produced.

\subsection{Time-of-flight secondary ion mass spectrometry analysis}

The time-of-flight secondary ion mass spectrometer (TOFSIMS) instrument used in this study is called IDLE, which was described by Henkel et al. (2006). The ion map manipulation and handling software used was the "spaceTOF" program (Chatzitheodoridis et al., 2005). During analysis, mass-resolved spectra were acquired from the sample by sputtering with a pulsed ${ }^{69} \mathrm{Ga}^{+}$primary ion beam of $25 \mathrm{kV}$ accelerating voltage. The beam size was smaller than $1 \mu \mathrm{m}$, defining the spatial resolution of the acquired ion maps. Prior to data collection, the surface of the sample was thoroughly cleaned by sputtering with a direct current primary ion beam in scanning mode. Subsequent positive and negative secondary ion spectra were acquired by using both low mass and high mass resolution (about 500 and 2500, respectively).

\subsection{Atomic force microscopy analysis}

A large set of atomic force microscope (AFM) images was acquired by a VECO instrument that was equipped with a scanning stage with three piezo-elements. Imaging was performed in tapping mode. The instrument is housed at the Williamson Research Centre, University of Manchester. New tips were used during AFM imaging of Nakhla in this study to ensure that the produced maps were free from analytical artifacts, minimizing the possibility that the edges of small nanocrystals or nanoparticles become smeared out during imaging.

\subsection{Raman spectroscopy}

The clay ovoid structure under investigation was originally discovered while examining the polished petrographic thin section of Nakhla with a high-magnification $(\times 100$ objective lens) optical microscope (Leica DMLM) attached to a Raman spectrometer (Renishaw Ramascope RM1000). Spectra were initially acquired from the ovoid with this Raman instrument (National Technical University of Athens) with a $632.8 \mathrm{~nm} \mathrm{He}-\mathrm{Ne}$ laser, but these preliminary spectra did not exhibit any characteristic peaks. The ovoid was then analyzed once again with a newer-generation inVia Raman instrument with a $457 \mathrm{~nm}$ green laser (installed on the premises of the manufacturing company of these instruments, called Renishaw) but once again yielded similar results. The lack of any characteristic Raman peaks from the area of the ovoid is probably due to the nanoscopic size of the crystals that make up the ovoid and/or its amorphous matrix. Nevertheless, we still present Raman spectra from some of the other mineral phases in the vicinity of the ovoid, which were taken with the aforementioned first instrument. The RM1000 is a confocal instrument. With the $\times 100$ objective lens of the optical microscope, a spot size smaller than $1.5 \mu \mathrm{m}$ 
can be achieved on the sample surface during Raman spectroscopic analysis. The beam intensity was set to $<5 \mathrm{~mW}$ of energy, attenuated with the use of neutral density optical filters. Furthermore, the entrance slit to the spectrometer was set to $50 \mu \mathrm{m}$, and a grating of 1800 lines $/ \mathrm{mm}$ analyzed the input signal into a spectrum that was then acquired by a Peltiercooled CCD camera in continuous scanning mode. The spectra provided are the accumulated scans of a few (5-10) individual measurements, each acquired from $10 \mathrm{~s}$ of integration time.

\section{Results}

\subsection{Morphological description of the ovoid structure}

The ovoid is a somewhat elliptically shaped hollow structure (now partly filled with polishing material and mineral polishing debris), with an overall size of about 80 $\mu \mathrm{m}$ long by about $60 \mu \mathrm{m}$ wide, that is characterized by very smooth and well-defined inner and outer surfaces (Figs. 1 and 2), defining a so-called wall or concentric shell com- posed of solid material that is distinctly orange-red in color when viewed in transmitted light (Fig. 1). It is situated within a narrow mesostasis area, composed of amorphous material (rhyolitic glass) that occurs at both ends of the ovoid (i.e., in contact with it), and also between the surfaces of two large clinopyroxene crystals (Fig. 2a) that directly border each side of the ovoid. The relatively large size of the ovoid, coupled with these observed textural relationships with surrounding material of igneous origin, ensure that this enigmatic structure originated on Mars.

The continuity of the ovoid concentric shell or wall is interrupted (i.e., crosscut) once by a symmetrical (hourglassshaped), now overprinted fissure (see overprinted fissure in Fig. 3b), while other more angular discontinuities are secondary fractures that might have been formed during sample preparation. The concentric wall that defines the main structure of the ovoid maintains a uniform thickness of about $8 \mu \mathrm{m}$ along the majority of its periphery (Fig. 2b). It is actually composed of multiple, texturally distinct layers observable by SEM (Figs. 3 and 4) and TEM (Fig. 5), which
FIG. 3. BSE SEM images of a part of the ovoid wall structure that is transected by a now infilled/overprinted fissure exhibiting a distinctive symmetrical hourglass shape. (a) Overview BSE image. (b) Close-up from (a), highlighting the ovoid wall and the now overprinted fissure that crosscuts it, which is now infilled with the fibrous layer L5. Also shown is the shrinkage gap that occurs between the amorphous mesostasis (rhyolitic glass) and the wall of the ovoid, the infilled hollow volume of the ovoid structure, and a clinopyroxene (Cpx) fragment. (c) Close-up from (a), highlighting some additional fractures/gaps (white arrows) present within the ovoid wall (and parallel to it) that seem to have formed due to mechanical stress, possibly due to the polishing process.

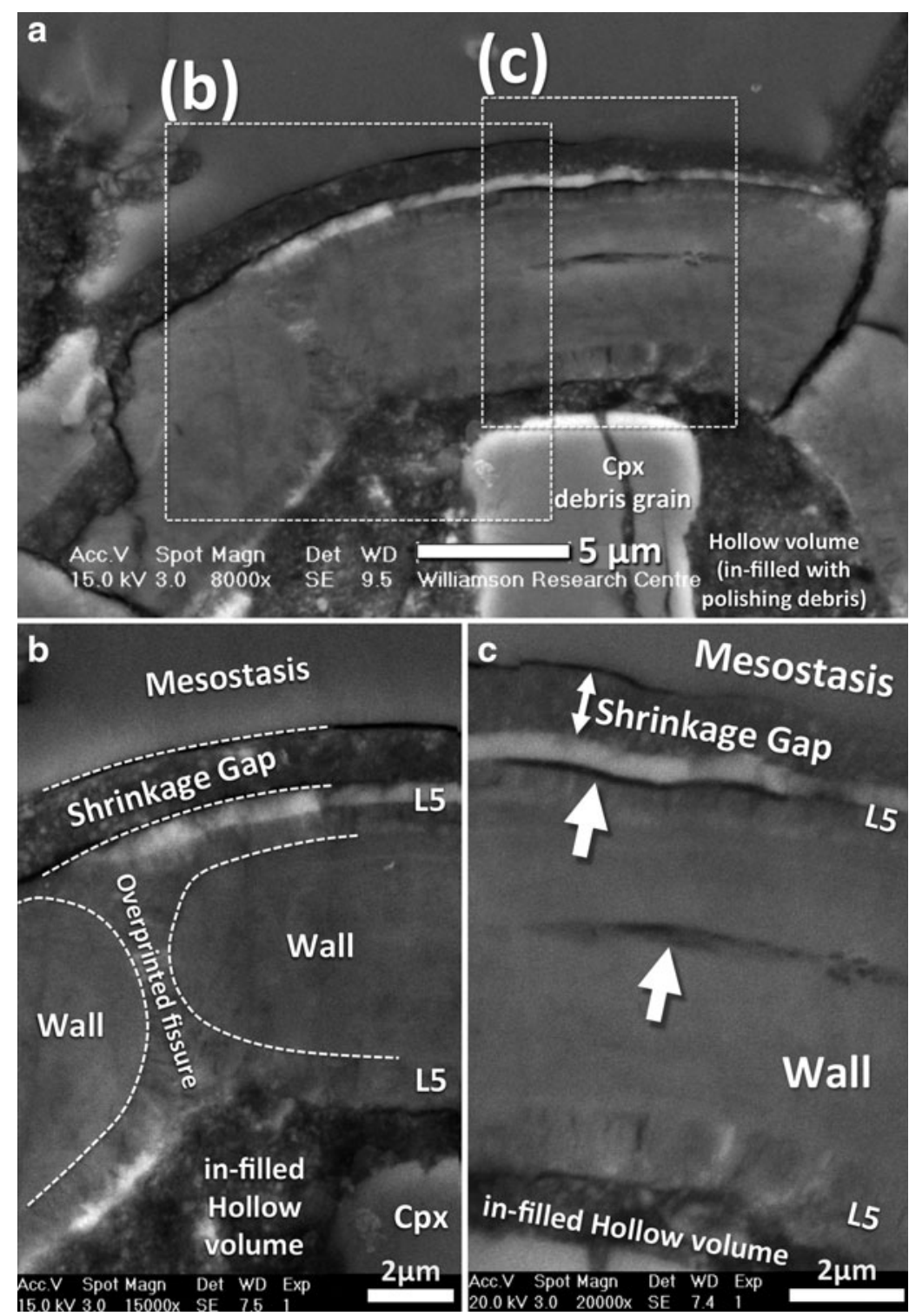



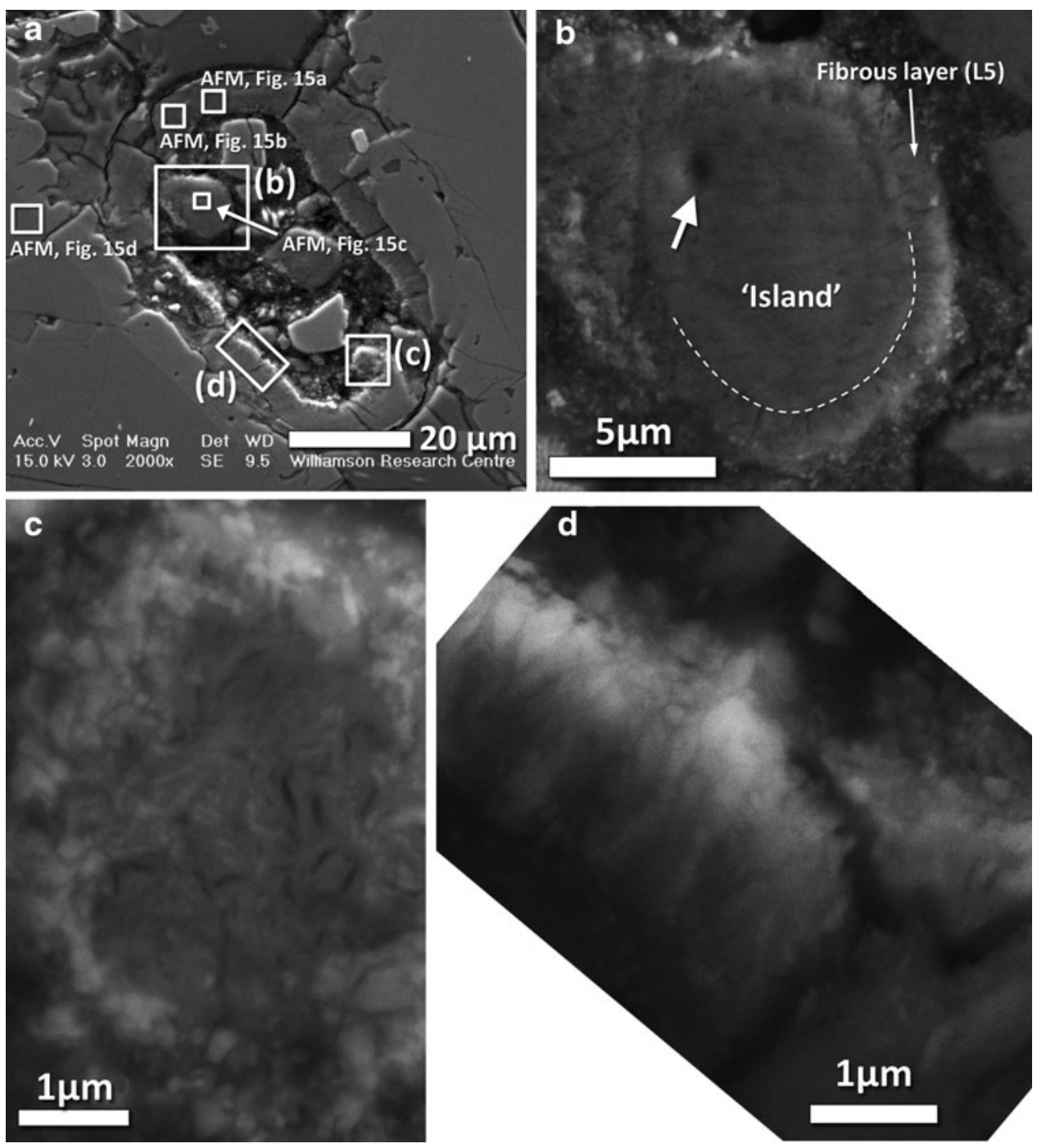

d
FIG. 4. High-resolution BSE SEM images of the interior of the ovoid structure, highlighting various structures that are coated in a thin layer of mottled fibrous material (corresponding to layer L5 discussed in the text). (a) Overview BSE image. The white squares labeled AFM highlight the areas where AFM topographic maps were acquired (see Fig. 15). (b) Close-up from (a), highlighting one of the islands, which is fully coated by a thin layer of fibrous material (L5) around its entire perimeter. The large white arrow points to an electron beam damage mark. (c) Close-up from (a), highlighting a round structure that has an internal microtexture similar to the mottled fibrous layer L5 shown in (d). (d) Close-up from (a), highlighting the distinctive internal microtexture present within a representative region of the mottled fibrous layer L5 where it coats the interior surface of the ovoid wall. are partly amorphous and partly crystalline. One layer is characteristically distinct, both texturally and chemically. It is iron-rich and composed of fibrous crystallites grown perpendicularly to the inner surface of the concentric shell.

In the originally hollow, internal area of the ovoid structure there are two circular masses (hereafter referred to as islands; see Fig. 2b), which are chemically and structurally similar to the material of the main concentric wall and thus interpreted to be part of the same overall structure. However, it is clear that several fragments of minerals in the hollow volume are debris that was introduced during polishing, the largest being two fragments of clinopyroxene that are easily recognized in the BSE images from their angular shape and higher brightness compared to the ovoid (Figs. $2 \mathrm{~b}$ and $3 \mathrm{a}$ ). Alumina polishing powder $\left(\mathrm{Al}_{2} \mathrm{O}_{3}\right)$ infills most of the remaining interstices of the hollow volume, as it is stuck in the resin that was used to glue the Nakhla sample onto the glass slide (Fig. 3a). This is better demonstrated in the TEM images (Figs. 5a and 11a) where the polishing debris (Fig. 5a) is observed as granular material over a volume of araldite (Fig. 5a). This clearly indicates that the polishing debris material is material introduced during the preparation of the thin section.
To describe this unusual ovoid structure in detail and investigate its significance, we employed a wide variety of scientific instruments ideally suited for in situ chemical and structural analysis and mapping at the submicron scale. Apart from the well-defined elliptical shape of the main structure of the ovoid, perhaps the most striking geometrical feature present is the symmetrical (i.e., hourglass-shaped) overprinted fissure that crosscuts the ovoid wall (Figs. 2b and $3 \mathrm{a}, 3 \mathrm{~b}$ ). This fissure is clearly visible in BSE images and transects the main wall structure orthogonally. At its narrowest point, the fissure tapers to about $1 \mu \mathrm{m}$ wide and is now entirely infilled by the fibrous layer (see overprinted fissure in Fig. 3b). This thin fibrous layer blankets the entire inner surface of the ovoid wall structure and also forms a thin layer that coats the periphery of the islands and continues outside the fissure covering part of the outer surface of the wall of the ovoid-with the internal fibrous fabric maintaining perpendicularity to all these various surfaces that it coats (Figs. 3 and 4b, 4d). Some of the fine internal details of these fibrous materials can be seen in high-resolution BSE images (Figs. 3 and 4), including close-ups of where this fibrous layer coats the inner wall of the ovoid (Figs. 3 and 4d), where it coats one of the round islands (Fig. 

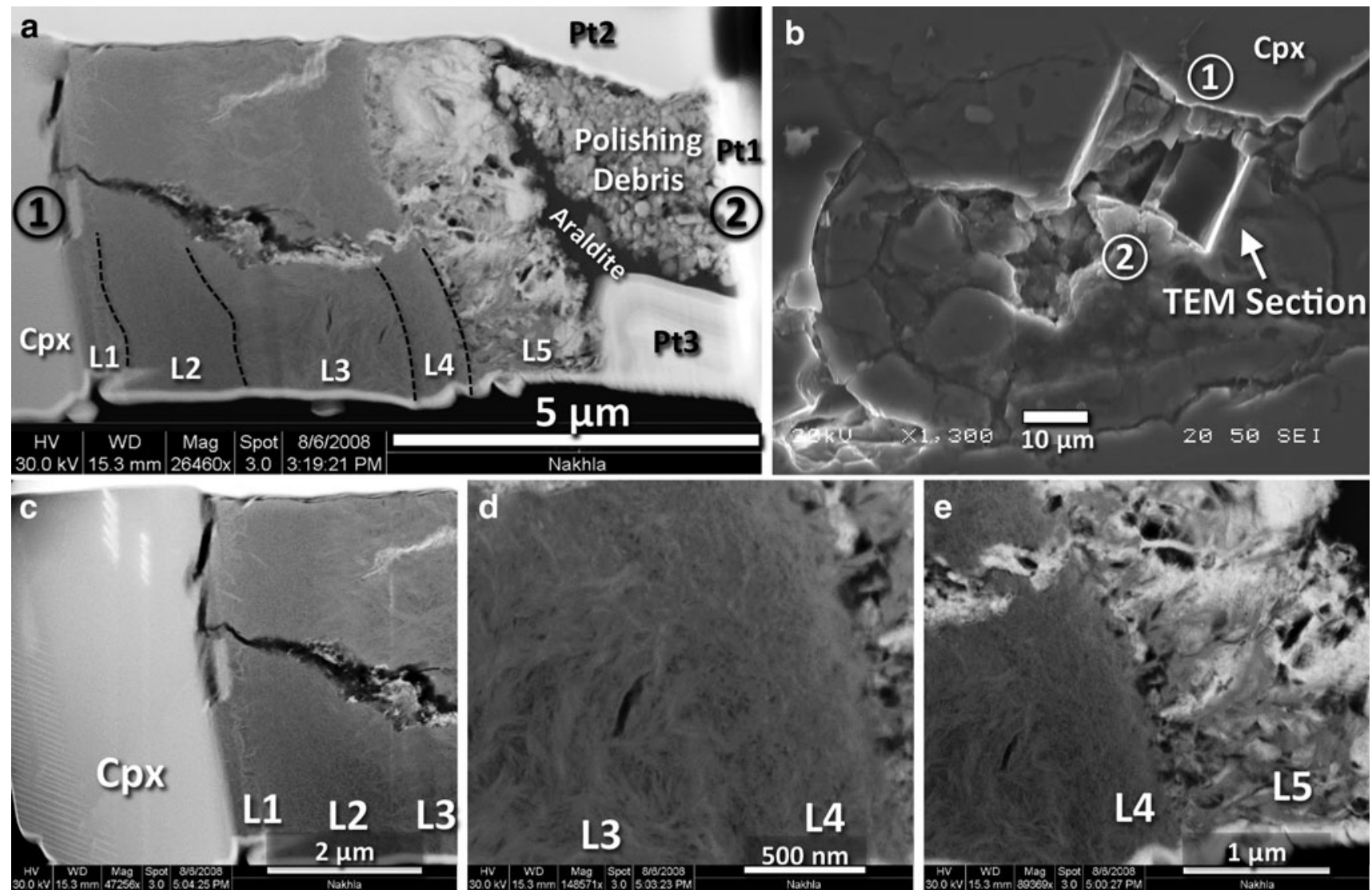

FIG. 5. SEM images highlighting the overall microstructure, textural features, and internal layering within the studied TEM slice, as well as its petrographic context in the ovoid structure from which it was extracted. (a) Overview BSE SEM image of the TEM slice removed from the wall of the ovoid structure using FIB milling. The granular textured region to the right is composed of material (labeled polishing debris) that was incorporated into the sample during sample preparation (i.e., fabrication of the petrographic thin section). (b) SEM secondary electron image of the FIB pit [section (1)-(2)], highlighting the petrographic context of the TEM slice extracted from within the ovoid wall (and its perpendicular crosssectional angle to the wall) from which it was extracted. (c-e) Close-up images from (a) highlighting the boundaries between the different phases and layers, starting with clinopyroxene (Cpx) on the left and progressing through layers L1, L2, L3, L4, and L5. The bright region on the right-hand side of (a) is the platinum metal capping layer (Pt1). Further Pt layers on either edge of the slice (Pt2 and Pt3) were deposited to provide stability to the thin sample slice and were added during FIB sample preparation. Black or very dark parts of these images, that is, in (a) and (c-e), represent vacuum or regions of low atomic mass, such as the araldite epoxy glue used in the preparation of the petrographic thin section.

$4 \mathrm{~b}$ ), and also where it coats a different type of rounded structure (Fig. 4c) that-in contrast-has an interior composed of fibrous crystalline material that exhibits more randomly oriented fabrics. Collectively, these high-resolution BSE images clearly demonstrate the presence of a chemically heterogeneous, fibrous layer that contains patches of an atomically heavy material (observed as relatively bright colors in the close-up BSE images). It is possible that this fibrous layer and the aforementioned round structure that shows internal fibrous fabrics (Fig. 4c) formed concomitantly, in one case as a thin veneer that blankets the ovoid wall (Figs. 3 and 4d) and islands (Fig. 4b), and in the other case as a colloform segregate (Fig. 4c).

The internal microstructure of the ovoid wall was investigated by HRTEM imaging of an electron-transparent cross section (Fig. 5a) that was extracted from the wall of the ovoid by FIB milling (Fig. 5b). From these images, a set of visually (i.e., texturally) distinct micron-scale layers has been defined (L1 to L5), which are highlighted in Fig. 5c-5e for clarity of discussion.

\subsection{Chemical analysis and Raman spectroscopy of nearby mineral phases}

The results of quantitative chemical analysis (by electron microprobe WDX) of the various mineral phases identified in the mesostasis area of the ovoid structure are reported in Table 1, and the petrographic context (spot locations) of each of these analyses is shown in Fig. 2. As highlighted above (in Section 3.1), the surrounding materials of igneous origin that host the ovoid structure include clinopyroxene (identified here as augite: i.e., Al-rich rim $\mathrm{Cpx}$, Fe-rich rim $\mathrm{Cpx}$, and core Cpx in Table 1, Fig. 2), as well as amorphous material (i.e., mesostasis glass) of rhyolitic composition (M1, M2, and M3 in Table 1, Fig. 2). Some additional minor phases include several acicular apatites (Ap; Fig. 2b), a few small olivine crystals (Ol; Table 1, Fig. 2b), a single small sulfide crystal (S; Fig. 2b), and Ti magnetite (Ti-Mt; Table 1, Fig. 2a) to which a rhoenite crystal is attached (Rho; Table 1, Fig. 2).

In addition, a set of color-coded chemical maps produced by electron microprobe X-ray mapping (WDX mode) gives 


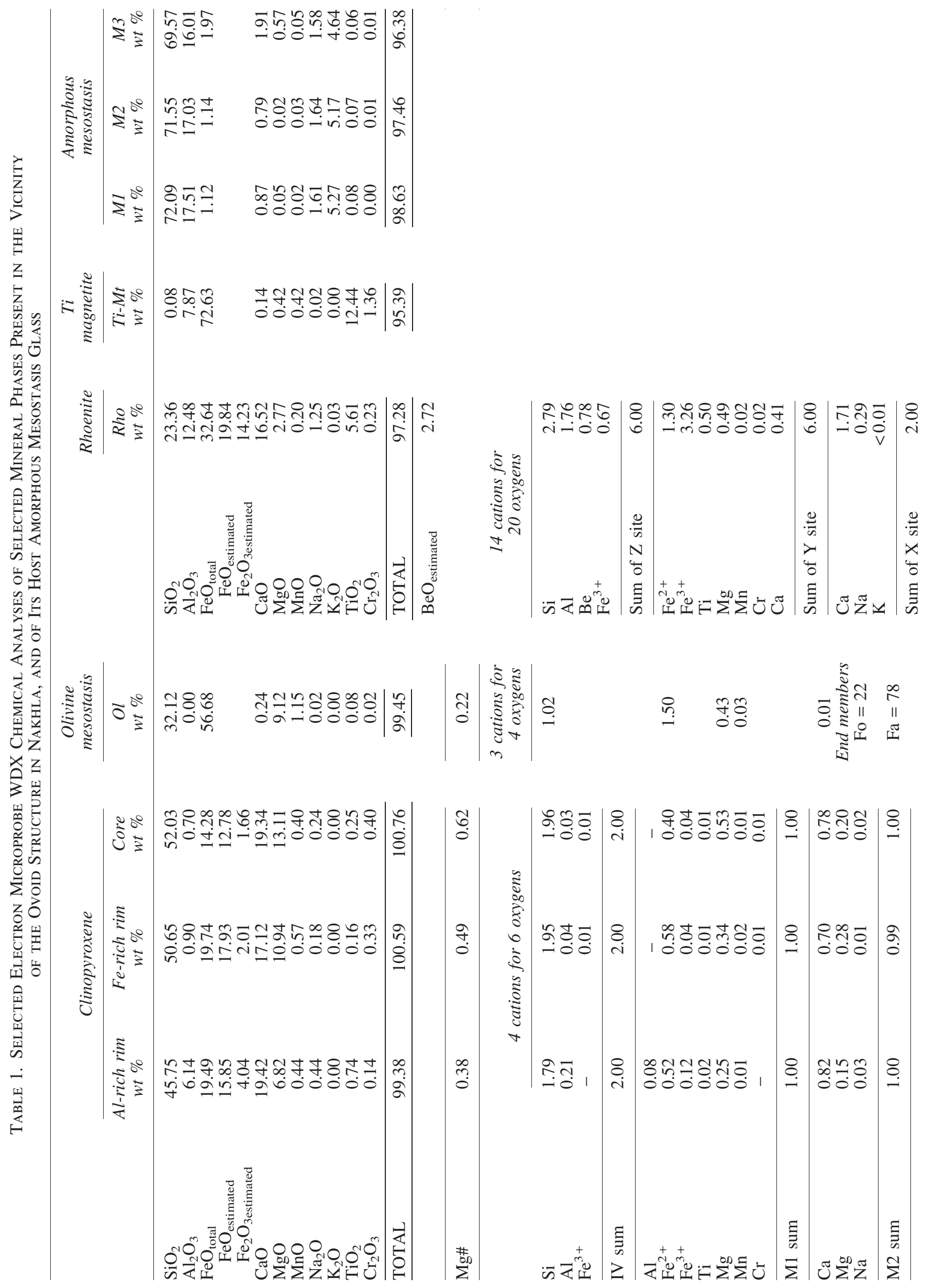



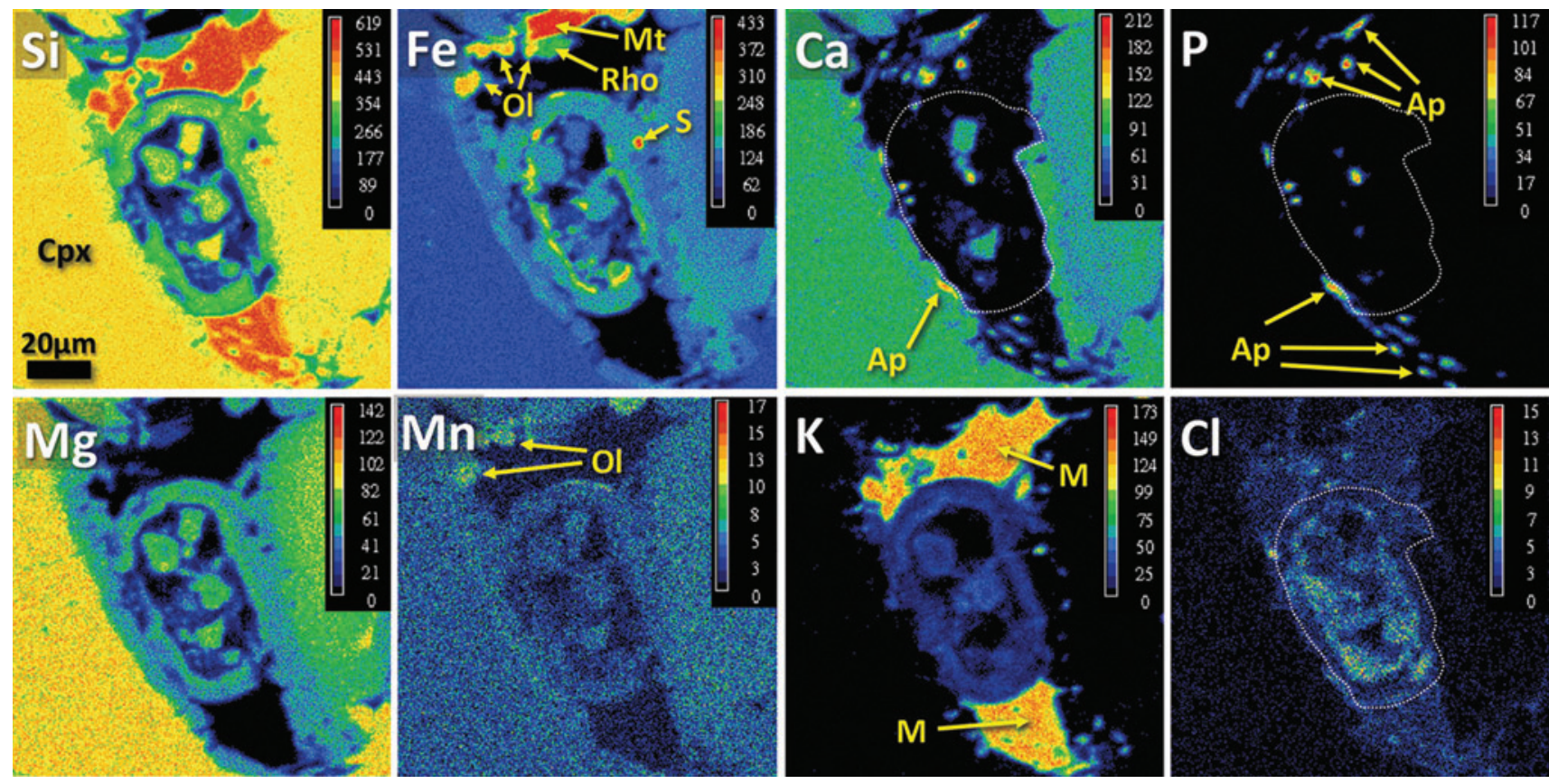

FIG. 6. Chemical maps of the ovoid structure, obtained with the Cameca SX100 electron microprobe in WDX mode. The scale bar shown for the silicon chemical map is the same for all images. Concentration is shown with pseudocolors, and the color scales (at upper right in each image) indicate relative elemental abundances between maps (arbitrary units). The dotted white lines in the $\mathrm{Ca}, \mathrm{P}$, and $\mathrm{Cl}$ maps indicate the approximate margins of area occupied by the ovoid structure. Abbreviations: Ap, apatite; Cpx, clinopyroxene; M, mesostasis (rhyolitic glass); Mt, Ti-rich magnetite; Ol, olivine; Rho, rhoenite; S, sulfide.

a general geochemical overview of the ovoid itself and the phases around it (Fig. 6). High silica values (red in the $\mathrm{Si}$ map of Fig. 6) indicate areas of the amorphous mesostasis (analyses M1 and M2 in Table 1). The M3 analysis is acquired from a separate (but nearby) inclusion of amorphous mesostasis that occurs within clinopyroxene rims (M3 analysis in Fig. 2a). Intermediate silica values (yellow-orange in the Si map of Fig. 6) indicate clinopyroxene, while lower values (in green) largely correlate with the ovoid wall structure (Fig. 6). The blue and black areas demarcate the interior hollow region of the ovoid, as well as some additional cracks and the magnetite crystal (at the top of the $\mathrm{Si}$ map of Fig. 6). On the iron map (Fe map in Fig. 6), the highest values (in red) correlate with the magnetite (Mt) and sulfide (S) crystals, whereas the intermediate values (yellow to orange hues) match up with the olivine crystals. Finally, the green-yellow-orange hues match up with the Fe-rich fibrous layer that occurs around the interior of the ovoid wall, while even lower values (blue and black) indicate the large clinopyroxene crystals and the mesostasis regions, respectively. The calcium map ( $\mathrm{Ca}$ map in Fig. 6) mainly reveals the presence of clinopyroxene, but in combination with the phosphorus map (P map in Fig. 6), the additional presence of numerous apatite microcrystals is also apparent. Magnesium is clearly depleted in the Cpx rims ( $\mathrm{Mg}$ map in Fig. 6; Al-rich rim and Fe-rich rim Cpx in Table 1), which distinguishes the Al-rich rim having a $\mathrm{Mg \#}$ of 0.38 and the intercumulus overgrowths having a $\mathrm{Mg \#}$ of 0.49 from the cumulus pyroxene cores having a $\mathrm{Mg \#}$ of 0.62 ( $\mathrm{Mg}$ map in Fig. 6; core Cpx in Table 1; also see Fig. 2b for these Cpx Al-rich and Fe-rich rim versus core relationships). In contrast, manganese shows a weak zonation in clinopyroxene
(Mn map in Fig. 6), but higher values of Mn clearly highlight a few small olivine crystals $(\mathrm{Ol})$. The ovoid wall and the islands also contain small amounts of manganese (Fig. 6). The potassium map ( $\mathrm{K}$ map in Fig. 6) clearly distinguishes the amorphous mesostasis of rhyolitic composition ( $\mathrm{M}$; bright orange colors) from all other surrounding materials. Lower potassium values (blue in $\mathrm{K}$ map of Fig. 6) correlate with the ovoid structure, and it is evenly distributed both in the matrix of the ovoid wall and in the islands. The chlorine map ( $\mathrm{Cl}$ map in Fig. 6) demonstrates that the mesostasis (M) and the ovoid structure both contain chlorine, possibly indicating a fluid infiltration event of a common source. Several EDX spot analyses indicated that chlorine is concentrated mainly in the fibrous iron-rich layer of the ovoid (layer L5), whereas sulfur seems to be spatially associated with the matrix of all other layers. However, it is not entirely clear as to the exact chemical state of this chlorine or sulfur in and around the ovoid.

3.2.1. Clinopyroxene core, Al-rich rim, and Fe-rich rim compositions. The aluminum oxide $\left(\mathrm{Al}_{2} \mathrm{O}_{3}\right)$ content of clinopyroxene in Nakhla is generally low (i.e., below $1 \mathrm{wt}$ $\%$; see core and Fe-rich rim clinopyroxene analyses in Table $1)$; however, we have located some relatively narrow $(\sim 5-$ $10 \mu \mathrm{m}$ thick) clinopyroxene rims that are quite rich in $\mathrm{Al}_{2} \mathrm{O}_{3}$ (i.e., exceeding $5 \mathrm{wt} \%$; see Al-rich rim clinopyroxene analysis in Table 1; also see bright clinopyroxene domains visible in BSE images in Fig. 2 labeled Al-rich rim $\mathrm{Cpx}$ ). This is coupled with some enrichment in $\mathrm{TiO}_{2}$, when compared with the clinopyroxene cores (Table 1). The excess alumina content in this clinopyroxene rim material is compensated by lower silica. Also note that this excess 
alumina does not represent contamination from the $\mathrm{Al}_{2} \mathrm{O}_{3}$ polishing powder, as evidenced by replicable geochemical analyses of these rims and from the analyses of nearby minerals that do not contain any $\mathrm{Al}_{2} \mathrm{O}_{3}$. Generally, this type of Al-rich rim composition is uncommon for mesostasis clinopyroxenes in Nakhla, except in the case of clinopyroxene crystals that crystallized from melt inclusions inside olivine (Treiman, 1993). In fact, similar high concentrations of $\mathrm{Al}_{2} \mathrm{O}_{3}$ (i.e., exceeding $5 \mathrm{wt} \%$ ) in augite rims have only been reported for martian meteorite MIL03346 (Treiman, 2005), which in this case are explained as a result of the failure of plagioclase to form in the mesostasis, which would normally incorporate most of the available alumina. Concentrations of 4-12 wt \% $\mathrm{Al}_{2} \mathrm{O}_{3}$ in pyroxenes have also been reported in lunar rocks (Bence et al., 1970; Engelhardt et al., 1989) and experimentally confirmed by Engelhardt et al. (1989), whereby the Al-rich clinopyroxenes tend to be skeletal in form, indicating rapid growth in supercooled melts. Such rapid nucleation of clinopyroxene would have inhibited plagioclase crystallization in its vicinity by consuming the alumina, which is locally available, from the melt. The absence of plagioclase (i.e., its anorthite component) or other Al-rich minerals in the mesostasis where the ovoid is located might be taken as evidence of alumina partitioning into the clinopyroxene rims due to phase disequilibrium caused by supercooling, chemical disequilibrium, or a combination of the two. A geothermometer based on the strong dependence of $\mathrm{Al}_{2} \mathrm{O}_{3}$ content (wt \%) in clinopyroxenes has been proposed (France et al., 2010), in which the alumina content behaves linearly for concentrations up to about 3 wt $\% \mathrm{Al}_{2} \mathrm{O}_{3}$, but when extrapolating to higher concentrations results in temperatures above $1300^{\circ} \mathrm{C}$, that is, higher than the liquidus of clinopyroxene.

Collectively, the observed $\mathrm{Al}_{2} \mathrm{O}_{3}$-rich composition of the clinopyroxene, and its correspondingly lower $\mathrm{SiO}_{2}$ contents, coupled with the very high temperatures estimated with the aforementioned geothermometer, suggest an exotic process for the origin of the Al-rich rim clinopyroxene in Nakhla. Such a process might include the partial melting of the rims of the original clinopyroxene crystals due to a localized heating and high-pressure event, such as a shock event induced from a nearby bolide impact. Rapid cooling of melted clinopyroxene rims, however, did allow recrystallization of Al-rich clinopyroxene to take place, as evidenced by the Raman spectrum for this material, which shows the characteristic pyroxene peaks (Fig. 7). This shock event might also coincide with the age of resetting of radiogenic ${ }^{40} \mathrm{Ar}$ distribution in Nakhla clinopyroxenes at $913 \pm 9 \mathrm{Ma}$ observed by Cassata et al. (2010), which records a geological event that caused extensive fracturing of clinopyroxene grains and highly localized heating. Most probably, it occurred at pressures between 20 and $40 \mathrm{GPa}$, a range that is

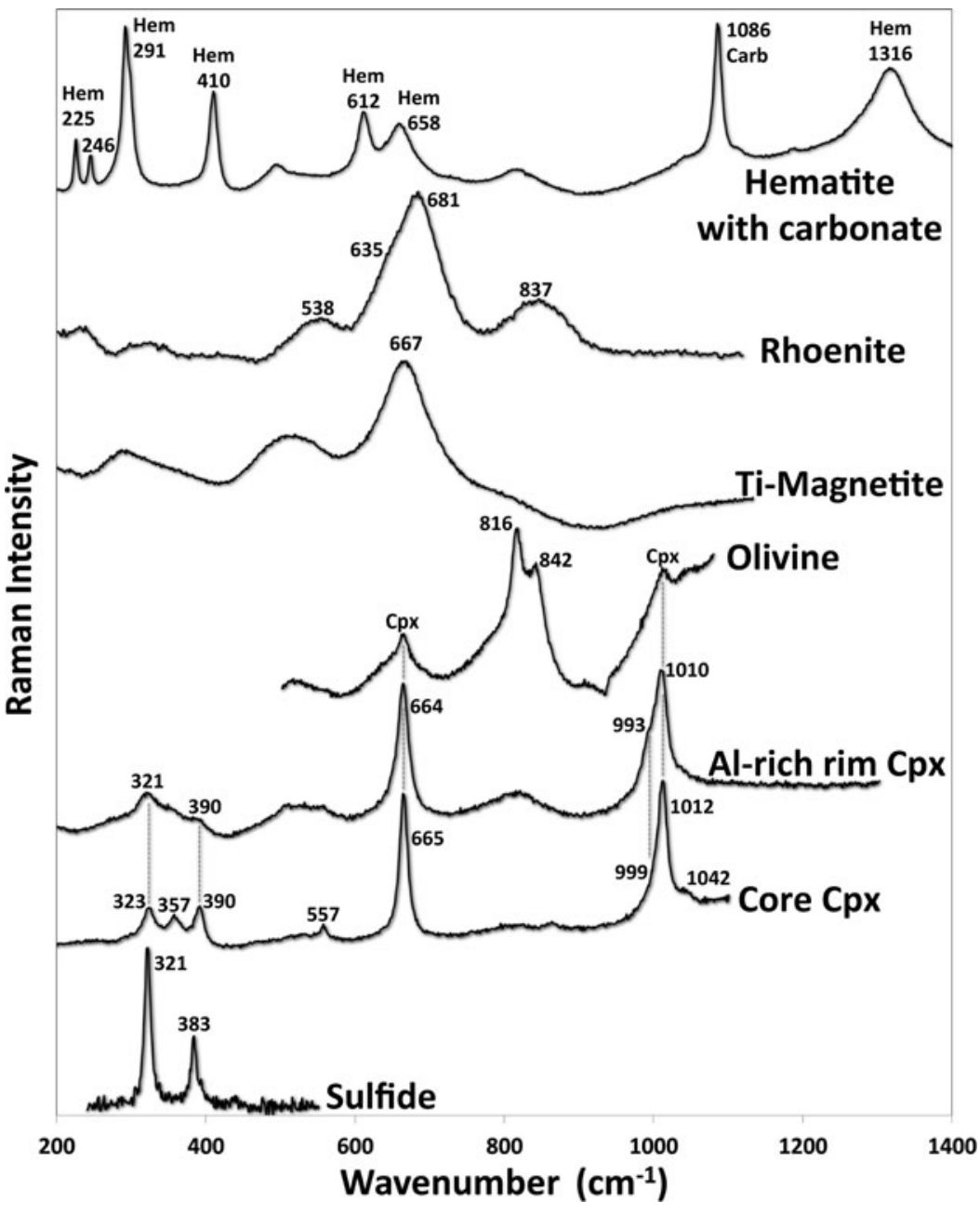

FIG. 7. Raman spectra of the main minerals in the mesostasis area of the ovoid structure (Fig. 2b), exclusive of the hematite-carbonate spectrum, which is from another mesostasis area. The olivine spectrum also contains two peaks from a neighboring clinopyroxene crystal. In the top spectrum, Hem indicates characteristic hematite peaks and Carb indicates the main characteristic peak of the carbonate (Fe-Mn siderite). The numbers beside each peak denote their individual wavenumbers, which are taken from the de-convoluted spectra peaks. 
suggested by other textural evidence such as shock melt veins in pyroxene fractures in Nakhla (Lambert, 1987).

Alternatively, the $\mathrm{Al}^{\mathrm{VI}}+\mathrm{Al}^{\mathrm{IV}}$ for $\mathrm{R}^{\mathrm{VI}(2+)}+\mathrm{Si}^{\mathrm{IV}}$ substitution might also account for the formation of the Al-rich clinopyroxene rims in Nakhla at lower pressures or shallow depths in a melt with low $\mathrm{SiO}_{2}$ activity; however, this substitution is mainly observed in phenocryst clinopyroxenes rather than clinopyroxene rims in lunar rocks (Bence et al., 1970).

3.2.2. Olivine. A few olivine crystals were observed within the studied mesostasis region in Nakhla, and one of these grains is just barely discernible (slightly brighter in BSE images) from the rim clinopyroxene that is adjacent to it (Fig. 2b). Another such olivine grain is juxtaposed with a rhoenite grain that we describe here (see Fig. 8, which shows both of these olivine grains; rhoenite is introduced in a later section below). These mesostasis olivine crystals are relatively iron-rich (with end members $\mathrm{Fo}_{22} \mathrm{Fa}_{78}$ ) when compared to the large rock-forming olivine crystals present elsewhere within the thin section $\left(\mathrm{Fo}_{40} \mathrm{Fa}_{60}\right)$, but they are quite similar in composition to these larger olivine phenocrysts with respect to some of the other oxides, having $1.15 \mathrm{wt} \% \mathrm{MnO}, 0.24 \mathrm{wt} \% \mathrm{CaO}$, and traces of $\mathrm{TiO}_{2}$ and $\mathrm{Cr}_{2} \mathrm{O}_{3}$ (see $\mathrm{Ol}$ in Table 1). Raman spectra of these olivines show peaks at 816 and $842 \mathrm{~cm}^{-1}$ (Fig. 7), although in the larger olivine phenocrysts the latter peak is slightly displaced at $844 \mathrm{~cm}^{-1}$. Peak shifts in olivine were interpreted by Kuebler et al. (2006) to have been caused by chemical variations expressed in end-member compositions, and the small peak difference measured between the cumulus and the mesostasis Nakhla olivines is predicted by their calibration curves. Similar peak values were also reported by Rull et al. (2004) for other olivine grains in Nakhla. The small mesostasis olivine crystals of Nakhla do not show any signs of alteration, in contrast with the cumulus olivine crystals of the same petrographic thin section, which are extensively altered.

3.2.3. Sulfide. A single sulfide crystal with dimensions of $\sim 4 \times 2 \mu \mathrm{m}$ was observed on the thicker side of the ovoid wall ( $\mathrm{S}$ in Fig. 2b). Electron microprobe analysis of the
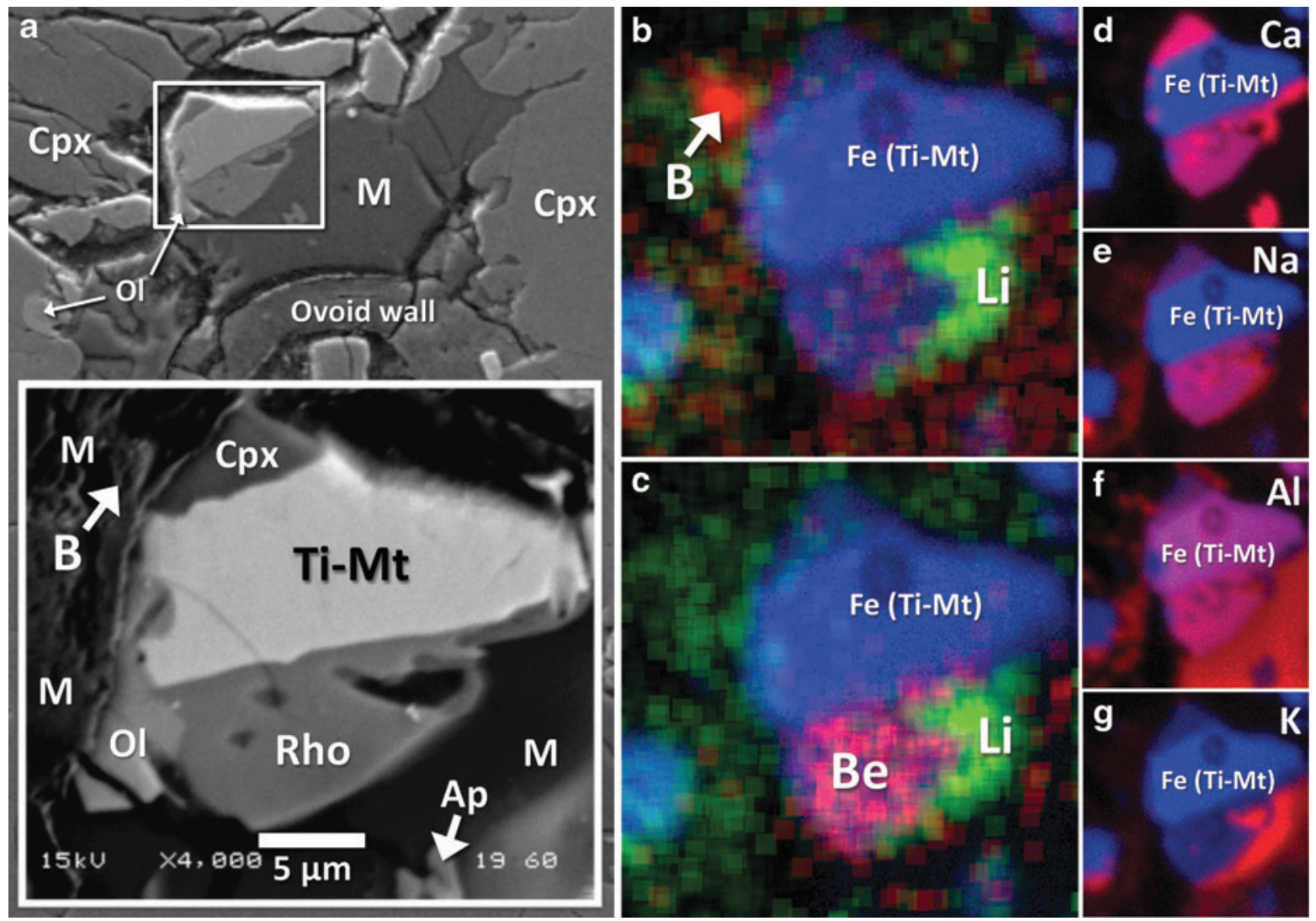

FIG. 8. BSE SEM images and TOF-SIMS ion maps of a mesostasis region near the ovoid in Nakhla and some mineral phases contained within it. (a) Overview BSE image of the mesostasis area, in which the inset shows a close-up of the area mapped by TOF-SIMS (b-g). Abbreviations: Ap, apatite; B, location of boron enrichment [see TOF-SIMS image (b) of this figure]; Cpx, clinopyroxene; M, amorphous mesostasis (rhyolitic glass); Ol, olivine; Rho, rhoenite; Ti-Mt, titanium magnetite. (b, c) TOF-SIMS ion maps of lithium (Li; green), boron (B; red), and beryllium (Be; magenta), shown as overlays onto the iron (blue) map, which is used (for reference) to demarcate the Ti-rich magnetite crystal [bright phase labeled TiMt on the inset BSE image in (a)]. Some lithium and boron are distributed sparsely throughout the amorphous mesostasis phase (rhyolitic glass), whereas beryllium occurs for the most part only within the rhoenite (Rho) in (a). (d-g) TOF-SIMS ion maps of $\mathrm{Ca}, \mathrm{Na}, \mathrm{Al}$, and $\mathrm{K}$, with red to magenta colors shown as overlays onto the iron (blue) map, which is used to demarcate the Ti-rich magnetite crystal. Only in (f) does the magnetite crystal appear with a magenta color; this is because it contains both of the elements $\mathrm{Al}$ and Fe. 
sulfide gives $56.7 \mathrm{wt} \% \mathrm{Fe}$ and $43 \mathrm{wt} \% \mathrm{~S}$, and in addition there is some trace nickel present $(0.3 \mathrm{wt} \%)$. A proportionate atomic deficiency in iron $(\mathrm{Fe}: \mathrm{S}=0.76: 1)$ indicates a sulfide with the formula $\mathrm{Fe}_{1-x} \mathrm{~S}$, where $x=0.24$, which is well outside the range for pyrrhotites (Geines et al., 1977). Stoichiometrically, the chemistry of this grain corresponds to that of greigite $\left(\mathrm{Fe}^{2+} \mathrm{Fe}_{2}^{3+} \mathrm{S}_{4}\right)$. Additional analyses performed on sulfide grains from two different Nakhla thin sections provided a range of chemistries with $x$ ranging between 0.03 , close to the composition of troilite or mackinawite, and up to about 0.25 , reaching greigite stoichiometry. In comparison, Nakhla pyrrhotite compositions reported by Chevrier et al. (2011) and Greenwood et al. (2000) have $x$ values that range between 0.125 and 0.153 .

To assist in our interpretations, a few Raman spectra were also acquired from the same sulfide grain analyzed by electron microprobe, which show two distinct peaks, including a stronger peak at $321 \mathrm{~cm}^{-1}$ and a weaker peak at $383.2 \mathrm{~cm}^{-1}$ (Fig. 7). These spectra were initially acquired using a relatively low laser intensity (well below $2 \mathrm{~mW}$ ), whereas in higher power new peaks appeared, probably due to phase modifications during the analysis. The spectrum acquired is very similar to that determined on marcasite by Hope et al. (2001), both in terms of identical peak positions at 321 and $384 \mathrm{~cm}^{-1}$ but also with respect to their relative intensities. Moreover, other similar spectra were also measured for marcasite by Mernagh and Trudu (1993), who observed peaks at 324 and $387 \mathrm{~cm}^{-1}$, and also by White (2009), who found peaks at 323 and $386 \mathrm{~cm}^{-1}$. In contrast, however, the spectrum determined on the Nakhla sulfide crystal here is not very similar to that for greigite measured by Bourdoiseau et al. (2011), which instead reveals two major peaks at 350 and $365 \mathrm{~cm}^{-1}$, nor is it similar to precursor minerals such as mackinawite, which has two major peaks at 296 and $207 \mathrm{~cm}^{-1}$, as measured by these same authors.

Based on stoichiometry alone, the sulfide we analyzed here should be greigite $\left(\mathrm{Fe}_{3} \mathrm{~S}_{4}\right)$. This is very significant, considering that quite commonly on Earth the mineral produced through intracellular biomineralization in magnetotactic bacteria is greigite (Mann et al., 1990). However, the mode of occurrence and grain size of the sulfide identified in this study do not compare well with the nanoscale crystallites produced by magnetotactic bacteria. This, together with the observed differences in Raman spectra between this crystal and those determined on greigite (discussed above), requires the investigation of other possible alternative origins for this Nakhla sulfide grain.

Combining the Raman spectra and the electron microprobe chemical data, the sulfide crystal identified in the ovoid area in this study could be a mixture of marcasite and pyrrhotite in an approximate weight ratio of $2: 1$ within the same grain. Pyrrhotite can be a precursor of marcasite in cases where the removal of iron causes an excess of sulfur to remain in the crystal, which results in the collapse of the pyrrhotite structure to form marcasite such that in the end a combined mixture of marcasite and residual pyrrhotite remains (Fleet, 1978). This type of transformation is possible under hydrothermal conditions over a range of $\mathrm{pH}$ values and is facilitated by increasing temperature of the system (Fleet, 1978).

A combined mixture of marcasite and pyrrhotite should not be reflected in the resulting Raman spectrum because pyrrhotite does not exhibit any Raman peaks. Mernagh and Trudu (1993) did not observe any Raman peaks for pyrrhotite, either in the case of the nonmagnetic monoclinic variety $\left(x=0.125 ; \mathrm{Fe}_{7} \mathrm{~S}_{8}\right)$ or for the magnetic hexagonal variety $\left(x=0.091 ; \mathrm{Fe}_{10} \mathrm{~S}_{11}\right)$. In another case, the Raman bands observed by White (2009) for pyrrhotite were highly variable and, therefore, attributed to other impurities in the crystal or to narrow-band fluorescence. Spectra reported by Breier et al. (2009) for pyrrhotite yielded peaks at 377, 471 , and $676 \mathrm{~cm}^{-1}$ as the most consistent measurements, although they also agree that the peak positions are quite variable, which might reflect variations in the chemical composition of the pyrrhotite being analyzed. Pyrrhotite in Zagami measured by Wang et al. (1999) shows only a single broad peak at $430 \mathrm{~cm}^{-1}$. In addition, Raman spectral data for pyrrhotite in the RRUFF database (http://rruff.info) indicate that two major peaks are present at 339 and $374 \mathrm{~cm}^{-1}$, with additional minor peaks at 323 and $424.4 \mathrm{~cm}^{-1}$. Consequently, according to the various Raman spectroscopic data reported for pyrrhotite above, and the Raman spectra that we acquired in this study from numerous pyrrhotite grains identified in the Nakhla thin section (i.e., with the use of energy-dispersive X-ray/scanning electron microscopy analysis), we conclude that the pyrrhotite in this study does not show any diagnostic or characteristic Raman spectral features that we can use to identify it reliably with that analytical technique.

Marcasite does not occur as a magmatic mineral and is known to form only at low temperatures in sediments and in metalliferous veins (Deer et al., 1992), but it has also been documented as the main alteration product of pyrrhotite after iron depletion in supergene environments (Fleet, 1978). Marcasite has also been found in other martian meteorites, such as in Lafayette, in which it is interpreted to have formed as a product of the hydrothermal alteration of pyrrhotite (Greenwood et al., 1998). Here, we conclude that the presence of marcasite within the area of the ovoid structure in Nakhla is an observation that represents compelling evidence for low-temperature alteration of the original pyrrhotite. Furthermore, the fact that not all the pyrrhotites that occur in the studied thin section have been transformed into marcasite indicates that this alteration of pyrrhotite to marcasite took place only locally within this rock. Finally, although this sulfide crystal does not exhibit any evidence of corrosion, sulfides with a spongy microtexture have been observed within certain altered areas of pristine Nakhla rock fragments (Chatzitheodoridis, 1990).

3.2.4. Mesostasis. In magmatic systems, the mesostasis represents the last interstitial material to solidify during the final stages of formation of an igneous rock, and in martian meteorites it is generally accepted that this term encompasses all the interstitial material that is present in between the large cumulate augite and olivine phenocryst assemblages (e.g., Treiman, 2005). The mesostasis volumes in Nakhla are generally infilled with radiating laths of plagioclase, along with crystals of $\mathrm{K}$ feldspar, titanomagnetite, apatite, as well as some secondary alteration minerals. Interstitial spaces that are infilled primarily with noncrystalline amorphous mesostasis materials (i.e., glass) are rare in Nakhla, although this is actually the case here for the mesostasis material juxtaposed with the ovoid structure (Figs. 1-3). Melt 

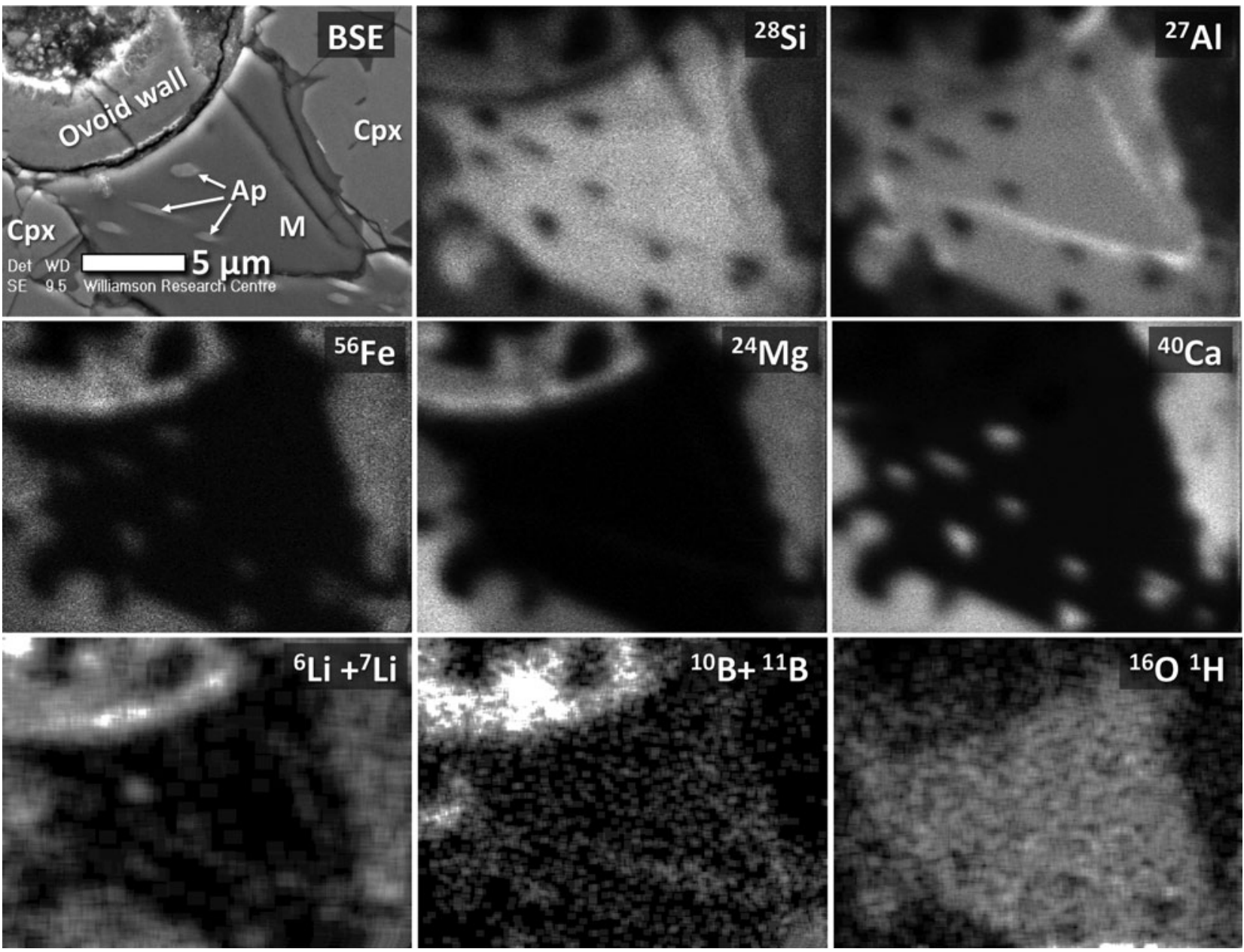

FIG. 9. TOF-SIMS ion maps of selected major elements ( $\mathrm{Si}, \mathrm{Al}, \mathrm{Fe}, \mathrm{Mg}$, and $\mathrm{Ca}$ ), light elements (Li and B), as well as hydroxyl ions $\left(\mathrm{OH}^{-}\right)$, obtained for a mesostasis region juxtaposed with the ovoid and some surrounding mineral phases. For reference, a BSE SEM image of the area mapped by TOF-SIMS is also shown at top left, allowing for direct comparison of the chemical maps to specific phases including acicular apatite needles (Ap), clinopyroxene (Cpx), and the amorphous mesostasis (M) phase (rhyolitic glass). Grayscale maps of $\mathrm{Li}, \mathrm{B}$, and $\mathrm{OH}^{-}$are contrast-enhanced to facilitate the separation of different phase regions. Data for beryllium is not shown, but it was found to exist in the mesostasis rhyolitic glass only.

pockets composed of glass with conspicuous textures have been observed in martian meteorites before, such as the round concentric features associated with an apparent vesicle in a melt pocket of ALH 77005 (see Fig. 6d in Fritz et al., 2005). Vesicular structures in melt glasses that have been subjected to shock pressures can be produced when the melt contains water (i.e., up to $15 \mathrm{wt} \% \mathrm{H}_{2} \mathrm{O}$; Allen et al., 1982).

In terms of chemical composition, the amorphous mesostasis described here is alkaline and somewhat feldspathic (analyses M1-M3 in Table 1). However, in terms of bulk composition, $\mathrm{SiO}_{2}$ is too high with respect to the collective abundances of $\mathrm{Al}_{2} \mathrm{O}_{3}$, alkali oxides, and $\mathrm{CaO}$ for this material to represent any kind of late-crystallizing feldspar. It is therefore reasonable to presume that this amorphous mesostasis material is a late-forming interstitial glass, which according to the total alkalis versus silica diagram of Le Maitre et al. (2002) — and after recalculating to account for the low chemical totals-is classified as rhyolitic in composition. Electron microprobe X-ray mapping of this mesostasis glass shows that $\mathrm{Cl}$ is homogeneously distributed (Cl map in Fig. 6). A TOF-SIMS map of the distribution of
${ }^{16} \mathrm{O}^{1} \mathrm{H}^{-}$(Fig. 9) in this material, coupled with the low chemical totals of the electron microprobe WDX chemical analyses (M1, M2, and M3 in Table 1), indicates that this amorphous mesostasis is also somewhat hydrous. In addition, the distributions of light elements, such as $\mathrm{Li}, \mathrm{B}$, and $\mathrm{Be}$, indicate that these elements are more heterogeneously disseminated throughout the mesostasis glass (TOF-SIMS images in Figs. 8 and 9). Additional TOF-SIMS ion maps of small areas within the mesostasis glass (not shown here) indicate that $\mathrm{Rb}, \mathrm{Sr}$, and $\mathrm{Ba}$ are also present.

In the literature, it has been suggested that the formation of the Nakhla mesostasis took place in association with the mixing of multiple different solutions rather than from a single parental igneous source (Gooding et al., 1990, 1991), one being magmatic fluid (or alternatively hydrothermal fluids associated with a nearby bolide impact), the other dilute brine waters, which upon mixing resulted in the formation of a hydrous silicate amorphous gel (Bridges and Hicks, 2011; Schwenzer and Bridges, 2011). To complicate matters, there is still no clear distinction between the various types of amorphous phases found within Nakhla, and overall 
their composition seems to be quite variable (e.g., when comparing our analyses with the analyses of amorphous mesostasis reported in other studies, such as that of Bridges and Hicks, 2011). This probably indicates that, in each case, the localized nature of each fluid infiltration event, combined with variable amounts of mixing of different types of fluids during mesostasis formation, has resulted in a diversity of hydrous and amorphous mesostasis compositions overall throughout Nakhla and its parent rock. Also important to reemphasize here is that the mesostasis glass surrounding the ovoid structure in Nakhla is indeed hydrous, as highlighted above.

3.2.5. Apatite and magnetite. Chlor-apatites are a common phosphate mineral in Nakhla, and they are present within the amorphous mesostasis phase or within melt inclusions in olivine crystals. They occur as randomly oriented apatite needles that exhibit (in cross section) various crystal shapes, ranging from equant to sub-equant to highly elongate (acicular; e.g., BSE image in Fig. 9), as well as skeletal forms (Fig. 2b). All the observed apatite crystals appear to be fully enveloped by the rhyolitic mesostasis glass, and their acicular and skeletal shapes are likely the result of rapid crystallization during quenching of the mesostasis. A few small apatite grains that are present inside the hollow area of the ovoid structure (e.g., Ca map and $\mathrm{P}$ map in Fig. 6) are most likely debris from polishing of the petrographic section, similar to the observed clinopyroxene fragments interpreted as debris (these inferences are based on observations made using both transmission electron microscopy-see Polishing Debris in the TEM cross section in Fig. 5a-and electron microprobe chemical analyses).

Magnetite is Ti-rich and has a chemical composition that is similar to the chemical composition reported by Treiman (2005) for Nakhla magnetite, although it is a few weight percent richer in $\mathrm{Al}_{2} \mathrm{O}_{3}$ than the average compositions reported by Bunch and Reid (1975). Its Raman spectrum gives a very broad peak at $667 \mathrm{~cm}^{-1}$ (Fig. 7), which is in agreement with the spectral measurements presented by Rull et al. (2004) for magnetite crystals in Nakhla.

3.2.6. Carbonate and hematite. Carbonate and hematite are also present in the studied thin section of Nakhla, and these minerals were generally found in the altered areas of olivine crystals, where they typically appear stained with a reddish color. In addition, numerous $\mathrm{Fe}-\mathrm{Mn}$ carbonates were also observed in other mesostasis regions, although not in the mesostasis region hosting the ovoid structure. In Fig. 7, a
$1086 \mathrm{~cm}^{-1}$. It is also important to highlight here that the hematite peak at $658 \mathrm{~cm}^{-1}$ coincides with a forbidden band in hematite spectra and is not a characteristic mode of a perfect hematite crystal. As it turns out, this mode at $658 \mathrm{~cm}^{-1}$ is exactly half the second harmonic vibration of the broad, but Raman active, $1316 \mathrm{~cm}^{-1}$ peak of hematite and is actually attributed to crystalline disorder or the occurrence of nanocrystals (Bersani et al., 1999).

3.2.7. Rhoenite. A single grain of a mineral belonging to the rhoenite (or rhönite) group was identified during the course of the present study (Rho in Fig. 8a). It measures $10 \times 6 \mu \mathrm{m}$ and is situated between the amorphous mesostasis of rhyolitic composition and a Ti-rich magnetite crystal. It is also juxtaposed with a small olivine grain. In transmitted light (i.e., under petrographic microscope), the rhoenite grain looks opaque (in agreement with the observations of Kunzmann, 1999) and is indistinguishable from the attached magnetite crystal (Fig. 1a). During electron microprobe WDX analysis of this rhoenite crystal, we used a $\sim 1 \mu \mathrm{m}$ beam diameter and were able to successfully determine its chemical composition. Quantitative chemical analysis of rhoenite is presented in Table 1 (analysis Rho).

In addition to the elements identified by WDX analysis, our qualitative EDX analyses revealed traces of vanadium in the rhoenite grain, and TOF-SIMS ion imaging has clearly resolved the presence of beryllium $(\mathrm{Be})$. Beryllium is preferentially enriched in rhoenite compared to other Nakhla phases (Fig. 8c). Additional TOF-SIMS ion maps for other elements in the mesostasis area surrounding the rhoenite crystal reveal overall heterogeneous elemental distributions; this includes the trace light elements Li and B (Fig. 8b, 8c), as well as some of the major elements, including $\mathrm{Ca}, \mathrm{Na}, \mathrm{Al}$, and $\mathrm{K}$ (Fig. 8d-8g).

The laser micro-Raman spectrum of the rhoenite shows a major diagnostic peak at $681 \mathrm{~cm}^{-1}$, with additional peaks at 538,837 , and $635 \mathrm{~cm}^{-1}$. This spectrum matches that obtained on rhoenite from the Mare Crisium lunar regolith that was returned to Earth by the Russian Luna 24 spacecraft (Treiman, 2008). Small variations in the exact position of the peaks are attributed to differences in chemistry.

In terms of chemical composition (Table 1), the analysis of this mineral phase conforms to a new member of the rhoenite group with the general formula $X_{2} Y_{6} Z_{6} \mathrm{O}_{20}$, with $X$, $Y$, and $Z$ indicating eightfold, sixfold, and fourfold coordination sites, respectively (Kunzmann, 1999). A stoichiometric formula was obtained by using 20 oxygen atoms as shown below:

$$
\left(\mathrm{Ca}_{1.71} \mathrm{Na}_{0.29} \mathrm{~K}_{<0.01}\right) \cdot\left(\mathrm{Ca}_{0.41} \mathrm{Mg}_{0.49} \mathrm{Mn}_{0.02} \mathrm{Fe}_{1.30}^{2+} \mathrm{Fe}_{3.26}^{3+} \mathrm{Cr}_{0.02} \mathrm{Ti}_{0.50}\right) \cdot\left(\mathrm{Si}_{2.79} \mathrm{Be}_{0.78} \mathrm{Al}_{1.76} \mathrm{Fe}_{0.67}^{3+}\right) \mathrm{O}_{20}
$$

Raman spectrum of a red-colored, heterogeneously stained carbonate is depicted that is located in one of the mesostasis areas of Nakhla. This Raman spectrum essentially reflects a mixture of hematite and carbonate spectra (peaks indicated as Hem and Carb, respectively, in Fig. 7). The hematite spectrum from this composite material shows all the main peaks that are typical for hematite, whereas the carbonate component only reveals one major characteristic peak at
Calculations were made following those of Kunzmann (1999), where the $\mathrm{Fe}_{2} \mathrm{O}_{3}$ content is determined by charge balance on the basis of 14 cations. Part of the ferric iron occupies the tetrahedral $Z$-site in order to bring the total of this site to 6.0. Beryllium is a common element in some varieties of rhoenite, occupying tetrahedral sites (Johnston and Stout, 1985; Kunzmann, 1999). Since Be was not measured, we estimated its content arithmetically at about 
2.7 wt $\% \mathrm{BeO}$ (see Table 1). This amount of $\mathrm{BeO}$ satisfies charge balance and complies with the coupled substitution $2 \mathrm{Si}^{\mathrm{IV}}+2 \mathrm{Be}^{\mathrm{IV}} \leftrightarrows 4 \mathrm{Al}^{\mathrm{IV}}$. The presence of $\mathrm{BeO}$ has been reported for the høgtuavite rhoenite variety (Grauch et al., 1994), which, however, is different from the Nakhla rhoenite with respect to its abundances in some of the other major element oxides and in terms of its geological setting, as on Earth this variety of rhoenite is known to occur in certain types of metamorphosed igneous rocks, including granitic gneisses and metamorphosed mafic pegmatites. The rhoenite-group mineral identified in Nakhla in the present study is considered to be a new member of the rhoenite group. Compositionally, it falls into the specific category of the rhoenite classification scheme defined by $0.5 \leq \mathrm{Ti}<1.5$ and $2 \leq(\mathrm{Si}-\mathrm{Na})<3$ (Kunzmann, 1999), of which no members have been identified to date.

Rhoenite is a rare accessory mineral that occurs in a variety of different rock types. It mainly occurs in silicaundersaturated igneous rocks, such as in the groundmass of alkali basalts (Johnston and Stout, 1985; Kunzmann, 1999; Grapes and Keller, 2010), and in silicate melt microinclusions in olivine and clinopyroxene phenocrysts of most alkali and subalkali basalts (i.e., basanite), where it is often associated with clinopyroxenes that have $\mathrm{Al}_{2} \mathrm{O}_{3}$-rich and $\mathrm{SiO}_{2}$-poor rims, spinels (i.e., Ti magnetite), K-rich glass, sulfides, and bubbles of a gas phase (i.e., $\mathrm{CO}_{2}$ ) (Timina et al., 2006; Anan'ev and Selyangin, 2011; Sharygin et al., 2011). In alkali-basaltic rocks, the stability field of rhoenites ranges from $840^{\circ} \mathrm{C}$ to $1200^{\circ} \mathrm{C}$ at pressures lower than 600 bar, without any limits in oxygen fugacity (Kunzmann, 1999, and reference therein). Rhoenite is also found to occur as the breakdown product of Ti-rich Ca amphibole (Grapes et al., 2003, and references therein). In addition, rhoenite can crystallize under pneumatolytic conditions (Kunzmann, 1999) when magma goes through the $500^{\circ} \mathrm{C}$ temperature regime during its crystallization. Finally, rhoenite is also found as a primary magmatic mineral in "ocelli" (i.e., texturally globular structures or amygdules, which are the products of immiscible leucocratic material or the infillings of vesicles, respectively) that occur in some basaltic dykes where it likely crystallized at high temperatures within late-stage volatile-rich parts of the magma (Nédli and Tóth, 2003).

Rhoenite, in meteorites, was first reported from the Allende carbonaceous chondrite, where it displays a large compositional range probably reflecting rapid cooling (Fuchs, 1971). In the Efremovka (CV3) chondrite, rhoenite is found to exist in $\mathrm{Ca}, \mathrm{Al}$-rich inclusions mainly with fassaite and melilite, possibly as a metastable phase in melts formed from preexisting solid rocks, again indicating rapid cooling of a parent material with high Ti/Si ratio (Nazarov et al., 2000). A mineral phase similar to rhoenite has also been documented from the Elephant Moraine (EET) 96001 ureilite achondrite (Warren et al., 2006), a meteorite that is presumably formed from extremely depleted peridotites of asteroid mantles. Finally, an iron-bearing rhoenite was found to occur as a primary mineral in the Angrite NWA 4590, an olivine gabbro with cumulate Al-Tirich clinopyroxene, ulvöspinel, and other mineral phases, including glass (Kuehner and Irving, 2007).

Especially interesting is the occurrence of rhoenite in the lunar samples studied by Treiman (2008). Here, rhoenite was found in some multiphase inclusions situated at the rims of Al- and Ti-rich augitic pyroxenes, associated with ulvöspinel and Si-rich glass, suggesting that the Luna 24 basalts originate from magmas with a low volatile content. The occurrence of kaersutite amphibole instead of rhoenite in basaltic magmas would suggest volatile-rich melts, a case that could also apply to martian meteorites such as Nakhla, since the latter contains kaersutite in multiphase inclusions in olivines (Treiman, 1993). However, this kaersutite is oxykaersutite that contains nearly no $\mathrm{OH}$; and its origin, that is, dehydrogenation or oxidation of hydrous kaersutite versus formation of rhoenite, could provide clues to the volatile content of martian magmas (Treiman, 2008).

\subsection{TOF-SIMS chemical maps of light lithophile elements}

Time-of-flight secondary ion mass spectrometer ion mapping was extensively used in this study; however, with the current mass resolution of the instrument, it was not able to reveal any significant trace element patterns or other signatures directly from the ovoid structure itself. This is largely because the returned signal was generally very low (especially when analyzing the matrix of the ovoid structure). However, high-quality data were obtained for the region where the rhoenite crystal is located (Fig. 8) and for the region centered on the amorphous mesostasis (Fig. 9). Overall, the ion maps for seven major elements (i.e., Al, Fe, $\mathrm{Ca}, \mathrm{Na}$, and $\mathrm{K}$ in Fig. 8 and $\mathrm{Si}, \mathrm{Al}, \mathrm{Fe}, \mathrm{Mg}$, and $\mathrm{Ca}$ in Fig. 9) yield similar distributions as the electron microprobe maps (Fig. 6). However, we were able to map a number of light elements-both from the amorphous mesostasis and from the ovoid structure. To provide a comparison of the mesostasis region on either side of the ovoid structure in terms of the areal distributions of light and major elements, the TOF-SIMS ion maps of lithium $\left({ }^{6} \mathrm{Li}+{ }^{7} \mathrm{Li}\right)$, boron $\left({ }^{10} \mathrm{~B}+{ }^{11} \mathrm{~B}\right)$, and beryllium $\left({ }^{9} \mathrm{Be}\right)$ are also shown (Figs. 8 and 9), together with the molecular ion $\left({ }^{16} \mathrm{OH}^{-}\right)$map produced from the lower mesostasis area (Fig. 9). It is important to highlight here that the relative intensities of these trace elements are not calibrated for concentration between these images (i.e., ion maps in Figs. 8 and 9); therefore, they only allow for qualitative comparisons. In addition, the ion maps produced for the light elements, and that of hydroxyl, are contrast-enhanced to improve visibility of the specific elemental/molecular distributions (i.e., the three bottom images shown in Fig. 9). In other instances, elemental maps were enhanced by using a combination of contrast and color overlays (Fig. 8). For clarity, the BSE images of the same areas mapped for element abundance with time-of-flight secondary ion mass spectrometry are also included in Figs. 8 and 9 and labeled according to the different mineral phases that are present. The electron microprobe (BSE) and TOF-SIMS ion images do not perfectly match one another because the ion maps appear slightly deformed due to the obliqueness of the ion beam with respect to the surface of the sample during analysis. Because there were no mass interferences present during measurement of each of these light element distribution maps, the final maps are considered to be accurate qualitative representations of their actual distributions. Also worth highlighting here is that the hydroxyl molecular ion map shows considerably high values in the amorphous mesostasis volume, supporting the case for a hydrous mesostasis glass. 
Table 2. Selected Electron Microprobe WDX Chemical Analyses of the Clay Ovoid Structure

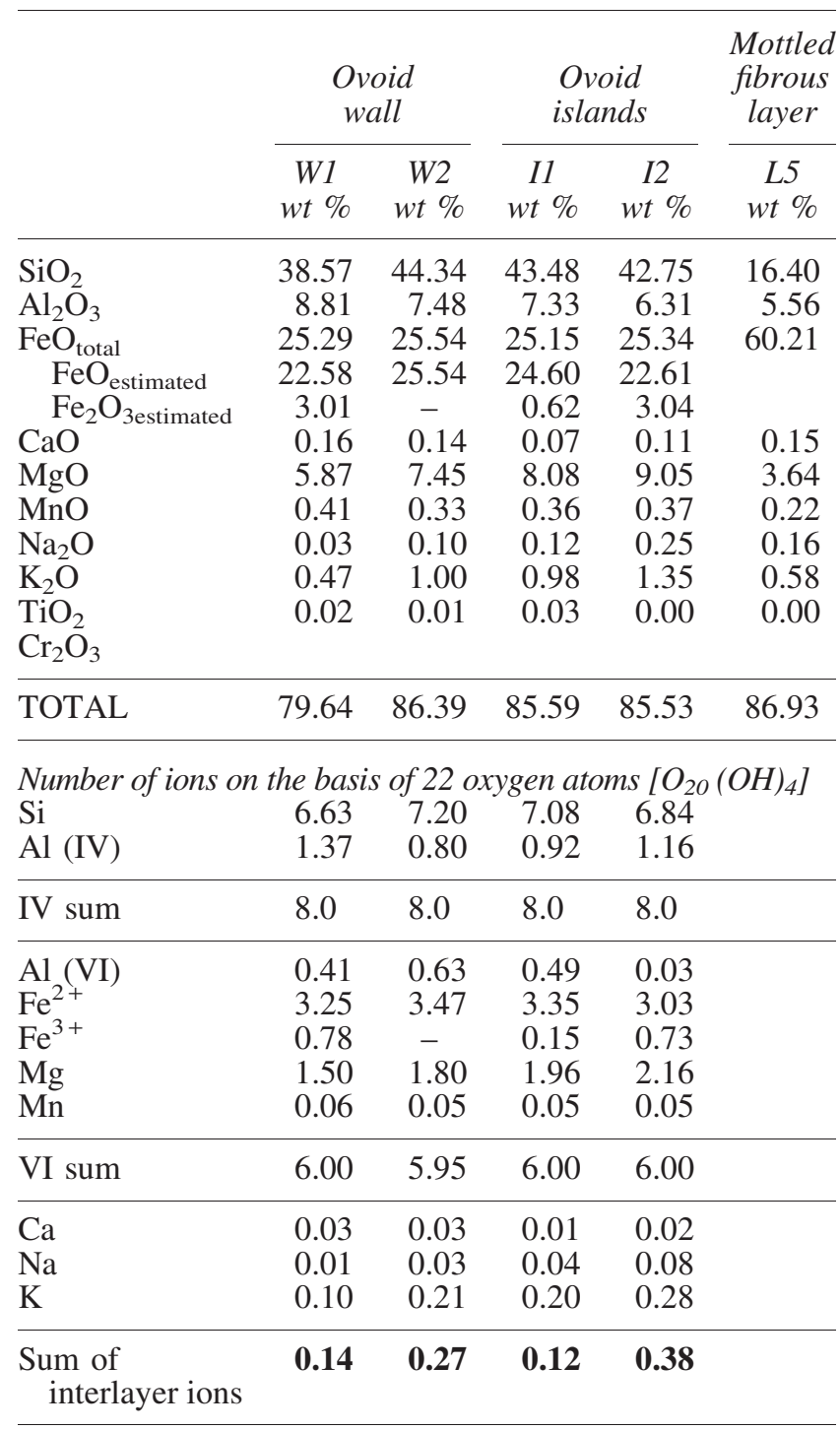

\subsection{Chemistry and mineralogy of the ovoid structure}

All electron microprobe chemical analyses reported in Table 2 were acquired by using WDX mode, and the analyses were performed with the aim of determining the chemical composition of the ovoid walls (analyses W1 and W2, represented by layers L1 to L4), the islands that occur within the central part of the ovoid structure (analyses I1 and I2), as well as the composition of the mottled fibrous layer of the ovoid (L5). The petrographic context (spot locations) of each of these analyses is shown in Fig. 2.
The WDX analysis of the mottled fibrous layer (Table 2) yielded a distinctive composition and indicated the presence of an iron-rich phase. This fibrous layer is also defined by substantially lower $\mathrm{Si}$ and $\mathrm{Mg}$ contents relative to the other two domains (ovoid wall and ovoid islands in Table 2). The alkalis are present in very low concentrations in this fibrous layer (Table 2) compared with their concentrations in the amorphous mesostasis (Table 1). The distribution of chlorine is noticeably different when comparing the amorphous mesostasis and the ovoid matrix in the $\mathrm{Cl}$ map of Fig. 6. For instance, chlorine distribution in the amorphous mesostasis is relatively homogeneous (even blue color in the $\mathrm{Cl}$ map of Fig. 6), whereas more irregular $\mathrm{Cl}$ distributions are observed within the wall and central volume of the ovoid structure. Higher $\mathrm{Cl}$ concentrations inside the hollow structure of the ovoid could be due to contamination from the redistribution of halite salts during the preparation of this halite-rich Nakhla sample. Sulfur is also present in trace, but variable, amounts within the ovoid matrix (i.e., wall and islands). We did not acquire a WDX chemical map for sulfur; however, many electron probe EDX analyses indicated a preferential distribution within the iron-rich fibrous layer L5 (e.g., that occurs around the periphery of the islands; Fig. 4).

The investigations of nanoscale microtextures present in the ovoid wall in which energy-filtered transmission electron microscopy and high-resolution transmission electron microscopy (following section) were used revealed a chemically and mineralogically inhomogeneous material. Nanocrystalline sheet silicates are mixed with amorphous material in layers L1 to L4, which all have the same chemical composition, and layer L5 contains iron-rich phases (possibly oxides or hydroxides). Careful Raman spectral analysis of the iron-rich parts of layer L5 did not yield any kind of characteristic spectrum. This suggests that these Fe-rich parts of the ovoid wall do not contain mineral phases that easily give Raman spectra (i.e., hematite), or that the Fe-rich phase of L5 is nanocrystalline or amorphous.

The internal textural heterogeneity of the ovoid structure, which is defined by variable mixtures of clay crystallites and an amorphous phase at the submicron scale, is intuitively expected to impart a non-stoichiometric chemical composition to the material analyzed. Surprisingly, the mineral formula calculated from the WDX chemical analyses of the ovoid wall and islands (W1, W2, I1, and I2 in Table 2) strongly indicates the presence of a single, stoichiometric clay mineral. Based on $\mathrm{O}_{20}(\mathrm{OH})_{4}$ (full cell, 22 oxygen atoms), stoichiometry reveals a ratio of tetrahedral over octahedral cations of 4:3, suggesting a trioctahedral clay, and is tentatively interpreted as an iron-rich saponite according to the following approximate formula (average of the three most stoichiometric analyses of Table 2):

$\left(1 / 2 \mathrm{Ca}_{0.02} \mathrm{~K}_{0.20} \mathrm{Na}_{0.04}\right)_{[0.26]}\left(\mathrm{Mn}_{0.05} \mathrm{Mg}_{1.88} \mathrm{Fe}_{3.21}^{2+} \mathrm{Fe}_{0.55}^{3+} \mathrm{Al}_{0.31}\right)_{[6]}\left(\mathrm{Si}_{6.85} \mathrm{Al}_{1.15}\right)_{[8]} \mathrm{O}_{20}(\mathrm{OH})_{4}$

Or the shorter formula : $\mathrm{M}_{0.26}^{+} \cdot\left(\mathrm{R}_{5.14}^{2+} \mathrm{R}_{0.86}^{3+}\right)_{[6]} \cdot\left(\mathrm{Si}_{6.85} \mathrm{Al}_{1.15}\right)_{[8]} \cdot \mathrm{O}_{20}(\mathrm{OH})_{4}$ 
A perfect $4: 3$ tetrahedral to octahedral ratio is actually achieved when converting $\sim 2 \mathrm{wt} \%$ of the analyzed ferrous iron $\left(\mathrm{Fe}^{2+}\right)$ into ferric iron $\left(\mathrm{Fe}^{3+}\right)$. Ferric iron is known to be present in Nakhla gels that include clays, which exhibit increasing ratios of $\mathrm{Fe}^{3+} / \Sigma \mathrm{Fe}$ from the edge to the center of the veins in which they occur (Hicks et al., 2011). A small proportion of $\mathrm{Fe}^{3+}$ over $\mathrm{Fe}^{2+}$ was suggested by Gooding (1985) with respect to the chemical analysis of the clay phase proposed by Bunch and Reid (1975) and indicated as "unknown." A small amount of ferric iron (1.6 wt $\% \mathrm{Fe}^{3+}$ ) has also been measured in chip samples of Nakhla (Solberg and Burns, 1989), which indicates an excess of ferric iron that equates to more than would be expected from bulk minerals and is most likely a pre-terrestrial geochemical signature (Burns and Martinez, 1991).

The presence of a minor amount of potassium in the ovoid structure $\left(\sim 1 \mathrm{wt} \% \mathrm{~K}_{2} \mathrm{O}\right.$; Table 2$)$ might indicate the presence of a small component of celadonite or illite in the ovoid matrix. Celadonite is a dioctahedral mica mineral that occurs mostly within vesicles of basaltic rocks and tends to form during their hydrothermal alteration (Deer et al., 1992; Meunier, 2005). Celadonite has been found to precipitate with Fe-rich smectites in the Lonal Lake impact structure, a classic Mars analog hydrothermal system activated by a bolide impact (Hagerty and Newsom, 2003). Geochemical modeling of Lonal Lake alteration carried out by these same authors indicates that this hydrothermal assemblage was deposited at temperatures of $130-200^{\circ} \mathrm{C}$ under non-ambient conditions. Illite, on the other hand, is a clay mineral, usually of dioctahedral structure, which can form within sediments, in hydrothermal environments, or as a result of the illitization of smectite in diagenetic environments at elevated temperatures (Deer et al., 1992; Meunier, 2005). Illitization requires a precursor dioctahedral smectite that contains some ferric $\mathrm{Fe}$ that is reduced and involves the substitution of Si by Al, with the resulting charge imbalance compensated by the incorporation of $\mathrm{K}$ originating from the altering fluids (Nadeau and Bain, 1986). The illitization of smectite has also been performed in the laboratory at very low temperatures and high $\mathrm{pH}$ and may take place in nature under these conditions (Eberl et al., 1993). In addition, the illitization of smectite may also be facilitated by microbial activity (Kim et al., 2004; Zhang et al., 2007). Finally, the illitization of smectite is also known to assist boron uptake from the hydrothermal fluid causing the alteration (Bottomley and Clark, 2004).

To calculate the mineral formula from the main clay phase that makes up the ovoid matrix, we followed the procedure suggested by Gooding (1985), and our resulting formula (above) fully satisfies the charge and elemental ranges observed between the tetrahedral and octahedral sites in natural saponites (Weaver and Pollard, 1973), especially in the case of saponites considered to be iron- and aluminarich. In this saponite, the tetrahedral charge is high, whereas the charge of the $2: 1$ layer is -0.29 , which is almost compensated by the interlayer ions $\left(\mathrm{M}^{+}\right.$in the general formula). Smectites in general tend to show a variable charge (Velde, 1985), and very low-charge smectites have been reported to exist in terrestrial samples (April, 1981). The formula we have calculated here, coupled with the relatively high silica content of the ovoid matrix, indicates a saponite, one that is probably slightly oxidized (Deer et al., 1992). This geochemical transformation takes place due to the high instability of iron- rich saponites when the geochemical environment undergoes a substantial change from the originally reducing conditions (Güven, 1988). Similarly, one cannot exclude the possibility that oxidation can also occur during sample storage, preparation, or analysis. Another possibility is that some of this putative ferric iron may have been released by iron-rich trioctahedral smectites (Badaut et al., 1985), which might then concentrate at the periphery of the clay particles in the ovoid matrix. Eventually, dioctahedral clays and Fe oxides (or hydroxides) are thought to have formed within this Nakhla sample, which could account for the observed orange-brown color exhibited by the ovoid matrix in transmitted light (Fig. 1).

The saponitic composition of the ovoid matrix in Nakhla is clearly evident on the $\mathrm{Fe}-\mathrm{Mg}-(\mathrm{Si}+\mathrm{Al})$ ternary diagram shown in Fig. 10, onto which the atomic concentrations of the elements are plotted. In this plot, the dashed lines indicate the stoichiometric composition of a number of phyllosilicate minerals based on their chemical formula, such as serpentine, saponite, and nontronite. All the individual data points plotted (from this and previous studies) in Fig. 10 indicate stoichiometric concentrations. The number of analyses shown on the ternary plot is larger than the number of data listed in Tables 1 and 2 because, in addition to these WDX analyses, we also performed some additional quantitative elemental analyses using the EDX system of the JEOL SEM. From this figure (Fig. 10), it is clear that all chemical analyses of the ovoid matrix, including data for the ovoid wall (black circles) and the ovoid islands (black triangles), plot close to the saponite composition. In contrast, the chemical analyses determined for the fibrous layer L5 (black boxes) extend toward more iron-rich compositions, which may indicate the presence of noncrystalline Fe-Si-Al-oxyhydroxides, such as the ferrihydrite reported by Eggleton (1987), which is also plotted on Fig. 10 as a black star symbol.

The identification of smectite within this conspicuous ovoid structure in Nakhla is clearly very significant for understanding aqueous alteration processes on Mars, especially in light of the recent discovery of trioctahedral smectites in mudstones at Yellowknife Bay in Gale Crater on Mars by the MSL Curiosity rover (Vaniman et al., 2014). This is discussed further in a later section.

\subsection{HRTEM and EFTEM imaging of the ovoid wall}

The high-resolution transmission electron microscopy carried out in this study revealed the presence of several distinctive nanotextural features within the ovoid structure and assisted in identifying mineral phases present within the ovoid based on their inherent structural information (i.e., determined from SAED patterns). An electron transparent section was prepared by FIB milling (Fig. 5) in such a way that it provided a representative cross section through the entire thickness of the ovoid wall (the SEM image in Fig. 5b shows what remains of the ovoid after extracting this crosssectional slice). The BSE image of the full FIB cross section prepared for transmission electron microscopy analysis in Fig. 5a was obtained by using backscattered electrons, so the brighter areas of highest intensity indicate greater scattering (due to higher average atomic number in that region), with darker areas indicating the presence of lighter elements. The bright, smooth-textured mineral phase present on the far left 


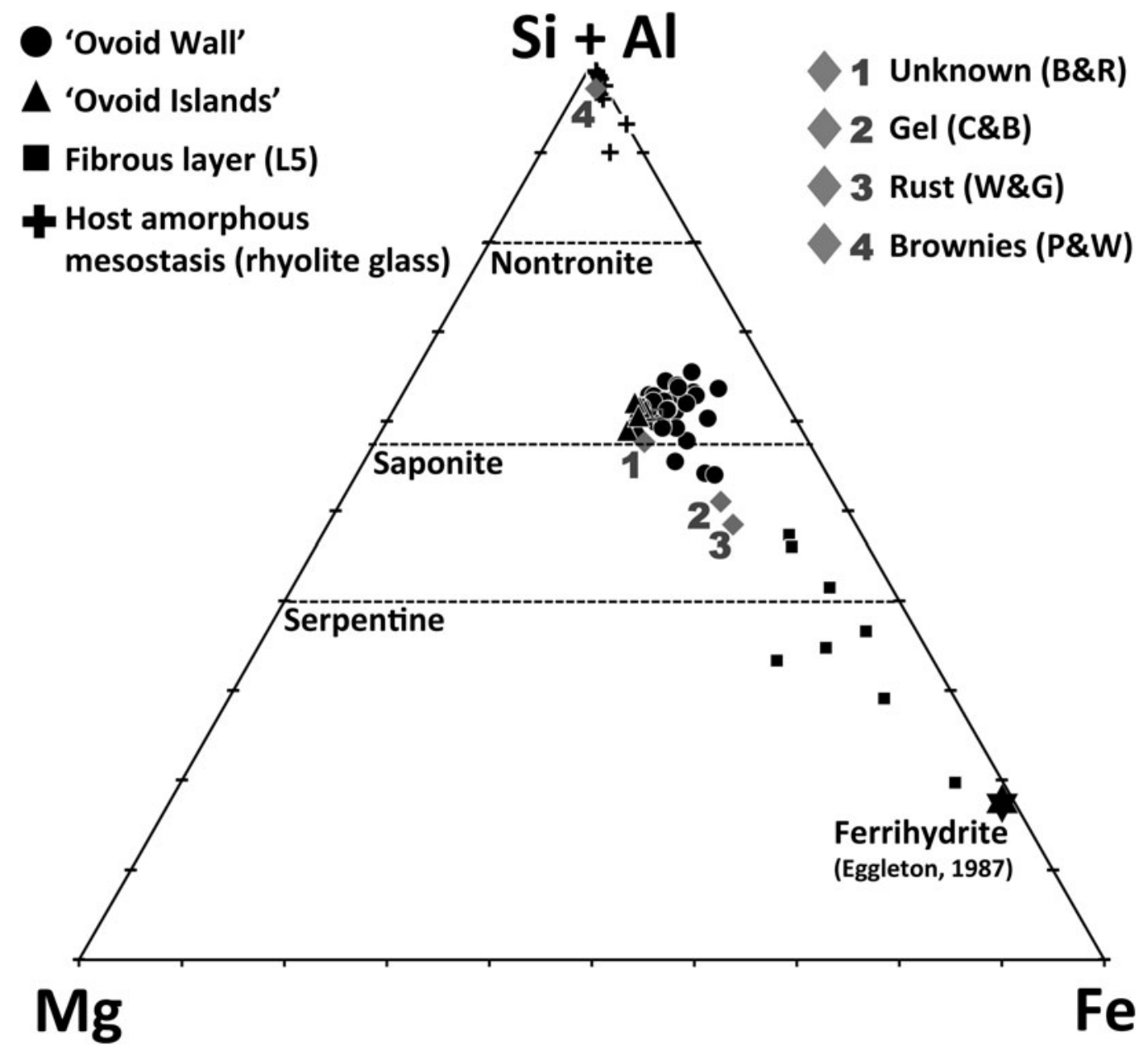

FIG. 10. Ternary diagram showing stoichiometric compositional data for the ovoid structure wall, islands, and the fibrous layer (L5), as well as the host amorphous mesostasis phase (rhyolite glass). Also shown for comparison are previously published geochemical results determined on other Nakhla mesostasis alteration phases including the unknown phase of Bunch and Reid (1975) and Reid and Bunch (1975) labeled here as "Unknown (B \& R)"; the gel material of Changela and Bridges (2011), representing the average of 13 analyses and labeled here as "Gel (C \& B)"; the rust material of Wentworth and Gooding (1990), representing an average of 78 analyses and labeled here as "Rust (W \& G)"; and finally, the brownies of Papanastassiou and Wasserberg (1974), labeled here as "Brownies (P \& W)." The dashed lines represent stoichiometric compositions of the minerals nontronite, saponite, and serpentine ( $c f$. Changela and Bridges, 2011). Ferrihydrite composition is marked with the black star symbol and is plotted from ferrihydrite compositions given in Eggleton (1987). Fe in this diagram represents total iron as $\mathrm{Fe}^{2+}$.

in Fig. 5a is clinopyroxene (Cpx), and the granular material on the far right in this image is a mixture of polishing powder debris. Immediately below the polishing debris material, the dark gray, smooth-textured material is araldite glue. Presumably, the volume that is now filled with araldite glue and polishing debris at the center of the ovoid structure was empty and hollow before sample preparation. Platinum (Pt) was deposited on the surface of the sample at the FIB milling stage to provide greater stability to the extracted cross section, and this $\mathrm{Pt}$ is visible on the right side of Fig. 5 a (Pt1), as well as on the top and bottom edges of the slice (Pt2, Pt3). The ovoid wall region of interest therefore occurs between the pyroxene crystal on the left and the araldite/ polishing debris/Pt1 on the right (Fig. 5a). The material in this cross section through the ovoid wall can be texturally separated into five distinct layers, labeled L1 through L5 (Fig. 5a). Zero-loss filtered energy-filtered transmission electron microscopy analysis (Fig. 14) revealed the thickness of the cross-sectional slice to be approximately constant and $\sim 100 \mathrm{~nm}$ for layers L1-L4; based on the uniform intensity observed in BSE SEM images for these four layers (e.g., Fig. 5a), we conclude that they are composed of material with constant average atomic weight.

Figures 11, 12, and 13 show a series of conventional bright-field TEM, HRTEM images, and SAED patterns obtained from the electron transparent slice through the ovoid wall (i.e., that shown previously in the BSE SEM images of Fig. 5), including one overview TEM image of the entire slice (Fig. 11a). This overview image (Fig. 11a) is actually a mosaic composed of 26 higher-resolution images. The squares marked on Fig. 11a with white dashed lines highlight the areas where the close-up images shown in Fig. 11b-11e were obtained. Similarly, the white dashed squares in Fig. 11b-11e demarcate the areas from which SAED 


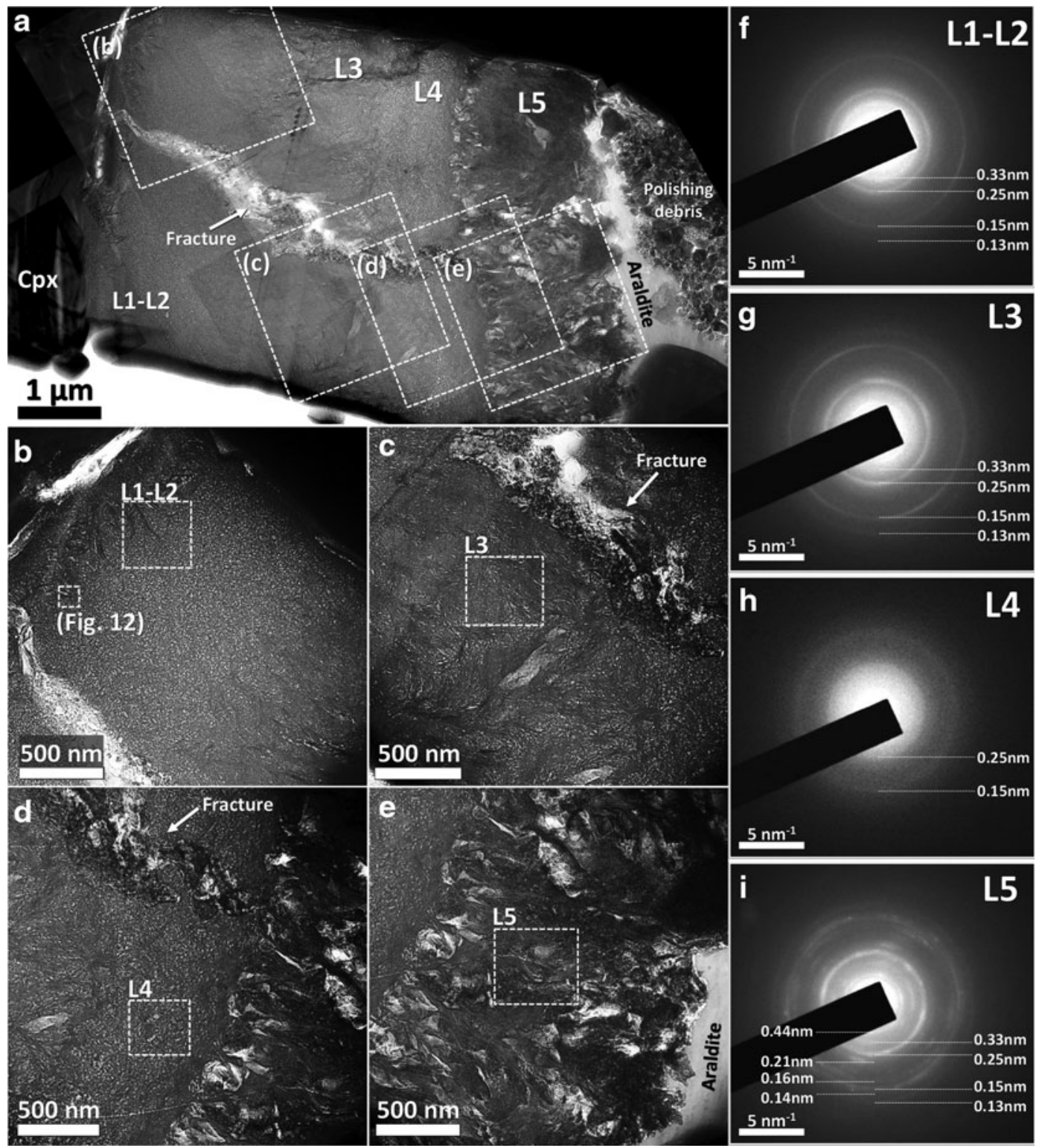

FIG. 11. Bright field TEM images of the FIB slice extracted from a perpendicular section through the ovoid wall. (a) Overview TEM image of the entire FIB slice. This image is a mosaic composed of several high-resolution images. Abbreviation: Cpx, clinopyroxene. (b-e) Close-up HRTEM images from (a), showing the four regions demarcated by the white squares in (a), corresponding to layers L1-L2, L3, L4, and L5. (f-i) SAED patterns obtained from within these same four regions, of which the corresponding selected area locations are demarcated as white squares within (b-e), and the corresponding lattice spacings are given in Table 3. Together, these data reveal the occurrence of several micron-scale texturally distinct layers within the ovoid wall cross section.

patterns were acquired (L1/L2, L3, L4, and L5 in Fig. 11f11i), as well as the close-up TEM image and its Fourier transform shown in Fig. 12. As shown in Figs. 11b and 12a, layer L1 contains large $(\sim 200 \mathrm{~nm})$ crystallites with large interplanar spacings in which the visible lattice planes are oriented almost perpendicular to the interface with clinopyroxene (see upper left in Fig. 11b). In contrast, HRTEM images of layer L2 show a highly disordered morphology (Figs. 11b and 12a), in which the visible crystalline regions are much smaller $(\leq 10 \mathrm{~nm})$, often appear curved and spherical in form, and are limited to only a few planes of crystalline material. Similar small domains with curved lattice structures have been documented previously in some terrestrial glasses and interpreted as evidence of the incipient formation of primitive clays (Tazaki et al., 1989) that might be nucleating around structural water present within the glass (Tazaki et al., 1992) — potentially analogous to the hydrous mesostasis glass described here. The SAED image of Fig. 11f includes information from a larger area at the interface between layers L1 and L2 and shows complete rings on a diffuse background. Higher spatial resolution analysis of the lattice fringe spacings from this region is possible by analyzing the Fourier transform (Fig. 12b) of the HRTEM image in Fig. 12a, which shows a region in layer L2 (area highlighted in Fig. 11b). The lattice spacings measured from the spots and small arc features in Fig. 12b 

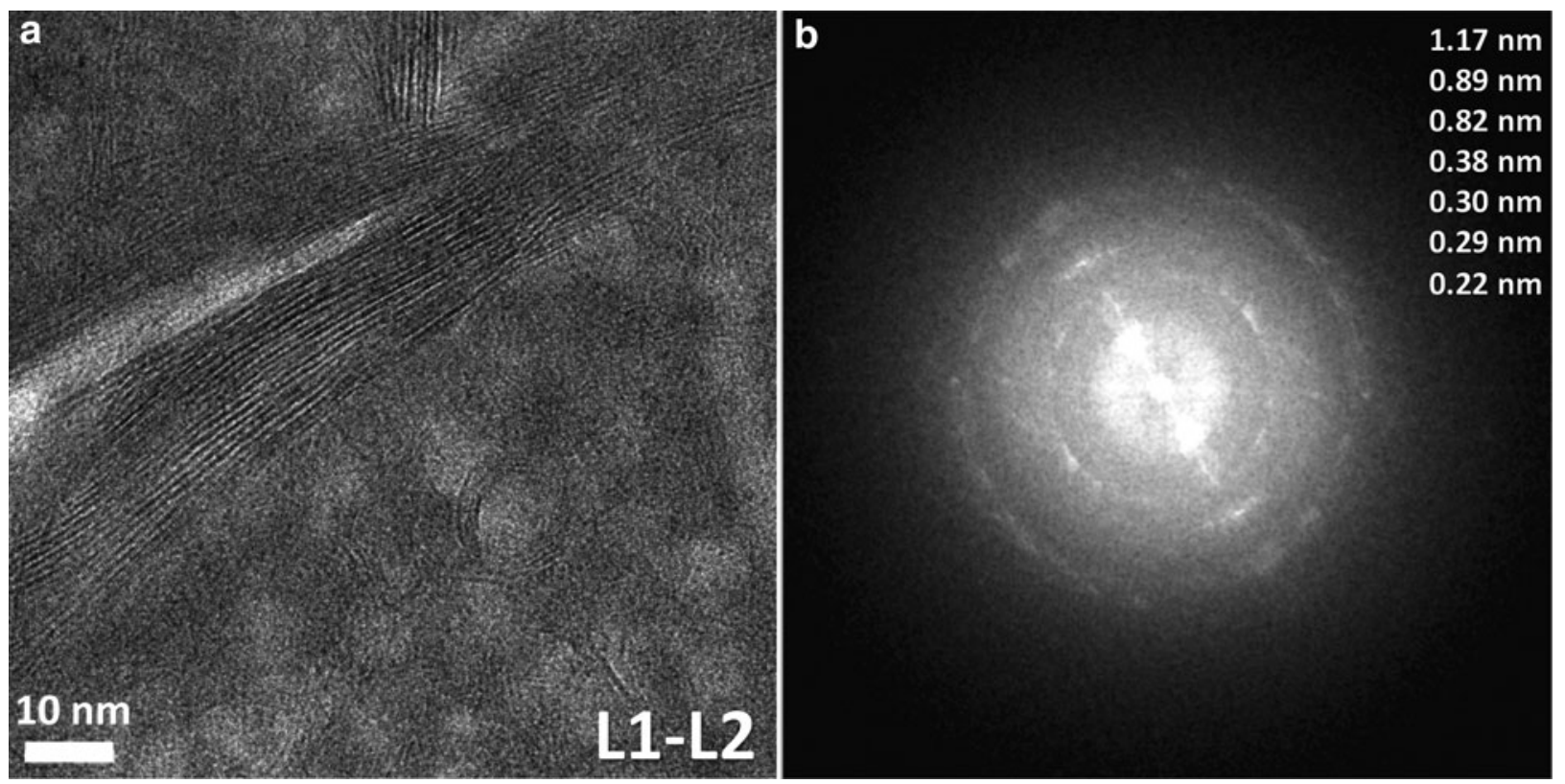

FIG. 12. HRTEM image and Fourier transform pattern of an area at the interface between layers L1 and L2. (a) HRTEM image (taken from approximately the location indicated in Fig. 11b and demarcated as Fig. 12). Lattice planes are visible both in large crystallites and in the less ordered region where they are observed in highly curved nanocrystallites grown around spherical features of amorphous material $\leq 10 \mathrm{~nm}$ in diameter. (b) The corresponding Fourier transform pattern obtained for the area shown in (a), which indicates that the planes visible in the HRTEM image in (a) correspond to lattice planes with spacings of $1.17,0.89,0.82,0.38,0.30,0.29$, and $0.22 \mathrm{~nm}$.

are characteristic of phyllosilicate mineral phases and are superimposed on a diffuse background, suggesting that this region also contains a significant amount of amorphous material. The SAED pattern from region L3 (Fig. 11g) is similar to that from region L1-L2 (Fig. 11f), except that in the L3 pattern the diffraction rings are brighter in comparison to the amorphous background, suggesting that layer L3 contains a greater proportion of variably oriented crystalline material. This interpretation is also supported by the greater contrast and textural variability observed within the close-up bright field TEM image of that layer (Fig. 11c). The change in crystalline morphology and overall microtexture from region L2 to L3 is quite gradual, whereas the textural transition from L3 to L4 is considerably more abrupt (Figs. $11 \mathrm{~d}$ and $13 \mathrm{c}, 13 \mathrm{~d})$. The SAED pattern determined from layer L4 (Fig. 11h) contains only very diffuse diffraction rings, which indicates that the L4 region is highly disordered and has a lower degree of crystallinity than layers L1-L3. The textural transition from L4 to L5 shown in Figs. 11e and 13d is also quite abrupt, with the L5 region exhibiting larger contrast and textural variations within the layer, which suggests the presence of larger crystallites. This interpretation is supported by the increased level of crystalline diffraction information shown in the inset SAED pattern (Fig. 11i) for layer L5, which attests to the higher degree of crystallinity exhibited by this layer.

A large fracture passes through the center of layers L1-L4 (Figs. 5a, 11a, and 13b, 13d), which has a width of $\sim 0.1 \mu \mathrm{m}$ in the vicinity of the clinopyroxene grain against which the fracture is terminated but then broadens to a thickness of $\sim 1 \mu \mathrm{m}$ as it passes through layers L2 and L3 (Figs. 5a and 13b). Close to layer L4, the fracture appears brighter in BSE SEM images (Fig. 5) and darker in the bright field TEM images (Fig. 11). This indicates that the whole length of the fracture may have been infilled with denser material, the appearance of which is similar to that of layer L5 (e.g., compare the fracture-fill and layer L5 material in Fig. 5e and in Fig. 11d). This suggests that the material in layer L5 may have formed later in time, after the fracture was formed, and consequently partially infilled the fracture during its formation. The presence of distinctly rounded, amoeboidshaped void spaces within the fracture (Figs. 11c and 13b) suggests that possible gaseous material may also have partially infilled the fracture at some stage after the fracture was formed. A microveinlet of higher brightness is also visible at the top of the cross section, where it transects a portion of layer L3 (Fig. 5a). It seems likely that this is a second smaller fracture that is genetically associated with the larger fracture.

The lattice spacings measured from each of the SAED patterns determined for the four main layers (L1/L2, L3, L4, and L5) of the ovoid structure (Fig. 11f-11i) are summarized in Table 3. Layers L1/L2, L3, L4, and L5 all include some information from the same set of crystalline diffraction rings, which correspond to lattice spacings of 0.33 , $0.25,0.15,0.13$, and $0.10 \mathrm{~nm}$, suggesting that all these layers are composed of the same crystalline phase. The fact that region L4 shows only the strongest of diffraction rings, which correspond to lattice spacings of 0.25 and $0.15 \mathrm{~nm}$, suggests that this particular layer contains a more disordered variety of the same crystalline phase. At the interface between layers L1 and L2, larger crystal flakes of phyllosilicates are observed, and the Fourier transform pattern from an HRTEM image at this interface (Fig. 12a) reveals some even larger lattice spacings, measured at 0.82, 0.89, and $1.17 \mathrm{~nm}$ (Fig. 12b). The value of $1.17 \mathrm{~nm}$ corresponds to the 


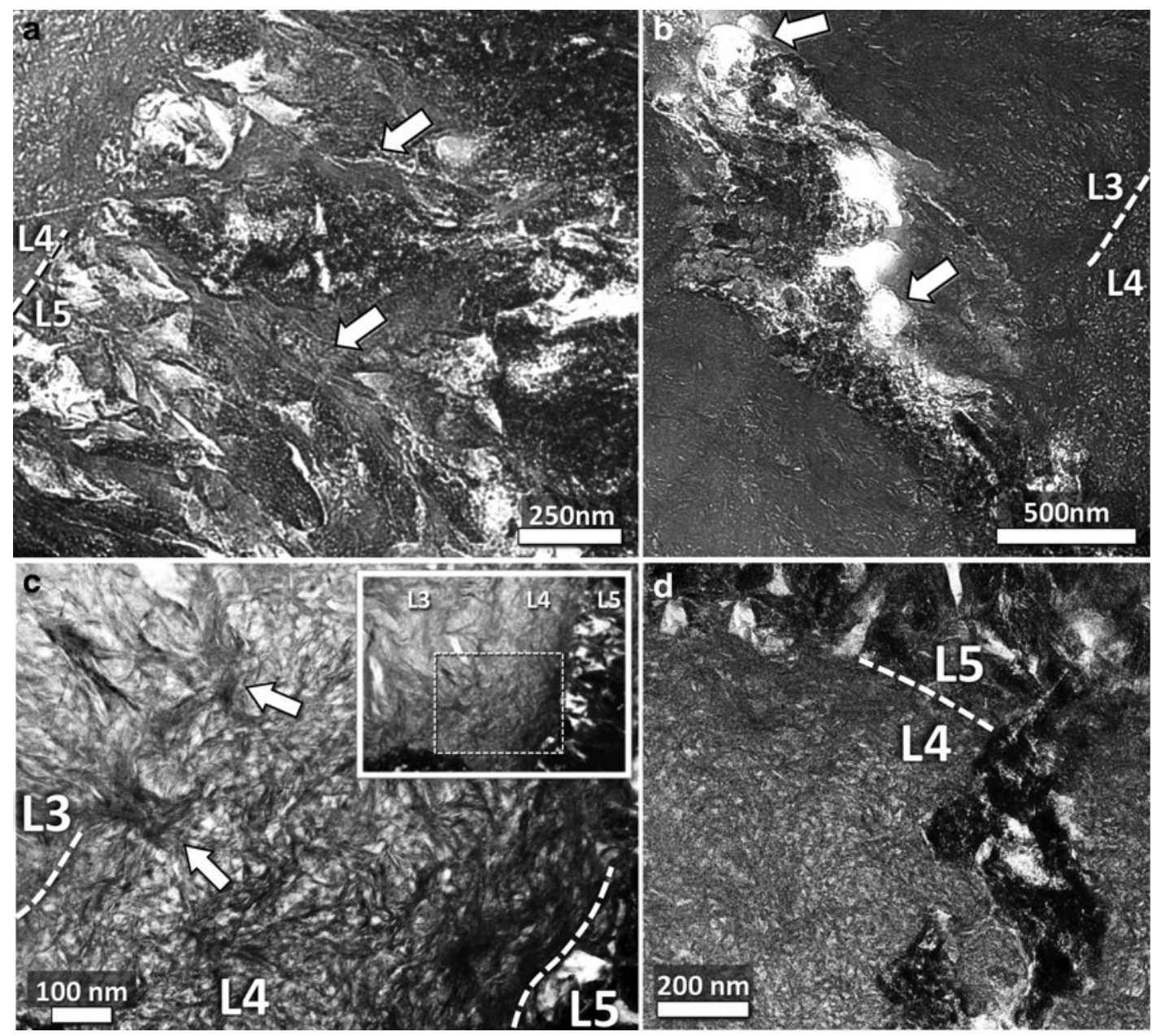

FIG. 13. Close-up bright field TEM images from the TEM slice shown in Figs. 5 and 11, highlighting selected microtextural features at higher magnification. (a) TEM image of a representative region of layer L5. The arrows highlight the presence of low-contrast elongate fibrous material oriented perpendicular to the L4-L5 interface. (b) TEM image of a region of an infilled fracture (microveinlet) that contains spheroidal to amoeboid bubble-like voids (arrows). (c) TEM image of a representative region of layer L4 and of its interfaces with layers L3 and L5 (inset image shows a larger overview). The arrows indicate places where the crystallites of L3 appear to be rooted inside the material of layer L4. (d) TEM image of the interface between layers L4 and L5 close to the infilled fracture of (b).

Table 3. Lattice Spacings (IN NM) Measured from the Selected Area Diffraction Patterns FOR THE FOUR MAIN LAYERS OF THE OVOID Structure Shown in Figure 11f-11i

\begin{tabular}{lccc}
\hline L1-L2 & L3 & L4 & L5 \\
\hline & 0.45 & & 0.44 \\
0.33 & 0.33 & & 0.33 \\
0.25 & 0.25 & 0.25 & 0.25 \\
& & & 0.21 \\
0.15 & 0.15 & 0.15 & 0.16 \\
& & & 0.15 \\
0.13 & 0.13 & & $0.14 *$ \\
0.10 & 0.10 & & 0.13 \\
& & & 0.10 \\
& & & $0.093^{*}$ \\
\hline
\end{tabular}

Measured lattice spacings are calibrated to an accuracy of better than $5 \%$. In column L5, the values denoted with an asterisk indicate lattice spacings that were measured from diffraction spots identified in the SAED image of Fig. 11i. basal lattice plane spacing for the larger phyllosilicate flake shown in Fig. 12a and is considered to be a representative analysis of a well-formed crystallite in the ovoid matrix. This spacing is consistent with layers L1-L4 being composed of a mineral having 2:1 phyllosilicate structure and is similar to the spacings measured from Lafayette smectites by Changela and Bridges (2011). For Nakhla, Gooding et al. (1991) reported lattice spacings that range between 1.1 and $1.3 \mathrm{~nm}$, which they interpret as evidence of a smectite being present-an idea that was later advanced even further to specify the presence of an iron-rich smectite (Treiman and Gooding, 1991). However, it is also important to note at this point that other detailed investigations of Nakhla were not able to find any evidence of clay minerals being present (Changela and Bridges, 2011). Nevertheless, one recent Nakhla study identified Fe-Mg silicates that crystallized within cracks in olivine and show 1.10-1.25 nm basal layer spacing, which were interpreted as collapsed smectite (Lee et al., 2013).

Fringe spacings slightly larger or equal to $1 \mathrm{~nm}$ are diagnostic of smectite, which inside the vacuum chamber of 
the TEM can collapse down to $1 \mathrm{~nm}$ due to dehydration (Eggleton, 1984; Alt and Mata, 2000; Zhang et al., 2007; Changela and Bridges, 2011), making it difficult to distinguish this clay from other possible clay minerals such as illite (Eggleton, 1984; Ahn and Peacor, 1986). Oxidation reactions can consume interlayer water as well (Kohyama et al., 1973), which tends to cause the clay mineral to acquire a red-brown color-similar in nature to the reddishorange to brownish color of the ovoid material (Fig. 1). Consequently, the variability observed in our measurements of lattice spacings at around $1 \mathrm{~nm}$ also suggests the presence of mixed-clay layers. Smectites with lattice spacings of about $1 \mathrm{~nm}$ have also been detected by the MSL Curiosity rover on Mars, indicating that little inter- layer hydration is present (Vaniman et al., 2014), an observation that is relevant to the present study in that, by comparison, the smectite in Nakhla may also have been already partially dehydrated on Mars, such that it is not necessarily a collapse effect due to the high vacuum of the TEM instrument. Nevertheless, clays with larger basal spacings of $\sim 1.32 \mathrm{~nm}$ were also detected in that study and interpreted as evidence of mixed clays being present, such as smectites with partially chloritized interlayers (Vaniman et al., 2014).

The fibrous layer L5 also shows some additional lattice spacings, implying the presence of a second crystalline phase, which we suggest is most likely to be the aforementioned Fe-rich phase indicated by WDX chemical
TEM Image

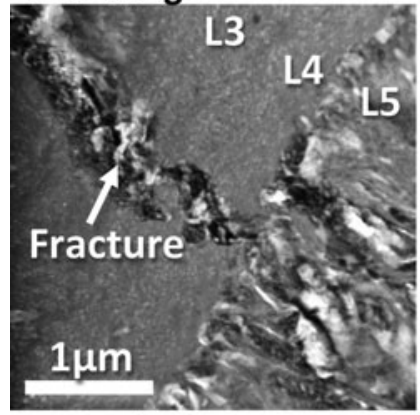

Fe L edge

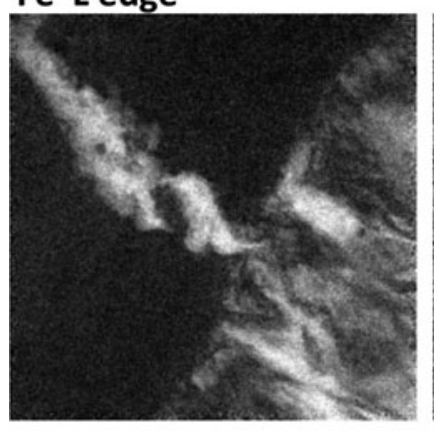

Si K edge

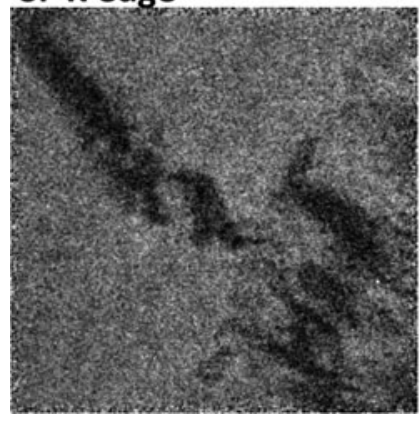

Thickness map

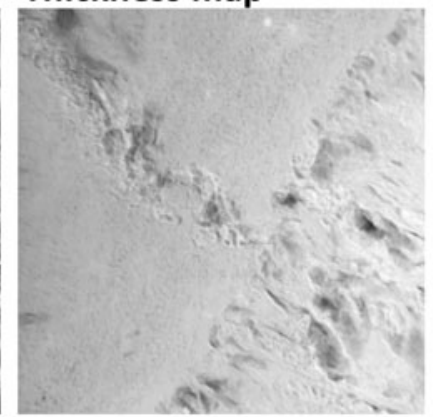

Mg K edge

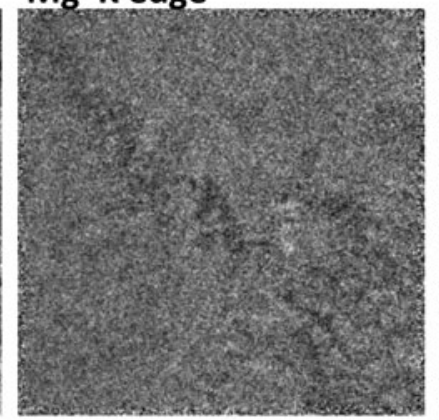

Na Kedge

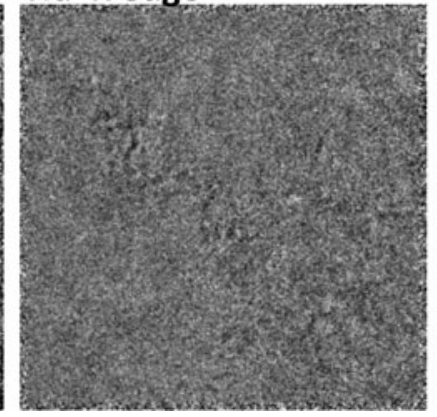

\section{O K edge}

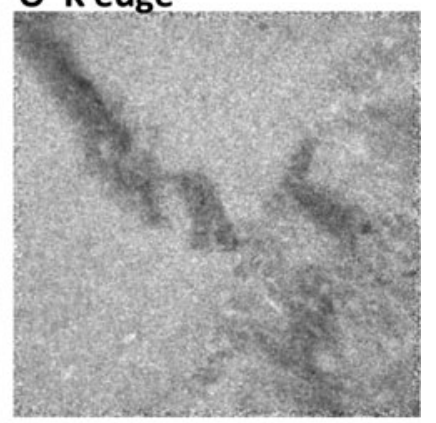

Mn L edge

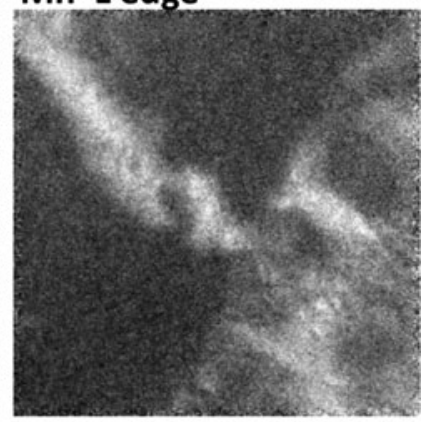

C K edge

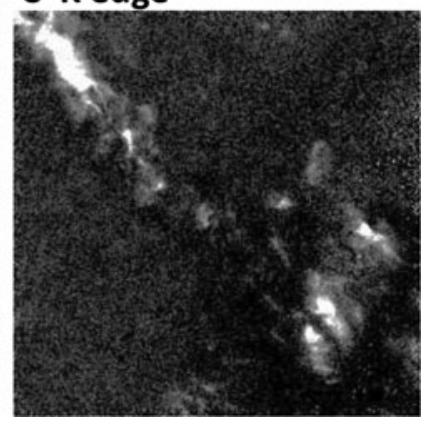

FIG. 14. EFTEM elemental maps obtained for a region of the TEM slice shown in Figs. 5 and 11, at the interface between layers L3, L4, and L5 (fibrous layer). For reference, a close-up bright field TEM image (from Fig. 11) is also shown (top left), and the scale bar in that image applies to all other images in this figure (which represent different chemical maps of the same region). As shown by the Fe map, a fracture that passes through layers L1-L4 is infilled with iron-rich material. This material also appears to be Mn-rich and Mg-poor. In addition, both the infilled fracture and layer L5 appear, in places, to be rich in carbon. In the bright field TEM image, bright colors indicate areas where the average atomic number of the material being imaged is relatively low (or places where the sample is thinner), that is, allowing more electrons to pass through, while the darker shades indicate places where the average atomic number is relatively high. In the thickness map, regions with the same color intensity indicate areas where the FIB slice has the same specimen thickness. All the other images are element maps in which the brighter colors correlate with higher elemental concentrations. 
analyses of this layer (Table 2). These additional lattice spacings observed for layer L5 are $0.44,0.21,0.16,0.14$, 0.09 , and $0.083 \mathrm{~nm}$ (Table 3); however, questions remain as to exactly what mineral or minerals they are attributed to. The lattice spacings of 0.16 and $0.14 \mathrm{~nm}$ overlap with those of the nontronite standard given by Changela and Bridges (2011), and these authors have also resolved in Lafayette an iron-rich phase of hexagonal symmetry with spacings of about $0.156 \mathrm{~nm}$ that is identified as ferrihydrite. Although this value coincides closely with one of the values measured by us in layer L5 $(0.16 \mathrm{~nm})$, it is difficult to state with much confidence that our iron-rich phase is unequivocally made up of ferrihydrite.

The results of EFTEM chemical mapping of the FIB slice are presented in Fig. 14. These elemental maps span an area that includes layers L3, L4, and L5, as well as a large portion of the infilled fracture where it passes through layers L3 and L4 (TEM image in Fig. 14). The thickness map of Fig. 14 shows that the FIB slice has a uniform thickness in this region except for in small areas where some material is vacant, such as within the fracture and in some areas between the fibrous materials in layer L5. Consequently, the majority of the nanoscale intensity variations in the elemental images are attributed to compositional changes. From the elemental maps shown in Fig. 14, it is evident that layers L3 and L4 are chemically indistinguishable from one another and that both layers contain similar and evenly distributed amounts of oxygen, magnesium, and silicon. These chemical traits are consistent with the idea that the entire zone comprising layers L1-L4 is composed of the same clay mineral phase and/or its disordered precursor material. Layer L5 seems to contain regions that are of similar composition to layers L3 and L4; however, this layer (L5) also exhibits localized regions where the material is substantially more iron- and manganese-rich, which might indicate the presence of a mixed iron-manganese hydroxide phase. Another feature that is readily apparent in the EFTEM data shown in Fig. 14 is the occurrence of carbonaceous regions within layer L5 and within the fracture passing through layers L3 and L4, although we cannot rule out the possibility that these carbonaceous areas represent carbon contamination, which is incorporated into porous regions during sample preparation. The large differences in energy losses of the mapped elements in Fig. 14 prevented quantitative chemical analysis by energy-filtered transmission electron microscopy; therefore, these chemical maps are only considered to depict qualitative differences in chemical composition.

In summary, the results of our TEM imaging and EFTEM chemical mapping study are consistent with layers L1-L4 comprising a uniform mixture of a crystalline clay mineral phase and amorphous material, which has an overall constant chemical composition but exhibits varied nanotextural domains between layers. Layer L5 appears to contain both a clay phase and a second nanocrystalline to amorphous phase enriched in iron and magnesium. The main fracture passing through layers L1-L4 is partially infilled with a material of similar microtexture and composition to L5, suggesting that the formation of this fracture occurred after the formation of layers L1-L4 of the ovoid wall but before the formation of layer L5.

\subsection{AFM imaging of the ovoid structure}

Atomic force microscope topographic imaging of the exposed surface of both the wall and the islands of the ovoid matrix revealed a nanograined structure that exhibits strong preferred orientation (Fig. 15). For comparison, we also
FIG. 15. Representative AFM topographic maps of the ovoid structure. (a, b) AFM topographic maps of the wall of the ovoid structure, (c) of one of the two islands inside the ovoid, and (d) of a clinopyroxene crystal, for comparison. The areas from which these images are taken are shown in Fig. 4a. The color scales at upper right in each of the four images indicate the absolute height dimensions (in nanometers) for that image.
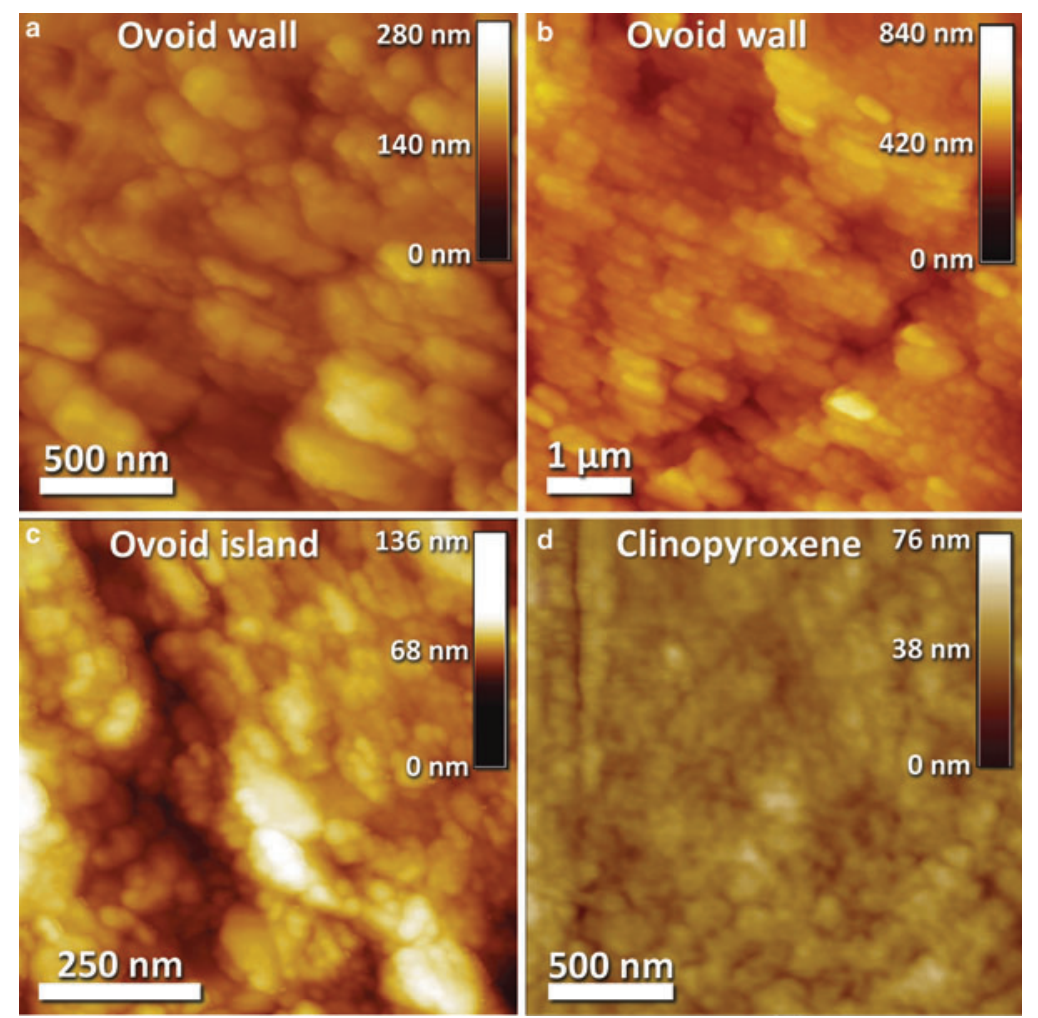
performed an AFM scan of a nearby clinopyroxene surface (Fig. 15d), and in contrast with the ovoid wall (Fig. 15a, 15b) and island (Fig. 15c) regions, the clinopyroxene surface shows no evidence of an oriented fabric, although some polishing scratches are evident. The nanograins present on the exposed surface of the ovoid wall are approximately one order of magnitude larger than those present in the island regions. In both cases, however, it seems that the nanograins are composite clusters of several smaller particles. The nanograin clusters from within the wall area range in size from about $100 \mathrm{~nm}$ (Fig. 15a) to over $500 \mathrm{~nm}$ in their longest dimension (Fig. 15b), whereas those of the islands range from about 20 to $100 \mathrm{~nm}$ long. In contrast, such composite clusters of nanoparticles are not visible on the topographic map of the clinopyroxene surface.

\section{Discussion}

There is strong textural and chemical evidence that the ovoid structure is indigenous to Nakhla and originated on Mars. The petrographic context of this highly elliptical ovoid structure within late-forming mesostasis glass, coupled with its relatively large size, distinct chemical composition, and complex microtextures, supports this idea and effectively rules out the possibility of an origin by contamination, as an artifact of sample preparation, or through formation during the time of curation since 1911. It is also important to highlight that this is the first time that such a conspicuous ovoid structure has been observed in a martian meteorite. It was mainly its unusual overall shape (i.e., ovoid structure with a concentric wall; Fig. 2) and highly symmetrical and fine-scale internal microstructures (Figs. 3 and 4) that prompted the present study. Although the full three-dimensional shape of this structure was lost during the preparation of the polished petrographic thin section, enough of the ovoid remained to allow for this detailed multidisciplinary study. To determine the nature of the ovoid (and its environs) and attempt to elucidate the likely sequence of geological events and processes that led to its formation, a detailed series of in situ chemical and structural investigations was carried out at the micrometer and nanometer scales, employing a wide range of imaging and analytical techniques. This is an ideal strategy for this type of study (Jongmans et al., 1999) and was carried out with the aim of exploring different hypotheses with regard to possible biotic or abiotic origins of the ovoid. The abiotic scenarios we evaluated include mechanisms such as the replacement of a previously existing phase through in situ alteration linked with fluid infiltration and dissolution, the space-filling of an originally hollow ovoid or tubular volume, or a process similar to palagonitization of basaltic glass in which the ovoid forms by alteration around a vesicle. Because of the possible far-reaching implications (i.e., for life on Mars), the somewhat biomorphic shape and concentric structure of the ovoid were also evaluated with regard to possible biotic formation scenarios.

\subsection{Mineralogy and chemistry of the ovoid structure}

Despite the textural heterogeneity of the ovoid structure (i.e., the occurrence of five distinct layers), the wall has an overall homogeneous chemical composition (e.g., appears even-toned in the BSE SEM map in Fig. 5a and the EFTEM elemental maps in Fig. 14), with the exception of layer L5, which is composed of more than one mineral phase, one of which is Fe- and Mn-rich (Fig. 14) and of higher average atomic number (appears brighter in the BSE SEM image in Fig. 5e). In comparison to some other previously documented secondary materials within Nakhla, the composition of the ovoid wall is quite similar, including for example the amorphous gel identified as the material infilling olivine fractures (diamond symbol 2 in Fig. 10) documented by Changela and Bridges (2011) or Lee et al. (2013) and the "rust" of Wentworth and Gooding (1990) and Gooding et al. (1991) (diamond symbol 3 in Fig. 10), and it is perhaps the most similar in composition to the phase described as "unknown" by Bunch and Reid (1975) and Reid and Bunch (1975) (diamond symbol 1 in Fig. 10) but notably quite different from their iddingsite. In contrast, the ovoid matrix is chemically very different from the so-called "brownies" (diamond symbol 4 in Fig. 10) of Papanastassiou and Wasserberg (1974), which, however, are very similar in composition to our unaltered amorphous mesostasis phase (rhyolitic glass; plus symbols in Fig. 10) that hosts the ovoid structure.

Nanoscale imaging revealed that layers L1 through L4 are texturally distinct from one another. They are composed of varying combinations of amorphous material, proto-crystalline material, and crystalline clay, but collectively (along with the ovoid islands) they seem to be stoichiometrically balanced to trioctahedral iron-rich saponitic clay (Table 2). This clay was most likely formed in situ (but possibly from chemical components sourced from the dissolution/hydrothermal alteration of more distal primary mineral phases), although it did not form as a result of shock-related processes because clay minerals are not known to form in this way (Allen et al., 1982). Finally, it is clear that the fibrous layer L5 is both texturally and chemically very distinct from the main ovoid matrix (L1-L4), and based on crosscutting relationships between these layers (and an infilled fracture), layer L5 was deposited chronologically last. Texturally (and at a larger scale), layer L5 is distinct in that it covers (or blankets) all the inner surfaces of the ovoid wall (Figs. 3b and 4d) as well as the periphery of the islands (Fig. 4b) and also passes through a fissure that crosscuts the ovoid wall (Fig. 3a, 3b) where it locally forms a thin veneer on the outer surface of the ovoid wall.

Time-of-flight secondary ion mass spectrometer ion imaging revealed heterogeneities in the distribution of light elements within the mesostasis region and the ovoid (Figs. 8 and 9). Clinopyroxene phenocrysts within Nakhla are known to contain a number of light lithophile elements (namely, Li, Be, and B), and as expected, they appear to have behaved incompatibly, increasing in concentration toward the rims of these crystals (Lentz et al., 2001). The TOF-SIMS ion maps produced in the present study of a mesostasis region within Nakhla (see images in Fig. 9) reveal the presence of $\mathrm{Li}$ in that region, and that this element is enriched within the clinopyroxene rims and in the matrix (i.e., clay) of the ovoid structure, relative to its concentration in the adjacent mesostasis glass. In contrast, the equivalent map for boron (Fig. 9) shows that, although this element is also preferentially enriched within the ovoid matrix relative to the mesostasis glass, it is almost entirely absent in the adjacent clinopyroxene rims. This observation is in accordance with quantitative measurements made by Spivak-Birndorf et al. (2008) that distinguished primary from secondary phases with respect to their B content, that is, the B-rich mesostasis 
iddingsite ( 4-7 ppm B) from the B-poor pyroxenes ( < 4 ppm B). Beryllium is not present within the ovoid structure, but it is present in very low concentrations within the mesostasis glass (data not shown) and in much higher concentrations within rhoenite (Fig. 8c). On Earth, B and Li concentrate preferentially within the low-temperature products of hydrothermal alteration (e.g., within the oceanic crust; Seyfried et al., 1984); therefore, by analogy, the presence of these elements in the Nakhla mesostasis region might imply the involvement of lowtemperature hydrothermal fluids of a magmatic origin. In Nakhla, this is most likely true for B in particular, because its isotopic signature - both in secondary phases and in primary igneous minerals such as pyroxenes-is identical (SpivakBirndorf et al., 2008). Beryllium is insoluble in water-rich fluids (Lentz et al., 2001, and references therein) and concentrates primarily within feldspars, micas, and clays, where it replaces $\mathrm{Si}^{4+}$ due to its similar ionic radius. The presence of $\mathrm{Be}$ in rhoenite, however, provides strong evidence that this element has a magmatic origin; therefore, the presence of $\mathrm{Be}$ in the amorphous mesostasis of Nakhla also suggests that at least a certain component of the mesostasis has a magmatic origin. This evidence is made more concrete by the additional detection of $\mathrm{Rb}, \mathrm{Sr}$, and $\mathrm{Ba}$ within the mesostasis (also determined here based on some new preliminary data obtained with highmass resolution time-of-flight secondary ion mass spectrometry analyses: not shown). On the other hand, however, all these three elements are also known to have a strong affinity to seawater, as well as evaporitic saline waters (Vengosh et al., 1991).

From the evidence provided in this section, it is clear that the ovoid matrix material is quite different from its host amorphous mesostasis material. The amorphous, hydrous mesostasis, in which the ovoid structure is hosted, has a rhyolitic composition and therefore might be the vitrified fraction of a highly fractionated basaltic magma that may also have intermixed with surface fluids. This composition is very different from the composition of the matrix of the ovoid structure itself, and the chemical, mineralogical, and textural evidence presented in this study is thus interpreted to reflect multiple stages of formation for these contrasting materials in the mesostasis region within Nakhla.

\subsection{Layered microstructures within the ovoid wall, islands, fissure, and the hollow volume}

The ovoid structure is both visibly (Fig. 1) and chemically (e.g., Figs. 6 and 9) distinct from surrounding host phases and exhibits sharp boundaries with the adjacent clinopyroxene crystals, as well as sharp contacts with the amorphous mesostasis. At the submicron scale, HRTEM imaging revealed a distinctly multilayered internal structure to the ovoid wall that is defined by five subparallel layers (L1-L5) that exhibit significantly different nanotextures (Figs. 5a and 11a). These layers vary with respect to the shapes, sizes, and textures of the crystallites they contain, as well as the varying amounts of amorphous matrix present. Despite these microtextural differences, layers L1 to L4 are chemically homogeneous. Subsequent to the formation of all five layers of the ovoid structure, mechanical stress incurred during preparation of the thin section seems to have opened up small fractures in, and around, the ovoid structure, including some layer-parallel fractures resulting from differential movement along the weak interfaces present within or between layers (see white arrows in Fig. 3c), as well as crosscutting fractures that transect the ovoid wall (and its internal layering) at high angles (see fractures at right and at lower left in Fig. 3a). In addition, along the outer perimeter of the ovoid structure, a shrinkage gap seems to have formed at some point after the formation of the ovoid wall and occurs between it and the amorphous mesostasis glass. The gap is now infilled with granular material that appears to be polishing debris (see this infilled shrinkage gap in Fig. 3b, 3c).

Layer L4 seems to have a uniform thickness of about $0.8 \mu \mathrm{m}$ and is texturally distinct from the other layers (Fig. 11a, 11d). Like layer L2, it seems to be composed primarily of disordered material; however, bright field TEM images and the SAED pattern for L4 indicate the presence of randomly oriented nanocrystallites (Figs. 11d, 11h, and 13c, 13d). Layer L4 is clearly more amorphous at the interface with layer L5, although it does exhibit more of an internal fabric (preferred orientation) that is parallel to the L4/L5 interface (Fig. 13c, 13d). Collectively, layers L1, L2, and L3 could be described as a single unit, based on the observation that the crystallites present in both layers L1 and L3 seem to extend at orthogonal angles into the middle layer L2 (i.e., are partially enveloped by L2 and/or progressively grade into it; Fig. 11b). Layer L1 is in direct contact with clinopyroxene and clearly contains several individual, large $(\sim 100$ $300 \mathrm{~nm}$ long) crystallites that are oriented at a high angle to this contact (Figs. 5c, 11a, 11b, and 12a). Layer L3 is significantly more crystalline than the adjacent layers L 2 and L4, and contains crystallites that at the contact with layer L4 often appear to be rooted inside it (arrows in Fig. 13c) but toward the L3 interior grade into a zone of more randomly oriented flaky crystallites, which toward layer L2 gradually become orthogonal to layering and partially extend outward into this more amorphous layer (L2). However, despite the more spotty and amorphous internal microtexture of layer L2, it also contains exceptionally small ( $\leq 10 \mathrm{~nm}$ ), curved crystallites of phyllosilicates that appear to be bent (i.e., curved) around amorphous centers (Fig. 12a). These tiny crystallites are interpreted as proto-crystalline material, which may be hydrous. Collectively, these various microtextural observations between layers L1, L2, L3, and L4 are taken to indicate that they formed contemporaneously. It is not exactly clear, however, as to whether or not the growth of these layers was a space-filling phenomenon or an alteration process that may have modified or replaced a preexisting phase. Relevant here is that two round internal masses present within the hollow of the ovoid are also of the same composition as layers L1-L4 (namely, the islands in Figs. 2b and 4a; Table 2).

Layer L5 is chemically and texturally distinct from all other layers that define the ovoid wall. It exhibits a highly heterogeneous texture in BSE and HRTEM images (Figs. 5a, 5e, 11e, and 13a, 13d), which can be described as a mottled fibrous texture, containing patches of material that are very rich in iron (i.e., bright areas in the BSE image of Fig. 5a and the EFTEM Fe map of Fig. 14, and the dark areas in the bright field TEM images of Fig. 13a, 13d). Many of those iron-rich grains (which appear dark in Fig. 13a) are directly attached to layer L4 (e.g., see L4/L5 contact in Fig. 13a) and often exhibit a distinctive fibrous microtexture (see arrows in Fig. 13a) defined by oriented crystallites (Fe-rich clay?) of variable length that appear to have nucleated on the L4 contact in an orthogonal fashion, all of which indicates that L4 had already formed prior to the growth of layer L5. 
In addition to diffraction circles, the SAED images for layer L5 also exhibit diffraction spots, indicating the presence of oriented crystallites. Iron-rich material similar in composition to the material of layer L5 now infills the fracture that cuts across layers L1 to L4 (Fig. 11a). This is demonstrated clearly by the distribution of iron in the EFTEM Fe map shown in Fig. 14, patterns that are also reflected in the Mn map of the same area. Similarly, and to add further support to the idea that the material of layer L5 is the last to have formed, is the observation that it also now occupies the opening of the symmetrical (hourglass-shaped) overprinted fissure that cuts across the ovoid wall (Fig. 3). Collectively, all the observations of layer L5 show that this $\sim 1-2 \mu \mathrm{m}$ thick layer exhibits great continuity, forms a thin veneer that blankets virtually the entire inner surface of the ovoid wall (Figs. 2b and 3), passes through the overprinted fissure where it also coats a significant portion of the outer surface of the ovoid wall (Fig. 3), and has developed as a coating around the periphery of the islands in the interior of the ovoid (Figs. 2b and 4b) and possibly as an isolated rounded granule that measures $\sim 5 \mu \mathrm{m}$ in diameter (Fig. 4c). From the available data, it is clear that layer L5 may have formed not only chronologically last but also through a distinctly different process or event than layers L1-L4. Although it is not definitely clear, layer L5 may have been precipitated directly from saturated fluids (e.g., during a drop in temperature or through evaporation), or alternatively, this layer may have formed due to the alteration of the previously existing ovoid matrix (layers L1-L4) during the late-stage influx of fluids with a different composition.

The interiors of the two rounded internal masses present within the hollow of the ovoid (namely, the islands in Figs. $2 \mathrm{~b}$ and $4 \mathrm{~b}$ ) have the same chemical composition as layers L1-L4 of the ovoid wall (Table 2). This geochemical correlation, taken together with the observation that both the islands and the wall are covered with a thin veneer of layer L5, suggests that these two domains were formed concomitantly as a single structure during the same geological event. Further support for this idea comes from the results of AFM imaging, which revealed that both the ovoid wall and the islands exhibit similar nanograined surfaces that show a distinct oriented fabric (Fig. 15), although the grains of the islands are about one order of magnitude smaller than those of the wall.

To explain the intriguing features summarized abovethe textural variability between the layers L1-L4 (despite their similar chemistry), the origin of the infilled fracture passing through these layers, the origin of layer L5, and the origin of the symmetrical (hourglass-shaped) overprinted fissure-a variety of scenarios can be invoked. Consequently, in the following section we evaluate several hypotheses surrounding the origin of this conspicuous ovoid structure within Nakhla.

\subsection{Abiotic formation scenarios for the origin of the ovoid structure in Nakhla}

Compelling evidence that the parent rock of Nakhla underwent a high-pressure and high-temperature event that caused highly localized and brief melting of some of its pyroxene rims is provided by their Al-rich composition. This is also supported by the discovery of the rhoenite crystal in Nakhla, which most likely represents a metastable phase that formed as a result of rapid cooling, similar to other known rhoenite occurrences in meteorites (Fuchs, 1971; Nazarov et al., 2000), as opposed to being a product of the breakdown of Kaersutite amphibole in Nakhla (Treiman, 1993). This geological event most likely occurred during a shock event associated with a bolide impact on Mars, which may have happened at $913 \pm 9 \mathrm{Ma}$, based on the timing of resetting of the ${ }^{40} \mathrm{Ar} /{ }^{39} \mathrm{Ar}$ isotopic system in Nakhla clinopyroxenes, as observed by Cassata et al. (2010). This shock event could have brecciated the parent rock of Nakhla, fractured its crystalline matrix, and possibly even resulted in the formation of the ovoid structure in Nakhla (i.e., as a vesicle during the quenching of its host mesostasis glass; see further discussion in Section 3.2.4.). A secondary effect of this bolide impact event might also have been to locally trigger a late hydrothermal system that would ultimately cause the first stage of alteration and/or mineral precipitation to take place. The fluids in this hydrothermal system may have migrated upward through the network of fractures in the Nakhla parent rock, where they could have become intermixed with the saline fluids present within the melted permafrost layer of the overlying sediments. This mixing of high-temperature magmatic fluids with comparatively cold saline permafrost waters would have resulted in a very rapid cooling of the hydrothermal system and may also be the reason for the low-temperature alteration of the nakhlites. The release of dissolved $\mathrm{CO}_{2}$ during this process would also act to change the overall conditions of the hydrothermal system to increasingly oxidizing. This is evident from the extensive presence of secondary minerals (i.e., serpentine, hematite, and siderite) derived from the alteration of the primary igneous minerals in Nakhla, observed within fractures in olivine phenocrysts and within the mesostasis. Variable degrees of drainage of the system would reduce the water/rock ratio in certain places and locally initiate evaporation processes and the associated deposition of late-stage evaporitic minerals such as sulfates and halides.

One recently proposed model scenario that also invokes mixing of fluid reservoirs resulting in the immediate deposition of carbonates was presented by Changela and Bridges (2011). Based on the precise sequence of alteration and mineral-formation events recorded within the nakhlites, these authors suggested that Nakhla was positioned at very shallow depths in the martian crust (i.e., about $10 \mathrm{~m}$ below the surface), where hydrothermal fluids were significantly less abundant (i.e., a low water/rock ratio prevailed) but nevertheless resulted in the deposition of a Fe-Mg-Al-rich hydrous silicate gel and siderite, accompanied by a very small amount of smectite/serpentine formation. Modeling studies of the nakhlites carried out by Bridges and Schwenzer (2012) also agree with the above scenario and go so far as to specify a temperature of about $100^{\circ} \mathrm{C}$ and an alkaline environment for this ancient hydrothermal system. The results of the present study of Nakhla, however, suggest that a larger range of temperatures could have been responsible for this hydrothermal alteration, albeit with temperature varying widely between different localities within the parent rock - and with different mixing ratios between the magmatic and saline (permafrost) fluid components. Numerical modeling results of impact-generated hydrothermal systems show that they can actually span a wide 
range of temperatures, may last a very long time, and can also produce a wide variety of secondary minerals (Abramov and Kring, 2005). Here, we propose a new model scenario that will serve as a basis for further discussion, which is characterized by the following sequence of geological events:

(i) An intense shock event took place in association with a bolide impact on Mars, which induced high pressures and temperatures causing partial melting of some of the rims of pyroxene grains in the Nakhla parent rock, potentially along with some of the other interstitial matter (i.e., the original felsic mesostasis). Immediately upon melting, the clinopyroxene rims recrystallized, absorbing additional Al from the mesostasis, and rhoenite formed, absorbing most of the Be. During the shock event, the parent rock of Nakhla became brecciated to variable degrees, and a hydrothermal system of magmatic origin was initiated, which eventually is mixed with permafrost fluids, and circulated throughout the newly formed system of fractures in the rock. This shock event might have locally remobilized the rhyolitic mesostasis into a glass and led to the formation of the ovoid by one of the following mechanisms: (a) trapping of a gas-filled vesicle within the glass and/or (b) at some point subsequent to the quenching of this glass, a system of perlitic concentric fractures (Giorgetti et al., 2006; Monecke et al., 2007) formed within it. Mixing of the mesostasis with permafrost fluids was due to the likely presence of $\mathrm{H}_{2} \mathrm{O}$ in the melt (constrained by the mapping of $\mathrm{OH}^{-}$ions in the mesostasis glass; see Fig. 9 and discussion in Section 3.3), which can drastically lower the glass transition temperatures (i.e., by a few hundred degrees Celsius, with only a few weight percent $\mathrm{H}_{2} \mathrm{O}$; see Table 2 in Giordano et al., 2005).

(ii) In this stage, precursor materials cooled more rapidly due to extensive mixing with permafrost fluids, and they solidified. Such a fluid-mixing model is supported by carbon and hydrogen isotopic data (summarized in Leshin and Vicenzi, 2006). Although we provide no clear evidence for fluid mixing in the present study, the mapped chlorine content (Fig. 6) in the mesostasis region (along with some of the other light elements, such as B and Li; Fig. 9) might be an indirect indicator of such a process; nevertheless, these elements could also have originated as part of a still not fully degassed magmatic fluid component (Meunier et al., 2012). It is possible that the vesicle actually formed at this stage due to the increased concentration of volatiles (i.e., not directly due to shock) and was followed right away by the complete formation of the entire ovoid structure and its claybearing matrix, either due to the clay alteration of vesicle walls, the increased hydration of the rhyolitic glass resulting in a perlitic system of fractures followed then by clay alteration, or possibly from another type of material, such as the alteration of a preexisting mineral phase that had already crystallized during the previous step (i.e., an olivine grain). Phosphate minerals (i.e., apatites) also appear to have quenched (grown rapidly as elongate needles and skeletal crystals) during stage i but probably occurred just prior to the quenching of the rhyolite glass, and this is because most apatites seem to be enveloped by this mesostasis glass (e.g., BSE image in Fig. 9). The degree of fluid mixing and associated hydrothermal alteration and precipitation of secondary phases likely varied between different localities within the Nakhla parent rock, such that during this stage, the system was probably not uniform or entirely open.

(iii) The first generation of Fe- and Mg-rich smectite clays was either deposited in the already-formed ovoid from magmatic fluids rich in $\mathrm{Fe}$ and $\mathrm{Mg}$ (and possibly $\mathrm{Si}, \mathrm{Al}$, and $\mathrm{K}$ ) during the early stages of the previous step (Meunier et al., 2012) or, alternatively, during the first stages of mixing of these magmatic fluids with infiltrating fluids from the melted permafrost. Permafrost fluids enriched in the most mobile elements (i.e., light elements and chlorine) might also have contributed to the composition of the mesostasis glass and of the ovoid. The textural variations between the main layers of the ovoid structure (i.e., L1-L4) might indicate either four consecutive (but ephemeral) episodes of clay-rich deposition of the ovoid wall from compositionally uniform fluids (i.e., partial space-filling of a vesicle from the wall inward) or, as an alternative scenario, by the alteration (i.e., overprinting) of preexisting interfaces (i.e., alteration of the vesicle wall outward into glass, overprinting of a hollow left behind by a dissolved-out mineral phase, or alteration of a system of circular perlitic fractures).

(iv) Episodic drainage of the rock system from hydrothermal fluids might have been the reason for dry periods just after the deposition of the first layers of the clay ovoid. A longer dry period might have been responsible for the shrinkage and fracturing of the ovoid wall (see shrinkage gap in Fig. 3) due to dehydration, which may also have caused the ovoid to acquire its red-orange hues (see Section 3.5).

(v) After this long dry period, a new influx of fluids of very low temperature and more oxidizing due to the higher contribution of permafrost waters might possibly have led to some corrosion of the ovoid structure followed by deposition of the fibrous layer L5 and its Fe-rich oxide/hydroxide phases. Oxidation of any sulfides present would also likely have taken place during this stage, which is evident from the low-temperature alteration of pyrrhotite to marcasite (Section 3.2.3). It also seems likely that at this point the fissure was formed as a crosscutting fracture orthogonal to the ovoid wall that could have acted as a drainage conduit for these fluids, which may have opened due to corrosion (or shrinkage during step iv), but was quickly infilled or overprinted (Fig. 3b) by the iron-rich material of layer L5. The presence of red-orange-colored fractures in the mesostasis that seem to have acted as conduits for this last fluid influx (see white arrows in Fig. 1c) supports such a scenario. The end of this stage would be marked by the eventual complete isolation of the ovoid structure from this late-stage, oxidizing, and low-temperature hydrothermal system (i.e., by infilling of the fissure and 

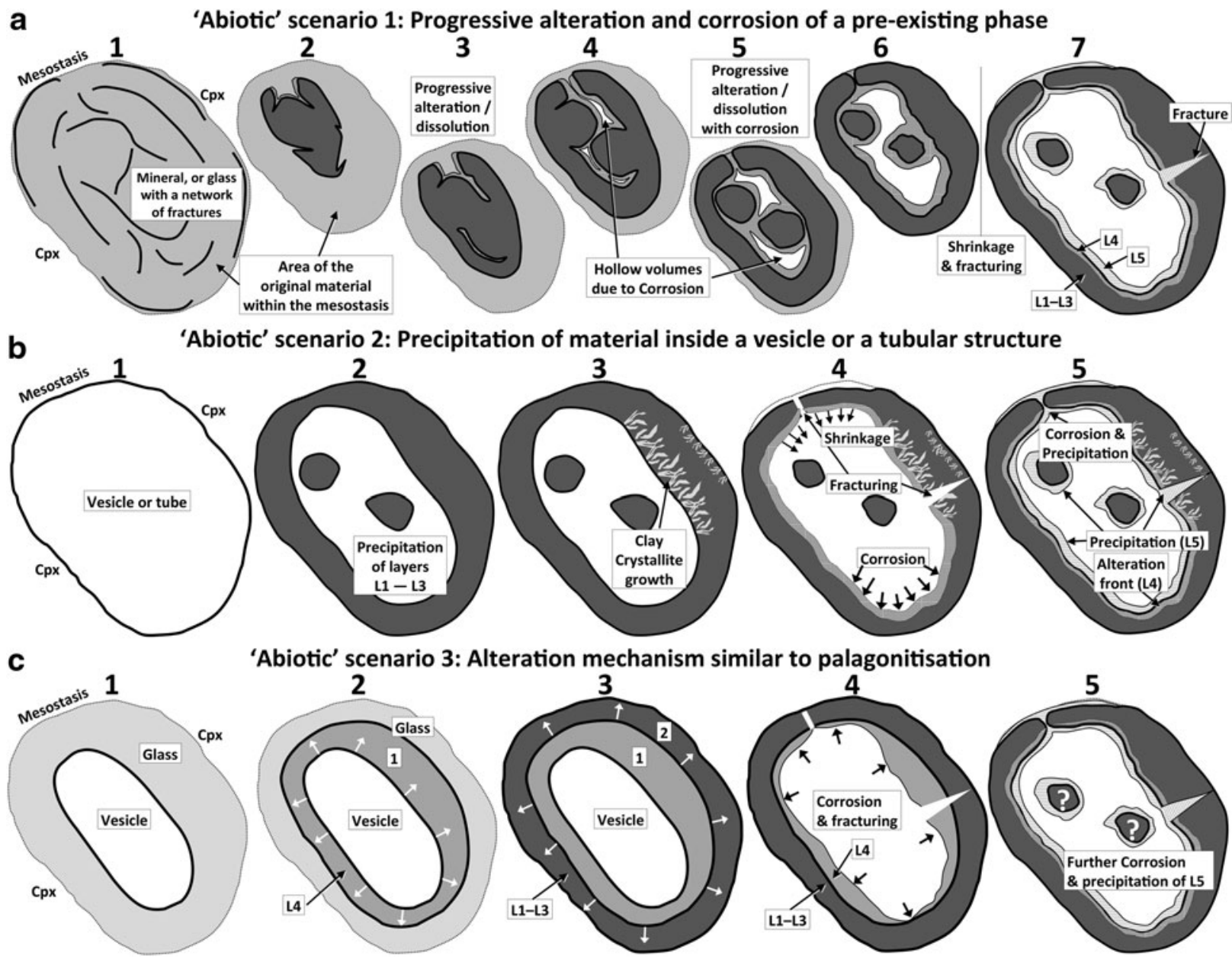

FIG. 16. Schematic diagrams illustrating three possible abiotic scenarios for the origin of the ovoid structure in Nakhla. (a) Formation of the ovoid structure by the complete alteration (replacement) of a preexisting phase (such as olivine or siderite, or alternatively, a set of perlitic fractures in the glass), followed by partial corrosion of the ovoid (forming hollows) and fracturing. (b) Formation of the ovoid structure by precipitation directly from solution, leading to the complete infilling of a preexisting vesicular or tubular hollow structure. (c) Formation of the ovoid structure through the progressive outward alteration of the glass surrounding a preexisting vesicle, by mechanisms similar to the palagonitization of basaltic glass.

the resultant closing off of the system to any further fluid influx).

(vi) In other locations within Nakhla, the hydrothermal system could still have remained active, resulting in the continued alteration of olivine and other mesostasis regions and the deposition of other secondary minerals such as serpentine, siderite, hematite, and carbonates. In areas where the water/rock ratio became substantially reduced, evaporation could have taken place, resulting in the precipitation of sulfates and halides.

Based on the above model scenario, three possible abiotic scenarios arise that explain in more detail the formation of the ovoid structure in Nakhla. These three scenarios are (1) the complete replacement of a preexisting mineral through fluid alteration (with or without dissolution) or the precipitation (i.e., space filling) of the void left behind by a previously dissolved mineral; (2) the infilling of a preexisting vesicle with secondary clay minerals (to form an amygdule); and (3) the concentric (i.e., outward) hydrothermal alter- ation of glass surrounding a preexisting vesicle (i.e., in a process similar to palagonitization of basaltic glass) that would have been linked to the hydrothermal system through connecting fractures. Schematic diagrams outlining these three proposed model scenarios for the formation of the conspicuous ovoid structure in Nakhla are presented in Fig. 16.

4.3.1. Abiotic formation scenario 1. Progressive alteration and corrosion of a preexisting phase. In this scenario, a preexisting mineral phase (i.e., initially present in the mesostasis before formation of the ovoid) undergoes hydrothermal alteration and is progressively replaced by secondary phases (including clay minerals) and partly corroded to leave behind the concentric ovoid wall structure and its internal hollow volume. In this abiotic scenario, we consider siderite and olivine to be the most likely precursor mineral phases to result in the formation of the ovoid structure after their complete alteration and partial corrosion. It is also possible that the ovoid formed simply by the alteration and corrosion of mesostasis glass; however, this scenario will be discussed later in the section on abiotic formation scenario 3 (Section 
4.3.3.) due to the similarity of that mechanism of glass alteration to the well-studied process of palagonitization. This first model scenario is summarized in a series of schematic illustrations in Fig. 16a. The first illustration in Fig. 16a (labeled 1) shows in light gray the entire area that is now occupied by the ovoid structure in the Nakhla mesostasis but was initially occupied by either a siderite grain, an olivine grain, or alternatively a network of perlitic fractures developed within the glass in that region, which, regardless of which of these three possibilities is considered, was hosted by the surrounding mesostasis glass and enveloped between two large clinopyroxene phenocrysts.

Carbonate minerals, especially the observed siderite in Nakhla, tend to form along fractures in corroded olivine grains, partially infilling them, and are thought to have precipitated from hydrothermal brines that released $\mathrm{CO}_{2}$ and metals into solution during the dissolution of olivine along these fractures. In the scenario we discuss here, however, we consider only the carbonate minerals that precipitate in the interstitial regions of Nakhla, such as the case of siderite grains reported by Chatzitheodoridis and Turner (1990), Bridges and Grady (1999), and Saxton et al. (2000). This scenario is in accordance with the model scenario of Changela and Bridges (2011), in which siderite appears to have been the first mineral to precipitate within olivine and possibly within the mesostasis, followed by phyllosilicates and ending with a thin layer of iron oxides/hydroxides. The precipitation of siderite in this model is first preceded by an influx of permafrost fluids rich in $\mathrm{CO}_{2}$, which lead to the formation of $\mathrm{HCO}_{3}^{-}$ions that would enter the hydrothermal system and cause the partial dissolution of both olivine and mesostasis regions, ultimately followed by siderite precipitation. Subsequent to this dissolution and siderite precipitation event, the hydrothermal fluids would become neutral due to the exhaustion of $\mathrm{CO}_{2}$ and then undergo a drop in temperature while still maintaining a capacity to transport the highly mobile lighter elements. These evolved fluids would then start altering pyrrhotite into marcasite and provide a mineralogical record indicating that by this point the hydrothermal system had now reached a low temperature (Fleet, 1978). In parallel to all this, the fluids might also have caused the complete alteration, replacement, and/or corrosion of the previously formed siderite grain (as there is no siderite currently present) and possibly dissolved some of the silicate gel mesostasis that was present, ultimately resulting in the formation of hollow void spaces in this region within Nakhla. During the process of dissolving some of the siderite and mesostasis glass, the chemistry of the hydrothermal fluids would change, acquiring $\mathrm{Fe}$ and $\mathrm{Mg}$ from siderite and $\mathrm{Si}, \mathrm{Al}$, and some $\mathrm{K}$ from the mesostasis glass, which might then be incorporated into the ovoid structure in the form of amorphous or fine-grained secondary silicate minerals, such as the Fe-rich clays of which the ovoid is composed (Fig. 16a, illustrations 2-6). After a shrinkage and fracturing event, occurring at a time between steps 6 and 7 of the sequence in Fig. 16a, a final step involving extensive corrosion through a new influx of fluids results in the formation of the final configuration of the ovoid structure and its hollow volume (Fig. 16a, illustration 7). This scenario requires an early, higher influx of permafrost fluids into the hydrothermal system, altering the rock and depositing siderite at a relatively early stage (i.e., step ii in Section 4.3), in between fractures of the brecciated Nakhla parent rock. This could be a valid scenario, especially if the mesostasis represents a late-stage hydrous silicate amorphous gel as suggested by Changela and Bridges (2011); however, textural information to support this claim is lacking here in the present example of the mesostasis containing the ovoid. Furthermore, the micron to submicron textural complexity of the ovoid structure is not easily explained in this case. Finally, the presence of crystalline clays might also suggest that Nakhla and Lafayette cannot be differentiated by their degree of alteration based on mineral assemblages, as inferred by these authors; nevertheless, it seems clear that all nakhlites have undergone localized alteration to varying degrees depending on their original location.

As opposed to a preexisting siderite grain, the complete dissolution and/or replacement of a preexisting olivine crystal also represents another plausible explanation for the origin and formation of the ovoid. Olivine is a mineral that is very susceptible to breakdown and replacement during hydrothermal alteration (Eggleton, 1984). Olivine will typically alter to serpentine; however, if the hydrothermal fluids carry additional silica and aluminum, the alteration of olivine may result in saponite formation instead (Delvigne et al., 1979), which might, for instance, take place during the concomitant dissolution of the adjacent felsic mesostasis. Iddingsite, which is a mixture of saponite clay and goethite, is also a common aqueous alteration product of olivine (e.g., Eggleton, 1984). Before final collapse upon dissolution, the structure of olivine can exhibit a boxwork texture (Delvigne et al., 1979) due to preferential corrosion along existing fractures of the olivine crystal (i.e., similar to the fracture system shown in illustration 1 in Fig. 16a), which to some degree might account for the peculiar morphology of the ovoid. However, we consider the idea that the original precursor mineral to the ovoid structure was an olivine grain (that has since been dissolved away and replaced) highly improbable, because near the ovoid, within the very same host mesostasis glass, we find pristine, unaltered olivine crystals, which are also much smaller in size than the ovoid structure.

4.3.2. Abiotic formation scenario 2. Precipitation of material inside a vesicle or a tubular structure. The second abiotic scenario (Fig. 16b) for the formation of the ovoid structure assumes the presence of a preexisting hollow volume within the mesostasis, such as a vesicle or a tubular structure (Fig. 16b, illustration 1). As already noted in Section 4.3, a vesicle can often be created from the shock due to an impact, within magmas supersaturated in volatiles that degas, or from gasses dissolved in the permafrost ice and released during melting. Tubular structures can result from extensive dissolution along fractures within rocks or by etch-tunneling (e.g., along defects in olivine; Tingle et al., 1992). Although it is possible that the shape of the ovoid is a reflection of a cross section through a tubular structure, it seems more likely that it instead represents a cross section through a vesicle (which started out as a vapor bubble). For the ovoid to have formed inside a preexisting vesicle within the rhyolitic mesostasis glass, the precursor chemical components of the ovoid would have to be either magmatic in origin (i.e., precipitate from residual magmaderived fluids, as is suggested by Meunier et al., 2012, for 
some Noachian clays on Mars) or, alternatively, allochthonous (i.e., originated elsewhere, and were hydrothermally transported from a certain distance). Allochthonous formation of secondary phases is quite common in terrestrial basaltic rocks in which the chemical components are transported to a different location from their source, where they finally precipitate as somewhat amorphous or cryptocrystalline clay phases, generally within pore spaces (Mulyanto and Stoops, 2003; Meunier, 2005). This type of direct precipitation of secondary materials geochemically sourced from another location, such that the chemistry of the final products reflects that of the original rock, is known as neoformation (Mulyanto and Stoops, 2003; Bristow and Milliken, 2011, and references therein). Illustration 2 in Fig. 16b shows in dark gray the layer of neoformed material (possibly coinciding with layers L1 to L3) precipitated around the interior wall of the vesiclepartially infilling it. Similarly, the islands of the ovoid (also shown in illustration 2 of Fig. 16b) might also have formed as a part of this same neoformed material, but in this case as more rounded colloform segregations in the central region of the vesicle. A pause in hydrothermal activity might have allowed time for the formation of clay crystallites (illustration 3 in Fig. 16b), followed later by shrinkage of the ovoid structure that induced fracturing (illustration 4 in Fig. 16b). Subsequently, a new influx of oxidizing, low-temperature, Fe-rich hydrothermal fluids might have initiated slight corrosion of the ovoid walls and allowed Fe oxides/oxyhydroxides to precipitate as layer L5 (illustration 5 in Fig. 16b). Thus, layer L4 might represent the alteration front during corrosion of the ovoid wall, with the overprinted fissure representing the extensive corrosion of an early-formed fracture that also acted as a conduit for fluid flow into and out of the ovoid structure (Fig. 3b), whereas the other fractures (observed to crosscut layers L1-L4; Fig. 11a) may have formed slightly later on and therefore are only infilled (possibly during the deposition of layer L5).

Typically, the hollow pore spaces in which new minerals crystallize are planar features such as fractures that result in the formation of veins or veinlets, but they can also be rounded, tubular, or more irregular (e.g., amoeboid) in shape, such as in the case of vesicles infilled with secondary minerals, which are known as amygdules in terrestrial volcanic rocks (Vernon, 2004). The somewhat hollow ovoid structure identified in the present study (Fig. 2) represents the first reported occurrence of such a large, rounded, hollow volume in Nakhla. This observation is important for understanding the alteration history of Nakhla, since water with a certain flow velocity and duration of flow is required to grow and stabilize these neoformed materials (Gooding, 1992), such as in the case of a cooling hydrothermal system. As outlined in the first abiotic scenario above, such apparent preexisting pore spaces may not necessarily have been vesicles or voids at all, but in that case, a preexisting mineral phase that has been fully replaced in situ by secondary phases during fluid alteration. Combining that idea, with this second abiotic scenario (i.e., infilling of a void space), the neogenesis of clay minerals could potentially also form pseudomorphs of a preexisting mineral that has already been completely dissolved out (Meunier, 2005), that is, as opposed to a vesicle. Nevertheless, in the case of Nakhla, it is possible that the original pore volume, within which the ovoid has formed, might have started out as a vesicle in the mesostasis glass and, therefore, may once have trapped some of the original martian magmatic volatiles, or even martian atmosphere that was dissolved in the permafrost water. If so, this would be a significant finding, because if another such vesicle occurrence is found completely intact in a martian meteorite, it might provide essential information on the magmatic volatiles of Mars and possibly even contain ancient (trapped) martian paleoatmosphere that could be directly analyzed here on Earth.

4.3.3. Abiotic formation scenario 3. An alteration mechanism similar to palagonitization. The palagonitization of volcanic glass is another alteration process that is known to form conspicuous microtextures, which in some cases exhibit spheroidal or elliptical structures (Thorseth et al., 1991; Stroncik and Schmincke, 2002; Drief and Schiffman, 2004; Cockell et al., 2009) that are morphologically relevant to evaluating the origin of the ovoid structure described here, especially when the palagonite grows as concentrically banded rinds around vesicle walls (e.g., see Figs. 11 and 14 in Walton and Schiffman, 2003; Fig. 1b in Drief and Schiffman, 2004; Fig. 7a in Walton, 2008; and Fig. 2 in Cockell et al., 2009). On Earth, palagonitization is known as an in situ alteration process; is generally thought to occur via microscale dissolution-precipitation mechanisms at very low temperatures during the hydration of basaltic glass (also known as sideromelane) by reaction with water (such as in submarine, subaerial, or near-surface hydrothermal environments); and commonly takes place along fractures in the glass, the outer surfaces of the glass shards (i.e., in hyaloclastites) or pillow lavas, and around vesicle walls. It typically results in the formation of a yellow-brown to orange-brown material (i.e., palagonite) that in its early stages of formation has a gel-like microstructure and appears smooth and isotropic (by transmitted light microscopy), or in more advanced stages of palagonitization appears fibrous and is composed of smectite that exhibits variable degrees of crystallinity (Allen et al., 1981; Jakobsson and Moore, 1986; Zhou and Fyfe, 1989; Stroncik and Schmincke, 2001, 2002).

Some of the larger-scale textural features of the ovoid in Nakhla are very similar to some palagonite occurrences around vesicles in terrestrial volcanic glasses, including overall size and shape (e.g., Fig. 2d, 2e in Cockell et al., 2009), concentrically zoned internal layering (e.g., Fig. 14 in Walton and Schiffman, 2003; Fig. 2c-2e in Cockell et al., 2009), presence of late radial fractures (e.g., Fig. 14 in Walton and Schiffman, 2003; Fig. 2d, 2e in Cockell et al., 2009), and rusty color (e.g., Fig. 11a in Walton and Schiffman, 2003; Fig. 7a in Walton, 2008). Furthermore, similarities also exist at the micro- and nanoscale. For example, according to Stroncik and Schmincke (2001), fibrous palagonite is a mixture of gel-palagonite and of crystallites that grow mainly perpendicular to the interfaces with glass or the gel-palagonite-similar in nature to the ovoid structure in Nakhla with respect to the fibrous layers L1 and L3 and to gel-like layers L2 and L4 (Fig. 11). However, the ovoid structure does not show the same gradual boundary between palagonite zones of differing evolutionary stage (Stroncik and Schmincke, 2001) but, rather, shows a layering structure defined by alternating crystalline and amorphous layers. Likewise, the boundary between layers L3 and L4 is notably quite sharp. The nanoscale similarities are stronger, 
however. For instance, in gel-like palagonite, spherical nanostructures that measure $20-60 \mathrm{~nm}$ in diameter are observed, which are considered to be the precursors of individual smectite grains (Eggleton and Keller, 1982; Zhou and Fyfe, 1989; Zhou et al., 1992); and similarly, the ovoid matrix material (especially layer L2-see lower half of Fig. 12a) also contains such tiny $(\leq 10 \mathrm{~nm})$ spherical nanostructures.

Chemically, palagonitization is an isovolumetric but not an isochemical process (Allen et al., 1981; Jercinovic et al., 1990), which involves no volume changes and no cracking apart from mass losses. Consequently, without changing the original volume of the glass that they replace, new minerals form, making palagonite a heterogeneous material composed primarily of clays (i.e., smectites such as montmorillonite and nontronite) but also variable amounts of other mineral constituents such as zeolites, carbonates, oxides, hydroxides, opal, and gypsum, among others (Allen et al., 1981; Stroncik and Schmincke, 2001, 2002). In comparison, the ovoid structure in Nakhla is composed primarily of smectite clays and smaller amounts of oxides/oxyhydroxides. Palagonitization is generally restricted to the lowtemperature aqueous alteration of basaltic glass. In contrast, however, the amorphous mesostasis in Nakhla (in which the ovoid structure is hosted) is actually a rhyolitic glass and contains a very low content of total iron oxide $(<2 \mathrm{wt} \%)$ and only a trace amount of magnesium oxide (see analyses M1, M2, and M3 in Table 1). If the ovoid in Nakhla is the end result of the alteration of the surrounding rhyolitic mesostasis glass (e.g., around a preexisting vesicle), it represents quite a drastic change in bulk geochemistry during the transformation into the iron- and magnesium-rich saponites that now compose the Nakhla ovoid ( $\sim 25 \mathrm{wt} \%$ of total $\mathrm{Fe}_{2} \mathrm{O}_{3}$ and 6-9 wt \% MgO; see analyses W1, W2, I1, and I2 in Table 2). However, in some instances, the palagonitization process can result in very large changes in bulk composition as the basaltic glass becomes altered [e.g., in one documented case over $60 \%$ weight loss (each) in $\mathrm{SiO}_{2}$, $\mathrm{Al}_{2} \mathrm{O}_{3}, \mathrm{MgO}, \mathrm{CaO}$, and $\mathrm{Na}_{2} \mathrm{O}$; Zhou and Fyfe, 1989]. Nevertheless, in the present case, it seems reasonable that the fluids circulating within the ovoid structure during its formation should have contained high concentrations of $\mathrm{Fe}$ and $\mathrm{Mg}$ during the replacement of significant volumes of glass as it transformed into Fe-rich clays that are also notably depleted in many other chemical components, especially during the formation of the iron oxide-rich layer L5. It was noted previously that, texturally, layer L5 appears to have been the last layer to form, as evidenced by the occurrence of this same Fe-rich material inside the fracture passing through layers L1-L4 of the ovoid wall (Fig. 14). Further evidence to support late formation of layer L5 comes from the observation that this layer also clearly passes through (i.e., infills or overprints) the overprinted fissure shown in Fig. 3b, which also crosscuts the ovoid wall. Especially in the case of the infilled fracture (Figs. 13d and 14), some of this textural evidence points to the precipitation of layer L5 directly from solution.

A sequence of events summarizing the formation of the ovoid structure in Nakhla through mechanisms similar to the palagonitization of vesicle walls in volcanic glass is illustrated in Fig. 16c (i.e., abiotic scenario 3). As outlined in Section 4.3.1, the ovoid might have formed through the development of a network of perlitic fractures within the mesostasis glass, that is, with or without the presence of a vesicle. Accordingly, in these abiotic scenarios (Fig. 16a, 16c), alteration of the glass is initiated either along preexisting perlitic fractures (scenario 1 ) or around the margins of a vesicle (scenario 3), in either case involving the hydrothermal depletion of some elements (i.e., $\mathrm{Si}, \mathrm{Al}$, and $\mathrm{K}$ ) and the concomitant enrichment in others (i.e., Fe and $\mathrm{Mg}$ ). Similarly, in either case (scenario 1 or 3 ) the alteration front progresses outward as it develops; that is, the opposite of scenario 2 in which the ovoid wall grows inward in a space-filling fashion (Fig. 16). In the later stages of scenario 1 , the isovolumetrically altered material (which may represent a series of intermediate alteration phases) starts to corrode, resulting in the formation of hollow volumes with shapes that are defined by the preexisting network of perlitic fractures. Eventually, corrosion progresses further until the layers L1L3 form the main matrix of the ovoid structure, with the growth of layer L4 possibly marking the cessation of chemical reactions between the alteration front and the hydrothermal fluids. Subsequently, a drying event takes placeprobably in combination with mechanical stress-which drains the ovoid system and creates a set of radial fractures/ fissures (i.e., Figs. $3 \mathrm{~b}$ and 11a). A new influx of fluids then further corrodes the ovoid structure, overprinting and infilling these fractures/fissures (i.e., Figs. 3b and 11a) and depositing the mottled, fibrous layer L5. A similar sequence of events is also invoked for the later stages of scenario 3 (i.e., starting with a vesicle instead of perlitic fractures); however, in this case it becomes more difficult to explain the presence of the islands inside the ovoid structure (Fig. 16c).

Although the term palagonitization is generally used to describe the aqueous alteration of basaltic glass, a similar alteration mechanism could be invoked for rhyolitic glasses. In this case, the geochemical conditions such as $\mathrm{pH}$ and temperature would define the rate of alteration, which is about an order of magnitude slower for rhyolitic glasses than for basaltic glasses (Wolff-Boenisch et al., 2004; Cockell et al., 2009). If the ovoid structure did form by the alteration of felsic glass, then the process might bear microtextural and chemical similarities with the alteration of feldspar discussed by Banfield and Eggleton (1990). Like feldspars, however, the felsic mesostasis glass of the ovoid does not contain adequate amounts of $\mathrm{Fe}$ and $\mathrm{Mg}$ to form smectites rich in these elements. Banfield and Eggleton (1990) suggested, however, that the excess Fe might be scavenged from the altering fluids, after having been released into solution during the breakdown of other Fe-rich minerals. The hydrothermal alteration of felsic glasses can proceed along fractures, such as the networks of circular and concentric fractures of perlitic texture that are common in felsic volcanic glasses (e.g., illustration 1 in Fig. 16a), and around vesicles interconnected with such fracture networks, as is observed in the low-temperature $\left(<150^{\circ} \mathrm{C}\right)$ hydrothermal alteration of dacitic glasses at the PACMANUS hydrothermal vent field, Manus Basin (Giorgetti et al., 2006; Monecke et al., 2007). In the PACMANUS hydrothermal vent field, the alteration includes dioctahedral smectite of the montmorillonite-beidellite series, in which $\mathrm{Mg}$ is supplied by the hydrothermal fluids and $\mathrm{Mg}$ abundance increases with increasing degree of alteration of glass. In a similar fashion, the $\mathrm{Fe}$ and $\mathrm{Mg}$ present in the ovoid matrix in Nakhla may have been supplied by the hydrothermal system that resulted in its formation and possibly through the 
conversion of smectite to illite. However, no metastable, primitive clays are observed in the PACMANUS alteration assemblages for which dissolution and precipitation processes are invoked (Giorgetti et al., 2006).

The palagonitization of basaltic glass is considered to be a viable process on Mars (Toulmin et al., 1977; Allen et al., 1981; Gooding, 1992). Allen et al. (1981) specifically suggested that hydrothermal palagonitization could take place down to depths of about $150 \mathrm{~m}$, and that after the initial quenching of magma with ground ice, further low-temperature alteration could continue for some time afterward through the interaction of subsurface waters with cooling volcanic material. Furthermore, Michalski et al. (2005) claimed that the poorly crystalline materials on Mars, which they have detected using the Thermal Emission Spectrometer (TES) instrument, might be palagonite.

\subsection{Could biological processes have formed the ovoid structure in Nakhla?}

One reason why we carried out this investigation into the origin of the ovoid structure in Nakhla is because the conspicuous rounded shape of the structure is somewhat reminiscent of a terrestrial cellular microorganism (Figs. 1 and 2). Despite the conspicuous shape and structure, the ovoid is very large, and martian microorganisms are expected to be chemotrophic and therefore probably very small $(<1 \mu \mathrm{m})$ in size (Westall et al., 2011). In the previous sections, we proposed three plausible abiotic scenarios for the origin of the ovoid structure. However, similar to Earth, early Mars would also have received all the required prebiotic molecules (i.e., the building blocks of life), from which, in the presence of the right minerals, water, energy from chemical reactions, environmental conditions, and time, life could have emerged (Westall et al., 2013). Nakhla has already yielded abundant evidence that some of these key conditions exist (or have existed) on Mars and therefore provides evidence for a protected subsurface environment on Mars that could potentially preserve evidence of microbial life. Consequently, in this section we consider the possibility that fractures and cavities in the Nakhla parent rock might once have hosted microbial life, especially given that, on Earth, a variety of redox reactions that take place in such environments are often mediated by microorganisms (Fisk and Giovannoni, 1999; Varnes et al., 2003). The potential that a microbial ecosystem may have developed in the martian subsurface seems increasingly plausible, and recent studies have identified some localities on Mars (e.g., McLaughlin Crater) that might preserve evidence of a deep biosphere associated with subsurface aquifers (Michalski et al., 2013). This potential is even higher after the recent discovery by the MSL Curiosity rover of an ancient lacustrine environment on Mars (at Yellowknife Bay, Gale Crater) that could represent an ancient habitable environment for chemolithoautotrophic microorganisms (Grotzinger et al., 2013). Parallel studies on past habitability and the search for traces of ancient life on Mars performed on analog martian (Noachian) environments (i.e., shallow water settings) show that volcanic sediments from the Early Archean Earth host, on the surfaces of mineral particles or in pore waters, very small $(<1 \mu \mathrm{m})$ silicified chemotrophic microorganisms, both in the form of colonies and biofilms (Westall et al., 2011).
From the evidence presented earlier, it is clear that at some point in the history of Nakhla an impact event brecciated the parent rock and initiated active hydrothermal fluids that operated along fractures created in the rock. These fractures may have provided suitable environments for supporting microbial life, as they represent an ecological niche that is situated away from the relatively harsh surface conditions on Mars, and this has been documented for several terrestrial analogs of potentially habitable martian subsurface environments (Hofmann and Farmer, 2000; Boston et al., 2001; Hofmann, 2008, and references therein). Similarly, examples of gas cavities or fractures that host microorganisms have also been documented in modern-day environments where hydrothermal fluids are active, such as in altered basaltic glass-bearing hyaloclastites in Iceland (Geptner et al., 2005). Relevant to our study is the case of fossilized microorganisms - most likely interpreted to be colonies of fungi-that have been found in association with minerals that are grown in deep fractures in the rock that precipitated from hydrothermal systems associated with impact structures, such as the $458 \mathrm{Ma}$ Lockne impact structure, Sweden (Ivarsson et al., 2013). In this case, the bacteria act as substrates onto which clay minerals and iron oxyhydroxides form, some of which resemble the ovoid structure described here, both in terms of morphology and mineralogical makeup, demonstrating that hydrothermal fossilization of microorganisms is possible in these environments (Geptner et al., 2005). Moreover, redox reactions often take place inside such tiny volumes (Geptner et al., 2005), which, along with the occurrence of certain types of mineral surfaces, might provide the organisms with the required energy for their metabolism (Fisk and Giovannoni, 1999; Varnes et al., 2003).

All the required chemicals necessary for autotrophic or chemolithotrophic microorganisms are available on Mars (Fisk and Giovannoni, 1999), such as $\mathrm{H}_{2}, \mathrm{CO}, \mathrm{CO}_{2}, \mathrm{CH}_{4}$, $\mathrm{Fe}^{2+}, \mathrm{Mn}^{2+}, \mathrm{H}_{2} \mathrm{~S}$, and $\mathrm{S}$ - chemicals likely to have also been available in the vicinity of the ovoid. It is also possible that the biologically mediated reduction of $\mathrm{FeS}$ by $\mathrm{H}_{2}$ that could potentially occur in this type of subsurface environment (i.e., $\mathrm{FeS}+\mathrm{H}_{2} \mathrm{~S} \rightarrow \mathrm{FeS}_{2}+\mathrm{H}_{2}$; Fisk and Giovannoni, 1999) seems to parallel the geochemical conversion of pyrrhotite to marcasite that we observed here. Inorganic compounds such as $\mathrm{H}_{2} \mathrm{O}, \mathrm{SO}_{2}, \mathrm{CO}_{2}$, and $\mathrm{O}_{2}$, as well as several simple organic compounds, have now been detected in the Rocknest eolian deposits (upon heating) by instruments on the MSL Curiosity rover (Leshin et al., 2013), increasing the likelihood that some other biologically important chemicals may also exist and be available for transport in hydrothermal fluids in the martian subsurface. Potassium is a common element in minerals, and it cannot be considered a biosignature; however, if other strong evidence for biological activity exists, a slight increase in potassium concentration at the glass-alteration interface in volcanic glasses (apparently affected by microbial alteration) can indicate the breakdown of microbial cells (Torsvik et al., 1998). In a similar fashion, K enrichment can also be a geochemical signature of biologically mediated illitization processes, which can occur at very low temperatures in comparison with abiotic illitization (Kim et al., 2004). Likewise, the detection of carbon in the ovoid structure (i.e., EFTEM map for $\mathrm{C}$ in Fig. 14) cannot be used to confirm the presence of indigenous carbon or identify any organic material. However, other studies of Nakhla have 
confirmed the presence of pre-terrestrial organic matter (Sephton et al., 2002) and determined that only a small part of it is attributed to terrestrial contamination (Glavin et al., 1999; Jull et al., 2000). In addition, reduced carbon has also been found in association with secondary phases within Nakhla (Gibson et al., 2006), including a possible kerogenlike material inside iddingsite (McKay et al., 2011).

Finally, because a process similar to palagonitization may have resulted in the formation of the ovoid in Nakhla (i.e., abiotic scenario 3; Fig. 16c), it is important to highlight that, in submarine glasses on Earth, there is increasing evidence that bacterial communities may actually cause the alteration of basaltic glasses (Thorseth et al., 1995; Torsvik et al., 1998; Cockell et al., 2009; Cavalazzi et al., 2011). Therefore, if subsurface palagonitization of volcanic glass is taking place on Mars, it will be important to fully understand this process, given that on Earth it is a process commonly associated with microbial activity (Thorseth et al., 1995; Torsvik et al., 1998; Cockell et al., 2009). Similarly, microbial activity is also considered to play an important role in the alteration of Si-rich minerals and glasses (Brehm et al., 2005; Herrera et al., 2008).

\section{Conclusions}

An unusual ovoid structure was discovered within the mesostasis of the martian meteorite Nakhla. Its conspicuous biomorphic-looking form (defined by an elliptically concentric wall of $\sim 5-10 \mu \mathrm{m}$ total thickness) invited interest and prompted a multidisciplinary investigation into the physical appearance, structure, chemical composition, mineralogy, and microtextural features of the ovoid. The ovoid structure is indigenous to the sample and is therefore of extraterrestrial origin (appears to have formed on Mars). It is situated within a hydrous, amorphous mesostasis matrix of rhyolitic composition (i.e., rhyolite glass) and exhibits sharp contacts with it. The main wall of the Nakhla ovoid studied here is composed of five main subparallel concentric layers (L1-L5) but reveals a high degree of internal textural complexity at the micron and submicron scale. The first four layers are chemically similar, exhibit varying degrees of crystallinity, and contain mixtures of amorphous and protocrystalline material, as well as tiny crystallites, the latter of which are identified as trioctahedral iron-rich clays (i.e., Fe-rich smectite). The last layer (L5) is Ferich and mineralogically heterogeneous at the submicron scale. It blankets the interior wall of the ovoid, partially infills a fracture that passes through layers L1-L4 of the ovoid wall, and also overprints a previously existing fissure that crosscut the ovoid wall, resulting in the formation of a symmetrical hourglass-shaped alteration zone observable by SEM. As such, this layer L5 was clearly deposited last. AFM topographic mapping of the exposed surfaces of the ovoid matrix also reveals the presence of nanograins that occur individually or in clusters, which exhibit evidence of an oriented fabric.

There is strong evidence that the Nakhla parent rock has undergone a shock event from a nearby bolide impact that resulted in localized melting, followed by rapid cooling and hydrothermal activity. This evidence includes (a) the presence of Al-rich and Si-depleted rims of clinopyroxene crystals (reported here for the first time) coupled with the failure of feldspar to form in the interstitial matter next to it and (b) the discovery of rhoenite, a rare mineral that forms at high temperatures (also reported to exist in Nakhla for the first time). After this heating event that caused partial melting, Nakhla underwent a wide range of sharp temperature gradients, during which hydrothermal activity took place. This hydrothermal system was initiated by the influx of magmatic fluids that possibly became intermixed with melted permafrost fluids, resulting in the late-stage formation of the mesostasis regions, before continuing to evolve until eventually the more saline permafrost fluids predominated and caused most of the known alteration in the nakhlites. The rhyolitic mesostasis glass is hydrous and enriched in light lithophile elements, which seem to be heterogeneously distributed between phases and within the volume of the mesostasis glass, probably as a result of rapid quenching during fluid mixing and the creation of sharp temperature gradients.

The consideration of possible biotic scenarios for the origin of the ovoid structure in Nakhla currently lacks any sort of compelling evidence. Therefore, based on the available data that we have obtained on the nature of this conspicuous ovoid structure in Nakhla, we conclude that the most reasonable explanation for its origin is that it formed through abiotic processes. A number of different abiotic scenarios were considered for the origin of the ovoid, and we presented three logical sequences of geological events that could have led to its formation. In one scenario, a previously existing mineral phase-or alternatively, a system of perlitic fractures-is hosted by the mesostasis glass and becomes progressively altered and corroded to the point of being completely overprinted by the secondary materials forming the ovoid structure. In the other two scenarios, a vesicle forms (or less likely a tubular structure) within the rhyolitic mesostasis, most likely through the degassing of volatiles (i.e., as a vapor bubble) prior to quenching of the glass. Then, in one of these two scenarios the vesicle essentially becomes infilled by the clay-bearing ovoid structure (i.e., involving a precipitation or space-filling process inward from the vesicle walls) —or alternatively, in the other scenario, infiltrating hydrothermal fluids cause the alteration of the glass surrounding the vesicle to take place (i.e., outward from the vesicle walls), resulting in the formation of a concentrically banded alteration rind around the vesicle, similar in nature to the palagonitization of vesicles in submarine basaltic glasses on Earth. Based on all the available scientific data and arguments, similarities with terrestrial examples, and the feasibility of these processes happening in the martian subsurface, we consider the second abiotic scenario (i.e., partial space-filling of a vesicle) to be the most reasonable explanation for the origin of the ovoid structure in Nakhla. Nevertheless, during the formation of the vesicle-shaped ovoid structure in both of the latter two scenarios outlined above, an episodic supply of rapidly cooling hydrothermal fluids probably resulted in the development of internal layering within the ovoid wall (layers L1-L4). Initially, magmatic fluids may have supplied the geochemical components during the formation of layers L1-L4, followed at a later stage by the influx of Fe-rich fluids and the formation of the Fe-rich layer L5 (with the Fe in these fluids derived from the dissolution of primary igneous minerals such as olivine elsewhere in the system). However, prior to the formation of layer L5 (but subsequent to the formation of layers L1-L4), radial fractures formed within the ovoid wall, accounting for some of the other complicated microtextures of the ovoid structure, (i.e., including a 
symmetrical, hourglass-shaped overprinted fissure and additional infilled fractures).

Some of the same mineral associations described in this work with respect to the composition of the ovoid structure in Nakhla have also recently been observed in sedimentary rocks on the surface of Mars based on analyses by the MSL Curiosity rover (i.e., the association of smectites, amorphous material, Fe oxides/hydroxides, and Fe sulfides; Vaniman et al., 2014). Martian meteorites can therefore provide valuable insights that are relevant to assisting current and future manned or robotic rover exploration missions on the surface of Mars. Furthermore, the evidence provided here on the composition and origin of the ovoid structure in Nakhla indicates that clays were also forming on Mars more recently than the Early Hesperian (i.e., during the Amazonian), which is a trend also reflected to some degree by recent MSL Curiosity rover results (Vaniman et al., 2014). Ultimately, the detailed microtextural, structural, mineralogical, and chemical investigation of martian meteorites provides a valuable tool for evaluating the biogenicity of possible microscopic morphological biosignatures identified during future astrobiology missions to Mars and provides a roadmap outlining the instruments with which they could be studied (Pullan et al., 2008). Furthermore, these studies may also be useful for assessing the possible habitability of the martian subsurface, both in the distant past and in the more recent geological history of Mars.

\section{Acknowledgments}

The authors would like to thank the Natural History Museum of London for providing the Nakhla thin section. Special thanks go to David Plant for assistance with analyses using the Cameca SX100 electron microprobe of the Williamson Research Centre at Manchester University. We would like to thank Professor Martin Lee at University of Glasgow for preparing the TEM slice and for a large amount of preliminary TEM work on the sample. Many thanks also go to Dr. Paul Wincott for his expert assistance in acquiring a large number of AFM maps, few of which are presented here. We would also like to thank Dr. Jason E. French, Dr. Frances Westall, and an unknown reviewer for their critical and detailed review of the manuscript. This work was supported by the Science and Technologies Facilities Council of the UK.

All data and images generated in this research programme are openly available through the University of Manchester Research Data Management Plan RDMP112. For access please apply to the authors.

\section{Author Disclosure Statement}

No competing financial interests exist.

\section{Abbreviations}

AFM, atomic force microscope.

BSE, backscattered electron.

EDX, energy-dispersive X-ray.

EFTEM, energy-filtered transmission electron microscope. FIB, focused ion beam.

HRTEM, high-resolution transmission electron microscope. MSL, Mars Science Laboratory.
SAED, selected area electron diffraction. SEM, scanning electron microscope.

TEM, transmission electron microscope.

TOF-SIMS, time-of-flight secondary ion mass spectrometer. WDX, wavelength-dispersive X-ray.

\section{References}

Abramov, O. and Kring, D.A. (2005) Impact-induced hydrothermal activity on early Mars. J Geophys Res 110, doi:10 .1029/2005JE002453.

Ahn, J.H. and Peacor, D.R. (1986) Transmission and analytical electron microscopy of the smectite-to-illite transition. Clays Clay Miner 34:165-179.

Allen, C.C., Gooding, J.L., Jercinovic, M., and Keil, K. (1981) Altered basaltic glass: a terrestrial analog to the soil of Mars. Icarus 45:347-369.

Allen, C.C., Jercinovic, M.J., See, T., and Keil, K. (1982) Experimental shock lithification of water-bearing rock powders. Geophys Res Lett 9:1013-1016.

Alt, J.C. and Mata, P. (2000) On the role of microbes in the alteration of submarine basaltic glass: a TEM study. Earth Planet Sci Lett 181:301-313.

Anan'ev, V.V. and Selyangin, O.B. (2011) Rhonite in molten inclusions from the olivine of allivalite nodules from Malyi Semyachik Volcano and basalts of Klyuchevskoi Volcano, Kamchatka. Journal of Volcanology and Seismology 5:335340.

April, R.H. (1981) Trioctahedral smectite and interstratified chlorite/smectite in Jurassic strata of the Connecticut Valley. Clays Clay Miner 29:31-39.

Arvidson, R.E., Poulet, F., Bibring, J.-P., Wolff, M., Gendrin, A., Morris, R.V., Freeman, J.J., Langevin, Y., Mangold, N., and Bellucci, G. (2005) Spectral reflectance and morphologic correlations in Eastern Terra Meridiani Mars. Science 307: 1591-1594.

Badaut, D., Besson, G., Decarreau, A., and Rautureau, R. (1985) Occurrence of a ferrous, trioctahedral smectite in recent sediments of Atlantis II Deep, Red Sea. Clay Miner 20:389-404.

Bailey, J.V., McKay, D.S., and Wentworth, S.J. (2003) Mn carbonates in the martian meteorite Nakhla: possible evidence of brine evaporation [abstract 2060]. In $34^{\text {th }}$ Lunar and Planetary Science Conference Abstracts, Lunar and Planetary Institute, Houston.

Bandfield, J.L. (2008) High-silica deposits of an aqueous origin in western Hellas Basin, Mars. Geophys Res Lett 35, doi:10.1029/2008GL033807.

Bandfield, J.L., Amador, E.S., and Thomas, N.H. (2013) Extensive hydrated silica materials in western Hellas Basin, Mars. Icarus 226:1489-1498.

Banfield, J.F. and Eggleton, R.A. (1990) Analytical transmission electron microscope studies of plagioclase, muscovite, and K-feldspar weathering. Clays Clay Miner 38:77-89.

Banfield, J.F., Moreau, J.W., Chan, C.S., Welch, S.A., and Little, B. (2001) Mineralogical biosignatures and the search for life on Mars. Astrobiology 1:447-465.

Bellucci, G., Helbert, J., Altieri, F., Reiss, D., Bibring, J.-P., van Gasselt, S., Hoffmann, H., Langevin, Y., Neukum, G., and Poulet, F. (2007) Evidence for enhanced hydration on the northern flank of Olympus Mons, Mars. Icarus 192:361377.

Bence, A.E., Papike, J.J., and Prewitt, C.T. (1970) Apollo 12 clinopyroxenes: chemical trends. Earth Planet Sci Lett 8: 393-399. 
Bersani, D., Lottici, P.P., and Montenero, A. (1999) MicroRaman investigation of iron oxide films and powders produced by sol-gel syntheses. J Raman Spectrosc 30:355360.

Bibring, J.-P., Langevin, Y., Poulet, F., Gendrin, A., Gondet, B., Berthé, M., Soufflot, A., Drossart, P., Combes, M., Bellucci, G., Moroz, V., Mangold, N., Schmitt, B., and the OMEGA Team. (2004) Perennial water ice identified in the south polar cap of Mars. Nature 428:627-630.

Bibring, J.-P., Langevin, Y., Gendrin, A., Gondet, B., Poulet, F., Berthe, M., Soufflot, A., Arvidson, R., Mangold, N., Mustard, J., Drossart, P., and the OMEGA Team. (2005) Mars surface diversity as revealed by the OMEGA/Mars Express observations. Science 307:1576-1581.

Bibring, J.-P., Langevin, Y., Mustard, J.F., Poulet, F., Arvidson, R., Gendrin, A., Gondet, B., Mangold, N., Pinet, P., Forget, F., and the OMEGA Team. (2006) Global mineralogical and aqueous Mars history derived from OMEGA/Mars Express data. Science 312:400-404.

Bibring, J.-P., Arvidson, R.E., Gendrin, A., Gondet, B., Langevin, Y., Le Mouelic, S., Mangold, N., Morris, R.V., Mustard, J.F., Poulet, F., Quantin, C., and Sotin, C. (2007) Coupled ferric oxides and sulfates on the martian surface. Science 317:1206-1210.

Bish, D.L., Blake, D.F., Vaniman, D.T., Chipera, S.J., Morris, R.V., Ming, D.W., Treiman, A.H., Sarrazin, P., Morrison, S.M., Downs, R.T., Achilles, C.N., Yen, A.S., Bristow, T.F., Crisp, J.A., Morookian, J.M., Farmer, J.D., Rampe, E.B., Stolper, E.M., Spanovich, N., and the MSL Science Team. (2013) X-ray diffraction results from Mars Science Laboratory: mineralogy of Rocknest at Gale Crater. Science 341, doi:10.1126/science.1238932.

Bishop, J.L., Dobrea, E.Z.N., McKeown, N.K., Parente, M., Ehlmann, B.L., Michalski, J.R., Milliken, R.E., Poulet, F., Swayze, G.A., Mustard, J.F., Murchie, S.L., and Bibring, J.-P. (2008) Phyllosilicate diversity and past aqueous activity revealed at Mawrth Vallis, Mars. Science 321:830-833.

Blake, D.F., Morris, R.V., Kocurek, G., Morrison, S.M., Downs, R.T., Bish, D., Ming, D.W., Edgett, K.S., Rubin, D., Goetz, W., Madsen, M.B., Sullivan, R., Gellert, R., Campbell, I., Treiman, A.H., McLennan, S.M., Yen, A.S., Grotzinger, J., Vaniman, D.T., Chipera, S.J., Achilles, C.N., Rampe, E.B., Sumner, D., Meslin, P.-Y., Maurice, S., Forni, O., Gasnault, O., Fisk, M., Schmidt, M., Mahaffy, P., Leshin, L.A., Glavin, D., Steele, A., Freissinet, C., Navarro-González, R., Yingst, R.A., Kah, L.C., Bridges, N., Lewis, K.W., Bristow, T.F., Farmer, J.D., Crisp, J.A., Stolper, E.M., Des Marais, D.J., Sarrazin, P., and the MSL Science Team. (2013) Curiosity at Gale Crater, Mars: characterization and analysis of the Rocknest sand shadow. Science 341, doi:10.1126/science .1239505 .

Boston, P.J., Spilde, M.N., Northup, D.E., Melim, L.A., Soroka, D.S., Kleina, L.G., Lavoie, K.H., Hose, L.D., Mallory, L.M., Dahm, C.N., Crossey, L.J., and Schelble, R.T. (2001) Cave biosignature suites: microbes, minerals, and Mars. Astrobiology 1:25-55.

Bottomley, D.J. and Clark, I.D. (2004) Potassium and boron codepletion in Canadian Shield brines: evidence for diagenetic interactions between marine brines and basin sediments. Chem Geol 203:225-236.

Bourdoiseau, J.-A., Jeannin, M., Rémazeilles, C., Sabot, R., and Refait, P. (2011) The transformation of mackinawite into greigite studied by Raman spectroscopy. J Raman Spectrosc 42:496-504.
Boynton, W.V., Feldman, W.C., Squyres, S.W., Prettyman, T.H., Brückner, J., Evans, L.G., Reedy, R.C., Starr, R., Arnold, J.R., Drake, D.M., Englert, P.A.J., Metzger, A.E., Mitrofanov, I., Trombka, J.I., d'Uston, C., Wänke, H., Gasnault, O., Hamara, D.K., Janes, D.M., Marcialis, R.L., Maurice, S., Mikheeva, I., Taylor, G.J., Tokar, R., and Shinohara, C. (2002) Distribution of hydrogen in the near surface of Mars: evidence for subsurface ice deposits. Science 297:81-85.

Boynton, W.V., Ming, D.W., Kounaves, S.P., Young, S.M.M., Arvidson, R.E., Hecht, M.H., Hoffman, J., Niles, P.B., Hamara, D.K., Quinn, R.C., Smith, P.H., Sutter, B., Catling, D.C., and Morris, R.V. (2009) Evidence for calcium carbonate at the Mars Phoenix landing site. Science 325:61-64.

Brehm, U., Gorbushina, A., and Mottershead, D. (2005) The role of microorganisms and biofilms in the breakdown and dissolution of quartz and glass. Palaeogeogr Palaeoclimatol Palaeoecol 219:117-129.

Breier, J.A., German, C.R., and White, S.N. (2009) Mineral phase analysis of deep-sea hydrothermal particulates by a Raman spectroscopy expert algorithm: toward autonomous in situ experimentation and exploration. Geochemistry, Geophysics, Geosystems 10, doi:10.1029/2008GC002314.

Bridges, J.C. and Grady, M.M. (1999) A halite-sideriteanhydrite-chlorapatite assemblage in Nakhla: mineralogical evidence for evaporites on Mars. Meteorit Planet Sci 34:407-415.

Bridges, J.C. and Grady, M.M. (2000) Evaporite mineral assemblages in the nakhlite (martian) meteorites. Earth Planet Sci Lett 176:267-279.

Bridges, J.C. and Hicks, L.J. (2011) Amorphous gel in the nakhlites: product of a rapidly cooled hydrothermal fluid [abstract 5262]. In 74 ${ }^{\text {th }}$ Annual Meeting of the Meteoritical Society, Meteorit Planet Sci 46(Supplement):A30.

Bridges, J.C. and Schwenzer, S.P. (2012) The nakhlite hydrothermal brine on Mars. Earth Planet Sci Lett 359-360:117123.

Bridges, J.C., Catling, D.C., Saxton, J.M., Swindle, T.D., Lyon, I.C., and Grady, M.M. (2001) Alteration assemblages in martian meteorites: implications for near-surface processes. Space Sci Rev 96:365-392.

Bristow, T.F. and Milliken, R.E. (2011) Terrestrial perspective on authigenic clay mineral production in ancient martian lakes. Clays Clay Miner 59:339-358.

Brown, A.J., Hook, S.J., Baldridge, A.M., Crowley, J.K., Bridges, N.T., Thomson, B.J., Marion, G.M., de Souza Filho, C.R., and Bishop, J.L. (2010) Hydrothermal formation of clay-carbonate alteration assemblages in the Nili Fossae region of Mars. Earth Planet Sci Lett 297:174-182.

Bunch, T.E. and Reid, A.M. (1975) The nakhlites part I: petrography and mineral chemistry. Meteoritics 10:303-315.

Burns, R.G. and Martinez, S.L. (1991) Mössbauer spectra of olivine-rich achondrites: evidence for preterrestrial redox reactions. In Proceedings of the $21^{\text {st }}$ Lunar and Planetary Science Conference, Lunar and Planetary Institute, Houston, pp 331-340.

Carter, J. and Poulet, F. (2012) Orbital identification of clays and carbonates in Gusev Crater. Icarus 219:250-253.

Carter, J., Poulet, F., Bibring, J.-P., and Murchie, S. (2010) Detection of hydrated silicates in crustal outcrops in the northern plains of Mars. Science 328:1682-1686.

Cassata, W.S., Shuster, D.L., Renne, P.R., and Weiss, B.P. (2010) Evidence for shock heating and constraints on martian surface temperatures revealed by ${ }^{40} \mathrm{Ar} /{ }^{39} \mathrm{Ar}$ thermochronometry of martian meteorites. Geochim Cosmochim Acta 74:6900-6920. 
Cavalazzi, B., Westall, F., Cady, S.L., Barbieri, R., and Foucher, F. (2011) Potential fossil endoliths in vesicular pillow basalt, Coral Patch Seamount, Eastern North Atlantic Ocean. Astrobiology 11:619-632.

Changela, H.G. and Bridges, J.C. (2011) Alteration assemblages in the nakhlites: variation with depth on Mars. Meteorit Planet Sci 45:1847-1867.

Chatzitheodoridis, E. (1990) A search for martian alteration products and atmospheric argon in the Nakhla meteorite. MSc thesis, Manchester University, Manchester, UK.

Chatzitheodoridis, E. and Turner, G. (1990) Secondary minerals in the Nakhla meteorite. Meteoritics 25:354.

Chatzitheodoridis, E., Lyon, I.C., and Vgenopoulos, A. (2005) Interactive geochemistry in the micro- and submicron scale: a visual software tool for ion map extraction, manipulation and analysis from TOF-SIMS spectra [poster]. In $4^{\text {th }}$ International Conference on Instrumental Methods of Analysis Modern Trends and Applications (IMA'05), Iraklion, Greece.

Chevrier, V., Lorand, J.-P., and Sautter, V. (2011) Sulfide petrology of four nakhlites: Northwest Africa 817, Northwest Africa 998, Nakhla and Governador Valadares. Meteorit Planet Sci 46:769-784.

Cockell, C.S., Olsson-Francis, K., Herrera, A., and Meunier, A. (2009) Alteration textures in terrestrial volcanic glass and the associated bacterial community. Geobiology 7:50-65.

Combe, J.-Ph., Le Mouélic, S., Sotin, C., Gendrin, A., Mustard, J.F., Le Deit, L., Launeau, P., Bibring, J.-P., Gondet, B., Langevin, Y., Pinet, P., and the OMEGA Science Team. (2008) Analysis of OMEGA/Mars Express data hyperspectral data using a Multiple-Endmember Linear Spectral Unmixing Model (MELSUM): methodology and first results. Planet Space Sci 56:951-975.

Deer, W.A., Howie, R.A., and Zussman, J. (1992) An Introduction to the Rock-Forming Minerals, $2^{\text {nd }}$ ed., Pearson Prentice Hall, Upper Saddle River, NJ.

Delvigne, J., Bisdom, E.B.A., Sleeman, J., and Stoops, G. (1979) Olivines: their pseudomorphs and secondary products. Pedologie XXIX:247-309.

Dohm, J.M., Baker, V.R., Boynton, W.V., Fairén, A.G., Ferris, J.C., Finch, M., Furfaro, R., Hare, T.M., Janes, D.M., Kargel, J.S., Karunatillake, S., Keller, J., Kerry, K., Kim, K.J., Komatsu, G., Mahaney, W.C., Schulze-Makuch, D., Marinangeli, L., Ori, G.G., Ruiz, J., and Wheelock, S.J. (2009) GRS evidence and the possibility of paleooceans on Mars. Planet Space Sci 57:664-684.

Drief, A. and Schiffman, P. (2004) Very low temperature alteration of sideromelane in hyaloclastites and hyalotuffs from Kilauea and Mauna Kea volcanoes: implications for the mechanism of palagonite formation. Clays Clay Miner 52: 623-635.

Eberl, D.D., Velde, B., and McCormick, T. (1993) Synthesis of illite-smectite from smectite at Earth surface temperatures and high pH. Clay Miner 28:49-60.

Eggleton, R.A. (1984) Formation of iddingsite rims on olivine: a transmission electron microscope study. Clays Clay Miner 32:1-11.

Eggleton, R.A. (1987) Noncrystalline Fe-Si-Al-oxyhydroxides. Clays Clay Miner 35:29-37.

Eggleton, R.A. and Keller, J. (1982) The palagonitization of limburgite glass-a TEM study. Neues Jahrbuch für Mineralogie Monatshefte 7:321-336.

Ehlmann, B.L., Mustard, J.F., Fassett, C.I., Schon, S.C., Head, J.W., III, Des Marais, D.J., Grant, J.A., and Murchie, S.L. (2008a) Clay minerals in delta deposits and organic preservation potential on Mars. Nat Geosci 1:355-358.

Ehlmann, B.L., Mustard, J.F., Murchie, S.L., Poulet, F., Bishop, J.L., Brown, A.J., Calvin, W.M., Clark, R.N., Des Marais, D.J., Milliken, R.E., Roach, L.H., Roush, T.L., Swayze, G.A., and Wray, J.J. (2008b) Orbital identification of carbonatebearing rocks on Mars. Science 322:1828-1832.

Ehlmann, B.L., Mustard, J.F., Swayze, G.A., Clark, R.N., Bishop, J.L., Poulet, F., Des Marais, D.J., Roach, L.H., Milliken, R.E., Wray, J.J., Barnouin-Jha, O., and Murchie, S.L. (2009) Identification of hydrated silicate minerals on Mars using MRO-CRISM: geologic context near Nili Fossae and implications for aqueous alteration. J Geophys Res 114, doi:10.1029/2009JE003339.

Ehlmann, B.L., Mustard, J.F., and Murchie, S.L. (2010) Geologic setting of serpentine deposits on Mars. Geophys Res Lett 37, doi:10.1029/2010GL042596.

Ehlmann, B.L., Mustard, J.F., Murchie, S.L., Bibring, J.-P., Meunier, A., Fraeman, A.A., and Langevin, Y. (2011) Subsurface water and clay mineral formation during the early history of Mars. Nature 479:53-60.

Engelhardt, W.v., Arndt, J., Pankau, H.-G., and Witzsche, A. (1989) Al-rich pyroxenes: metastable formation in supercooled lunar basaltic and terrestrial impact melts [abstract 1137]. In $20^{\text {th }}$ Lunar and Planetary Science Conference Abstracts, Lunar and Planetary Institute, Houston.

Eugster, O., Busemann, H., Lorenzetti, S., and Terribilini, D. (2002) Ejection ages from krypton-81-krypton-83 dating and pre-atmospheric sizes of martian meteorites. Meteorit Planet Sci 37:1345-1360.

Fairén, A.G., Schulze-Makuch, D., Rodríguez, A.P., Fink, W., Davila, A.F., Uceda, E.R., Furfaro, R., Amils, R., and McKay, C.P. (2009) Evidence for Amazonian acidic liquid water on Mars-a reinterpretation of MER mission results. Planet Space Sci 57:276-287.

Fairén, A.G., Chevrier, V., Abramov, O., Marzo, G.A., Gavin, P., Davila, A.F., Tornabene, L.L., Bishop, J.L., Roush, T.L., Gross, C., Kneissl, T., Uceda, E.R., Dohm, J.M., SchulzeMakuch, D., Rodríguez, J.A.P., Amils, R., and McKay, C.P. (2010) Noachian and more recent phyllosilicates in impact craters on Mars. Proc Natl Acad Sci USA 107:12095-12100.

Fishbaugh, K.E., Poulet, F., Chevrier, V., Langevin, Y., and Bibring, J.-P. (2007) On the origin of gypsum in the Mars north polar region. J Geophys Res 112, doi:10.1029/2006JE002862.

Fisk, M.R. and Giovannoni, S.J. (1999) Sources of nutrients and energy for a deep biosphere on Mars. J Geophys Res 104: $11805-11815$.

Fleet, M.E. (1978) The pyrrhotite-marcasite transformation. Can Mineral 16:31-35.

Formisano, V., Atreya, S., Encrenaz, T., Ignatiev, N., and Giuranna, M. (2004) Detection of methane in the atmosphere of Mars. Science 306:1758-1761.

France, L., Koepke, J., Ildefonse, B., Cichy, S.B., and Deschamps, F. (2010) Hydrous partial melting in the sheeted dike complex at fast spreading ridges: experimental and natural observations. Contrib Mineral Petrol 160:683-704.

Fritz, J., Artemieva, N., and Greshake, A. (2005) Ejection of martian meteorites. Meteorit Planet Sci 40:1393-1411.

Fuchs, L.H. (1971) Occurrence of wollastonite, rhönite, and andradite in the Allende meteorite. Am Mineral 56:20532068.

Ganapathy, R. and Anders, E. (1969) Ages of calcium-rich achondrites-II: Howardites, nakhlites, and the Angra dos Reis angrite. Geochim Cosmochim Acta 33:775-787. 
Geines, R.V., Skinner, H.C.W., Foord, E.E., Mason, B., and Rosenzweig, A. (1977) Dana's New Mineralogy, $8^{\text {th }}$ ed., John Wiley and Sons, New York.

Gendrin, A., Mangold, N., Bibring, J.-P., Langevin, Y., Gondet, B., Poulet, F., Bonello, G., Quantin, C., Mustard, J., Arvidson, R., and Lemouélic, S. (2005) Sulfates in martian layered terrains: the OMEGA/Mars Express view. Science 307:15871591.

Geptner, A.R., Ivanovskaya, T.A., and Pokrovskaya, E.V. (2005) Hydrothermal fossilization of microorganisms at the Earth's surface in Iceland. Lithology and Mineral Resources 40:505-520.

Gibson, E.K., Jr., McKay, D.S., Thomas-Keprta, K.L., Wentworth, S.J., Westall, F., Steele, A., Romanek, C.S., Bell, M.S., and Toporski, J. (2001) Life on Mars: evaluation of the evidence within martian meteorites ALH84001, Nakhla, and Shergotty. Precambrian Res 106:15-34.

Gibson, E.K., Jr., McKay, D.S., Clemett, S.J., Thomas-Keprta, K.L., Wentworth, S.J., Robert, F., Verchovsky, A.B., Wright, I.P., Pillinger, C.T., Rice, T., Van Leer, B., Meibom, A., Mostefaoui, S.M., Socki, R., and Le, L. (2006) Identification and analysis of carbon-bearing phases in the martian meteorite Nakhla. Proc SPIE 6309, doi:10.1117/12.690503.

Giordano, D., Nichols, A.R.L., and Dingwell, D.B. (2005) Glass transition temperatures of natural hydrous melts: a relationship with shear viscosity and implications for the welding process. Journal of Volcanology and Geothermal Research 142:105-118.

Giorgetti, G., Monecke, T., Kleeberg, R., and Hannington, M.D. (2006) Low-temperature hydrothermal alteration of silicic glass at the Pacmanus hydrothermal vent field, Manus Basin: an XRD, SEM and AEM-TEM study. Clays Clay Miner $54: 240-251$.

Glavin, D.P., Bada, J.L., Brinton, K.L.F., and McDonald, G.D. (1999) Amino acids in the martian meteorite Nakhla. Proc Natl Acad Sci USA 96:8835-8838.

Gooding, J.L. (1985) Clay minerals in meteorites: preliminary identification by analysis of goodness-of-fit to calculated structural formulas [abstract 1142]. In $16^{\text {th }}$ Lunar and Planetary Science Conference Abstracts, Lunar and Planetary Institute, Houston.

Gooding, J.L. (1992) Soil mineralogy and chemistry on Mars: possible clues from salts and clays in SNC meteorites. Icarus 99:28-41.

Gooding, J.L., Aggrey, K.E., and Muenow, D.W. (1990) Volatile compounds in shergottite and nakhlite meteorites. Meteoritics 25:281-289.

Gooding, J.L., Wentworth, S.J., and Zolensky, M.E. (1991) Aqueous alteration of the Nakhla meteorite. Meteoritics 26:135-143.

Grady, M.M., Wright, I.P., Douglas, C., and Pillinger, C.T. (1994) Carbon and nitrogen in ALH84001. Meteoritics 29: 469.

Grapes, R. and Keller, J. (2010) $\mathrm{Fe}^{2+}$-dominant rhönite in undersaturated alkaline basaltic rocks, Kaiserstuhl volcanic complex, Upper Rhine Graben, SW Germany. European Journal of Mineralogy 22:285-292.

Grapes, R.H., Wysoczanski, R.J., and Hoskin, P.W. (2003) Rhönite paragenesis in pyroxenite xenoliths, Mount Sidley Volcano, Marie Byrd Land, West Antarctica. Mineral Mag 67:639-651.

Grauch, R.I., Lindahl, I., Evans, H.T., Jr., Burt, D.M., Fitzpatrick, J.J., Foord, E.E., Graff P.-R., and Hysingjord, J. (1994) Høgtuvaite, a new beryllian member of the aenigmatite group from Norway, with new X-ray data on aenigmatite. Can Mineral 32:439-448.

Greenwood, J.P., Riciputi, L.R., Taylor, L.A., and McSween, H.Y. (1998) Hydrothermal modification of sulfides in Nakhla, Lafayette, and Chassigny. Meteorit Planet Sci 33:A62-A63. Greenwood, J.P., Riciputi, L.R., McSween, H.Y., and Taylor, L.A. (2000) Modified sulfur isotopic compositions of sulfides in the nakhlites and Chassigny. Geochim Cosmochim Acta 64:1121-1131.

Grotzinger, J.P., Sumner, D.Y., Kah, L.C., Stack, K., Gupta, S., Edgar, L., Rubin, D., Lewis, K., Schieber, J., Mangold, N., Milliken, R., Conrad, P.G., Des Marais, D., Farmer, J., Siebach, K., Calef, F., III, Hurowitz, J., McLennan, S.M., Ming, D., Vaniman, D., Crisp, J., Vasavada, A., Edgett, K.S., Malin, M., Blake, D., Gellert, R., Mahaffy, P., Wiens, R.C., Maurice, S., Grant, J.A., Wilson, S., Anderson, R.C., Beegle, L., Arvidson, R., Hallet, B., Sletten, R.S., Rice, M., Bell, J., III, Griffes, J., Ehlmann, B., Anderson, R.B., Bristow, T.F., Dietrich, W.E., Dromart, G., Eigenbrode, J., Fraeman, A., Hardgrove, C., Herkenhoff, K., Jandura, L., Kocurek, G., Lee, S., Leshin, L.A., Leveille, R., Limonadi, D., Maki, J., McCloskey, S., Meyer, M., Minitti, M., Newsom, H., Oehler, D., Okon, A., Palucis, M., Parker, T., Rowland, S., Schmidt, M., Squyres, S., Steele, A., Stolper, E., Summons, R., Treiman, A., Williams, R., Yingst, A., and the MSL Science Team. (2013) A habitable fluvio-lacustrine environment at Yellowknife Bay, Gale Crater, Mars. Science 343, doi:10 $.1126 /$ science. 1242777 .

Güven, N. (1988) Smectites. In Hydrous Phyllosilicates (Exclusive of Micas), Reviews in Mineralogy Vol. 19, edited by S.W. Bailey, Mineralogical Society of America, Washington, DC, pp 497-559.

Hagerty, J.J. and Newsom, H.E. (2003) Hydrothermal alteration at the Lonar Lake impact structure, India: implications for impact cratering on Mars. Meteorit Planet Sci 38:365-381.

Henkel, T., Tizard, J., Blagburn, D., and Lyon, I. (2006) Interstellar Dust Laser Explorer (IDLE): a new instrument for submicron analyses of stardust-quantification of laser SNMS. Appl Surf Sci 252:7117-7119.

Herrera, A., Cockell, C.S., Self, S., Blaxter, M., Reitner, J., Arp, G., Dröse, W., Thorsteinsson, T., and Tindle, A.G. (2008) Bacterial colonization and weathering of terrestrial obsidian in Iceland. Geomicrobiol J 25:25-37.

Hicks, L.J., Bridges, J.C., and Gurman, S.J. (2011) XANES and ferrous ferric ratios in the nakhlite secondary phases [abstract 5245]. In $74^{\text {th }}$ Annual Meeting of the Meteoritical Society, Meteorit Planet Sci 46(Supplement):A95.

Hofmann, B.A. (2008) Morphological biosignatures from subsurface environments: recognition on planetary missions. Space Sci Rev 135:245-254.

Hofmann, B.A. and Farmer, J.D. (2000) Filamentous fabrics in low-temperature mineral assemblages: are they fossil biomarkers? Implications for the search for a subsurface fossil record on the early Earth and Mars. Planet Space Sci 48:1077-1086.

Hope, G.A., Woods, R., and Munce, C.G. (2001) Raman microprobe mineral identification. Miner Eng 14:1565-1577.

Ivarsson, M., Broman, C., Sturkell, E., Ormö, J., Siljeström, S., van Zuilen, M., and Bengtson, S. (2013) Fungal colonization of an Ordovician impact-induced hydrothermal system. Sci Rep 3, doi:10.1038/srep03487.

Jakobsson, S.P. and Moore, J.G. (1986) Hydrothermal minerals and alteration rates at Surtsey Volcano, Iceland. Geol Soc Am Bull 97:648-659. 
James, J.F. (2011) A Student's Guide to Fourier Transforms, $3^{\text {rd }}$ ed., Cambridge University Press, New York.

Jercinovic, M.J., Keil, K., Smith, M.R., and Schmitt, R.A. (1990) Alteration of basaltic glasses from north-central British Columbia, Canada. Geochim Cosmochim Acta 54:2679-2696.

Johnston, A.D. and Stout, J.H. (1985) Compositional variation of naturally occurring rhoenite. Am Mineral 70:1211-1216.

Jongmans, A.G., van Oort, F., Denaix, L., and Jaunet A.M. (1999) Mineral micro- and nano-variability revealed by combined micromorphology and in situ submicroscopy. Catena 35:259-279.

Jull, A.J.T., Beck, J.W., and Burr, G.S. (2000) Isotopic evidence for extraterrestrial organic material in the martian meteorite, Nakhla. Geochim Cosmochim Acta 64:3763-3772.

Kim, J., Dong, H., Seabaugh, J., Newell, S.W., and Eberl, D.D. (2004) Roles of microbes in the smectite-to-illite reaction. Science 303:830-832.

Kohyama, N., Shimoda, S., and Sudo, T. (1973) Iron rich saponite (ferrous and ferric forms). Clays Clay Miner 21:229-237.

Korochantseva, E.V., Schwenzer, S.P., Buikin, A.I., Hopp, J., Ott, U., and Trieloff, M. (2011) ${ }^{40} \mathrm{Ar}-{ }^{39} \mathrm{Ar}$ and cosmic-ray exposure ages of nakhlites - Nakhla, Lafayette, Governador Valadaresand Chassigny. Meteorit Planet Sci 46:1397-1417.

Krasnopolsky, V.A., Maillard, J.-P., and Owen, T.C. (2004) Detection of methane in the martian atmosphere: evidence for life? Icarus 172:537-547.

Kuebler, K.E., Jolliff, B.L., Wang, A., and Haskin, L.A. (2006) Extracting olivine ( $\mathrm{Fo}-\mathrm{Fa}$ ) compositions from Raman spectral peak positions. Geochim Cosmochim Acta 70:6201-6222.

Kuehner, S.M. and Irving, A.J. (2007) Primary ferric iron-bearing rhönite in plutonic igneous Angrite NWA 4590: implications for redox conditions on the Angrite parent body [abstract P41A-0219]. In American Geophysical Union, Fall Meeting 2007, American Geophysical Union, Washington, DC.

Kunzmann, T. (1999) The aenigmatite-rhönite mineral group. European Journal of Mineralogy 11:743-756.

Lambert, P. (1987) SNC meteorites: the metamorphic record [abstract 1272]. In $18^{\text {th }}$ Lunar and Planetary Science Conference Abstracts, Lunar and Planetary Institute, Houston.

Langevin, Y., Poulet, F., Bibring, J.-P., and Gondet, B. (2005) Sulfates in the north polar region of Mars detected by OMEGA/Mars Express. Science 307:1584-1586.

Le Maitre, R.W., Streckeisen, A., Zanettin, B., Le Bas, M.J., Bonin, B., Bateman, P., Bellieni, G., Dudek, A., Efremova, S., Keller, J., Lamere, J., Sabine, P.A., Schmid, R., Sorensen, H., and Woolley, A.R. (2002) Igneous Rocks: A Classification and Glossary of Terms, Recommendations of the International Union of Geological Sciences, Subcommission of the Systematics of Igneous Rocks, Cambridge University Press, Cambridge.

Lee, M.R., Tomkinson, T., Mark, D.F., Stuart, F.M., and Smith, C.L. (2013) Evidence for silicate dissolution on Mars from the Nakhla meteorite. Meteorit Planet Sci 48:224-240.

Lentz, R.C.F., Taylor, G.J., and Treiman, A.H. (1999) Formation of a martian pyroxenite: a comparative study of the nakhlite meteorites and Theo's Flow. Meteorit Planet Sci 34:919-932.

Lentz, R.C.F., McSween, H.Y., Ryan, J., and Riciputi, L.R. (2001) Water in martian magmas: clues from light lithophile elements in shergottite and nakhlite pyroxenes. Geochim Cosmochim Acta 65:4551-4565.

Leshin, L.A. and Vicenzi, E. (2006) Aqueous processes recorded by martian meteorites: analyzing martian water on Earth. Elements 2:157-162.
Leshin, L.A., Epstein, S., and Stolper, E.M. (1996) Hydrogen isotope geochemistry of SNC meteorites. Geochim Cosmochim Acta 60:2635-2650.

Leshin, L.A., Mahaffy, P.R., Webster, C.R., Cabane, M., Coll, P., Conrad, P.G., Archer, P.D., Jr., Atreya, S.K., Brunner, A.E., Buch, A., Eigenbrode, J.L., Flesch, G.J., Franz, H.B., Freissinet, C., Glavin, D.P., McAdam, A.C., Miller, K.E., Ming, D.W., Morris, R.V., Navarro-González, R., Niles, P.B., Owen, T., Pepin, R.O., Squyres, S., Steele, A., Stern, J.C., Summons, R.E., Sumner, D.Y., Sutter, B., Szopa, C., Teinturier, S., Trainer, M.G., Wray, J.J., Grotzinger, J.P., and the MSL Science Team. (2013) Volatile, isotope, and organic analysis of martian fines with the Mars Curiosity Rover. Science 341, doi:10.1126/science.1238937.

Loizeau, D., Mangold, N., Poulet, F., Bibring, J.-P., Gendrin, A., Ansan, V., Gomez, C., Gondet, B., Langevin, Y., Masson, P., and Neukum, G. (2007) Phyllosilicates in the Mawrth Vallis region of Mars. J Geophys Res 112, doi:10.1029/ 2006JE002877.

Malin, M.C. and Edgett, K.S. (2003) Evidence for persistent flow and aqueous sedimentation on Early Mars. Science 302:1931-1934.

Mangold, N., Gendrin, A., Gondet, B., Lemouelic, S., Quantin, C., Ansan, V., Bibring, J.-P., Langevin, Y., Masson, P., and Neukum, G. (2008) Spectral and geological study of the sulfate-rich region of West Candor Chasma, Mars. Icarus 194:519-543.

Mann, S., Sparks, N.H.C., Frankel, R.B., Bazylinski, D.A., and Jannasch, H.W. (1990) Biomineralization of ferrimagnetic greigite $\left(\mathrm{Fe}_{3} \mathrm{~S}_{4}\right)$ and iron pyrite $\left(\mathrm{FeS}_{2}\right)$ in a magnetotactic bacterium. Nature 343:258-261.

Marzo, G.A., Roush, T.L., Lanza, N.L., McGuire, P.C., Newsom, H.E., Ollila, A.M., and Wiseman, S.M. (2009) Association of phyllosilicates and the inverted channel in Miyamoto Crater, Mars. Geophys Res Lett 36, doi: 10.1029/ 2009GL038703.

McCubbin, F.M., Smirnov, A., Nekvasil, H., Wang, J., Hauri, E., and Lindsley, D.H. (2010) Hydrous magmatism on Mars: a source of water for the surface and subsurface during the Amazonian. Earth Planet Sci Lett 292:132-138.

McKay, D.S., Gibson, E.K., Thomas-Keprta, K.L., Vali, H., Romanek, C.S., Clemett, S.J., Chillier, X.D.F., Maechling, C.R., and Zare, R.N. (1996) Search for past life on Mars: possible relic biogenic activity in martian meteorite ALH84001. Science 273:924-930.

McKay, D.S., Thomas-Keprta, K.L., Clemett, S.J., Gibson, E.K., Spencer, L., and Wentworth, S.J. (2009) Life on Mars: new evidence from martian meteorites. Proc SPIE 7441, doi:10.1117/12.832317.

McKay, D.S., Gibson, E.K., Thomas-Keprta, K.L., Clemett, S.J., Le, L., Rahman Z., and Wentworth, S.J. (2011) Nakhla: a martian meteorite with indigenous organic carbonaceous features [abstract 5051]. In $74^{\text {th }}$ Annual Meeting of the Meteoritical Society, Meteorit Planet Sci 46(Supplement):A154.

McSween, H.Y., Jr. and Treiman, A.H. (1998) Martian meteorites. In Planetary Materials, Reviews in Mineralogy Vol. 36, edited by J.J. Papike, Mineralogical Society of America, Washington, DC, pp 6.01-6.54.

Mernagh, T.P. and Trudu, A.G. (1993) A laser Raman microprobe study of some geologically important sulphide minerals. Chem Geol 103:113-127.

Meslin, P.-Y., Gasnault, O., Forni, O., Schröder, S., Cousin, A., Berger, G., Clegg, S.M., Lasue, J., Maurice, S., Sautter, V., 
Le Mouélic, S., Wiens, R.C., Fabre, C., Goetz, W., Bish, D., Mangold, N., Ehlmann, B., Lanza, N., Harri, A.-M., Anderson, R., Rampe, E., McConnochie, T.H., Pinet, P., Blaney, D., Léveillé, R., Archer, D., Barraclough, B., Bender, S., Blake, D., Blank, J.G., Bridges, N., Clark, B.C., DeFlores, L., Delapp, D., Dromart, G., Dyar, M.D., Fisk, M., Gondet, B., Grotzinger, J., Herkenhoff, K., Johnson, J., Lacour, J.-L., Langevin, Y., Leshin, L., Lewin, E., Madsen, M.B., Melikechi, N., Mezzacappa, A., Mischna, M.A., Moores, J.E., Newsom, H., Ollila, A., Perez, R., Renno, N., Sirven, J.-B., Tokar, R., de la Torre, M., d'Uston, L., Vaniman, D., Yingst, A., and the MSL Science Team. (2013) Soil diversity and hydration as observed by ChemCam at Gale Crater, Mars. Science 341, doi:10.1126/science.1238670.

Meunier, A. (2005) Clays, Springer, Berlin.

Meunier, A., Petit, S., Ehlmann, B.L., Dudoignon, P., Westall, F., Mas, A., El Albani, A., and Ferrage, E. (2012) Magmatic precipitation as a possible origin of Noachian clays on Mars. Nat Geosci 5:739-743.

Michalski, J.R. and Niles, P.B. (2010) Deep crustal carbonate rocks exposed by meteor impact on Mars. Nat Geosci 3:751-755.

Michalski, J.R., Kraft, M.D., Sharp, T.G., and Christensen, P.R. (2005) Palagonite-like alteration products on the Earth and Mars I: Spectroscopy (0.4-25 microns) of weathered basalts and silicate alteration products [abstract 1188]. In $36^{\text {th }}$ Lunar and Planetary Science Conference Abstracts, Lunar and Planetary Institute, Houston.

Michalski, J.R., Cuadros, J., Niles, P.B., Parnell, J., Rogers, A.D., and Wright, S.P. (2013) Groundwater activity on Mars and implications for a deep biosphere. Nat Geosci 6:133-138.

Milliken, R.E., Swayze, G.A., Arvidson, R.E., Bishop, J.L., Clark, R.N., Ehlmann, B.L., Green, R.O., Grotzinger, J.P., Morris, R.V., Murchie, S.L., Mustard, J.F., and Weitz, C. (2008) Opaline silica in young deposits on Mars. Geology $36: 847-850$

Monecke, T., Giorgetti, G., Scholtysek, O., Kleeberg, R., Götze, J., Hannington, M.D., and Petersen, S. (2007) Textural and mineralogical changes associated with the incipient hydrothermal alteration of glassy dacite at the submarine pacmanus hydrothermal system, eastern Manus Basin. Journal of Volcanology and Geothermal Research 160:23-41.

Morris, R.V., Ruff, S.W., Gellert, R., Ming, D.W., Arvidson, R.E., Clark, B.C., Golden, D.C., Siebach, K., Klingelhöfer, G., Schröder, C., Fleischer, I., Yen, A.S., and Squyres, S.W. (2010) Identification of carbonate-rich outcrops on Mars by the Spirit Rover. Science 329:421-424.

Mulyanto, B. and Stoops, G. (2003) Mineral neoformation in pore spaces during alteration and weathering of andesitic rocks in humid tropical Indonesia. Catena 54:385-391.

Mumma, M.J., Villanueva, G.L., Novak, R.E., Hewagama, T., Bonev, B.P., DiSanti, M.A., Mandell, A.M., and Smith, M.D. (2009) Strong release of methane on Mars in northern summer 2003. Science 323:1041-1045.

Mustard, J.F., Murchie, S.L., Pelkey, S.M., Ehlmann, B.L., Milliken, R.E., Grant, J.A., Bibring, J.-P., Poulet, F., Bishop, J., Dobrea, E.N., Roach, L., Seelos, F., Arvidson, R.E., Wiseman, S., Green, R., Hash, C., Humm, D., Malaret, E., McGovern, J.A., Seelos, K., Clancy, T., Clark, R., Des Marais, D., Izenberg, N., Knudson, A., Langevin, Y., Martin, T., McGuire, P., Morris, R., Robinson, M., Roush, T., Smith, M., Swayze, G., Taylor, H., Titus, T., and Wolff, M. (2008) Hydrated silicate minerals on Mars observed by the Mars Reconnaissance Orbiter CRISM instrument. Nature 454:305-309.
Nadeau, P.H. and Bain, D.C. (1986) Composition of some smectites and diagenetic illitic clays and implications for their origin. Clays Clay Miner 34:455-464.

Nazarov, M.A., Patchen, A., and Taylor, L.A. (2000) Rhonitebearing $\mathrm{Ca}, \mathrm{Al}$-rich inclusions of the Efremovka (CV3) chondrite [abstract 1242]. In $31^{\text {st }}$ Lunar and Planetary Science Conference Abstracts, Lunar and Planetary Institute, Houston.

Nédli, Z. and Tóth, T.M. (2003) Petrography and mineral chemistry of rhönite in ocelli of alkali basalt from Villány Mts, SW Hungary. Acta Mineralogica-Petrographica 44:51-56.

Orofino, V., Blanco, A., D'Elia, M., Licchelli, D., Fonti, S., and Marzo, G.A. (2010) Study of terrestrial fossils in phyllosilicate-rich soils: implication in the search for biosignatures on Mars. Icarus 208:202-206.

Papanastassiou, D.A. and Wasserberg, G.J. (1974) Evidence for late formation and young metamorphism in the achondrite Nakhla. Geophys Res Lett 1:23-26.

Perron, J.T., Mitrovica, J.X., Manga, M., Matsuyama, I., and Richards, M.A. (2007) Evidence for an ancient martian ocean in the topography of deformed shorelines. Nature 447:840-843.

Poulet, F., Bibring, J.-P., Mustard, J.F., Gendrin, A., Mangold, N., Langevin, Y., Arvidson, R.E., Gondet, B., Gomez, C., and the OMEGA Team. (2005) Phyllosilicates on Mars and implications for early martian climate. Nature 438:623-627.

Poulet, F., Mangold, N., Loizeau, D., Bibring, J.-P., Langevin, Y., Michalski, J., and Gondet, B. (2008a) Abundance of minerals in the phyllosilicate-rich units on Mars. Astron Astrophys 487:L41-L44.

Poulet, F., Arvidson, R.E., Gomez, C., Morris, R.V., Bibring, J.P., Langevin, Y., Gondet, B., and Griffes, J. (2008b) Mineralogy of Terra Meridiani and western Arabia Terra from OMEGA/MEX and implications for their formation. Icarus 195:106-130.

Pullan, D., Westall, F., Hofmann, B.A., Parnell, J., Cockell, C.S., Edwards, H.G.M., Jorge Villar, S.E., Schröder, C., Cressey, G., Marinangeli, L., Richter, L., and Klingelhöfer, G. (2008) Identification of morphological biosignatures in martian analogue field specimens using in situ planetary instrumentation. Astrobiology 8:119-156.

Reid, A.M. and Bunch, T.E. (1975) The nakhlites-part II: where, when, and how. Meteoritics 10:317-324.

Rice, M.S., Bell, J.F., III, Cloutis, E.A., Wang, A., Ruff, S.W., Craig, M.A., Bailey, D.T., Johnson, J.R., de Souza, P.A., and Farrand, W.H. (2010) Silica-rich deposits and hydrated minerals at Gusev Crater, Mars: vis-NIR spectral characterization and regional mapping. Icarus 205:375-395.

Rull, F., Martinez-Frias, J., Sansano, A., Medina, J., and Edwards, H.G.M. (2004) Comparative micro-Raman study of the Nakhla and Vaca Muerta meteorites. J Raman Spectrosc 35:497-503.

Saxton, J.M., Lyon, I.C., Chatzitheodoridis, E., and Turner, G. (2000) Oxygen isotopic composition of carbonate in the Nakhla meteorite: implications for the hydrosphere and atmosphere of Mars. Geochim Cosmochim Acta 64:1299-1309.

Schwenzer, S.P. and Bridges, J.C. (2011) The secondary mineral forming fluid in the nakhlites [abstract 5276]. In $74^{\text {th }}$ Annual Meeting of the Meteoritical Society, Meteorit Planet Sci 46(Supplement):A209.

Sephton, M.A., Wright, I.P., Gilmour, I., de Leeuw, J.W., Grady, M.M., and Pillinger, C.T. (2002) High molecular weight organic matter in martian meteorites. Planet Space Sci 50:711-716.

Seyfried, W.E., Jr., Janecky, D.R., and Mottl, M.J. (1984) Alteration of the oceanic crust: implications for geochemical 
cycles of lithium and boron. Geochim Cosmochim Acta 48:557-569.

Sharygin, V.V., Kóthay, K., Szabó, Cs., Timina, T.Ju., Török, K., Vapnik, Ye., and Kuzmin, D.V. (2011) Rhönite in alkali basalts: silicate melt inclusions in olivine phenocrysts. Russian Geology and Geophysics 52:1334-1352.

Smith, P.H., Tamppari, L.K., Arvidson, R.E., Bass, D., Blaney, D., Boynton, W.V., Carswell, A., Catling, D.C., Clark, B.C., Duck, T., DeJong, E., Fisher, D., Goetz, W., Gunnlaugsson, H.P., Hecht, M.H., Hipkin, V., Hoffman, J., Hviid, S.F., Keller, H.U., Kounaves, S.P., Lange, C.F., Lemmon, M.T., Madsen, M.B., Markiewicz, W.J., Marshall, J., McKay, C.P., Mellon, M.T., Ming, D.W., Morris, R.V., Pike, W.T., Renno, N., Staufer, U., Stoker, C., Taylor, P., Whiteway, J.A., and Zent, A.P. (2009) $\mathrm{H}_{2} \mathrm{O}$ at the Phoenix landing site. Science 325:58-61.

Solberg, T.C. and Burns, R.G. (1989) Iron Mossbauer spectral study of weathered Antarctic and SNC meteorites. In Proceedings of the $19^{\text {th }}$ Lunar and Planetary Science Conference, Lunar and Planetary Institute, Houston, pp 313-322.

Spivak-Birndorf, L.J., Wadhwa, M., and Williams, L.B. (2008) Boron isotopes in the nakhlites: implications for crustal fluids on Mars. In Goldschmidt Conference Abstracts, Geochim Cosmochim Acta 72:A889.

Squyres, S.W., Arvidson, R.E., Ruff, S., Gellert, R., Morris, R.V., Ming, D.W., Crumpler, L., Farmer, J.D., Des Marais, D.J., Yen, A., McLennan, S.M., Calvin, W., Bell, J.F., III, Clark, B.C., Wang, A., McCoy, T.J., Schmidt, M.E., and De Souza, P.A., Jr. (2008) Detection of silica-rich deposits on Mars. Science 320:1063-1067.

Stroncik, N.A. and Schmincke, H.-U. (2001) Evolution of palagonite: crystallization, chemical changes, and element budget. Geochemistry, Geophysics, Geosystems 2, doi:10.1029/ 2000GC000102.

Stroncik, N.A. and Schmincke, H.-U. (2002) Palagonite-a review. International Journal of Earth Sciences 91:680-697.

Swindle, T.D., Treiman, A.H., Lindstrom, D.J., Burkland, M.K., Cohen, B.A., Grier, J.A., Li, B., and Olson, E.K. (2000) Noble gases in iddingsite from the Lafayette meteorite: evidence for liquid water on Mars in the last few hundred million years. Meteorit Planet Sci 35:107-115.

Tazaki, K., Fyfe, W.S., and van der Gaast, S.J. (1989) Growth of clay minerals in natural and synthetic glasses. Clays Clay Miner 37:348-354.

Tazaki, K., Tiba, T., Aratani, M., and Miyachi, M. (1992) Structural water in volcanic glass. Clays Clay Miner 40:122127.

Thorseth, I.H., Furnes, H., and Tumyr, O. (1991) A textural and chemical study of Icelandic palagonite of varied composition and its bearing on the mechanisms of the glass-palagonite transformation. Geochim Cosmochim Acta 55:731-749.

Thorseth, I.H., Torsvik, T., Furnes, H., and Muehlenbachs, K. (1995) Microbes play an important role in the alteration of oceanic crust. Chem Geol 126:137-146.

Timina, T.Yu., Sharygin, V.V., and Golovin, A.V. (2006) Melt evolution during the crystallization of the Tergesh Pipe, Northern Minusinsk Depression. Geochemistry International 44:752-770.

Tingle, T.N., Roedder, E., and Green, H.W., II. (1992) Formation of fluid inclusions and etch tunnels in olivine at high pressure. Am Mineral 77:296-302.

Tomkinson, T., Lee, M.R., Mark, D.F., and Stuart, F. (2011) "Dogged" search of fresh Nakhla surfaces reveals new alteration textures [abstract 5464]. In $74^{\text {th }}$ Annual Meeting of the Meteoritical Society, Meteorit Planet Sci 46(Supplement):A236.

Torsvik, T., Furnes, H., Muehlenbachs, K., Thorseth, I.H., and Tumyr, O. (1998) Evidence for microbial activity at the glassalteration interface in oceanic basalts. Earth Planet Sci Lett 162:165-176.

Toulmin, P., III, Baird, A.K., Clark, B.C., Keil, K., Rose, H.J., Jr., Christian, R.P., Evans, P.H., and Kelliher, W.C. (1977) Geochemical and mineralogical interpretation of the Viking inorganic chemical results. J Geophys Res 82:4625-4634.

Treiman, A.H. (1993) The parent magma of the Nakhla (SNC) meteorite, inferred from magmatic inclusions. Geochim Cosmochim Acta 57:4753-4767.

Treiman, A.H. (2005) The nakhlite meteorites: augite-rich igneous rocks from Mars. Chem Erde 65:203-270.

Treiman, A.H. (2008) Rhönite in Luna 24 pyroxenes: first find from the Moon, and implications for volatiles in planetary magmas. Am Mineral 93:488-491.

Treiman, A.H. and Gooding, J.L. (1991) Iddingsite in the Nakhla meteorite-TEM study of mineralogy and texture of pre-terrestrial (martian?) alterations. In $54^{\text {th }}$ Annual Meeting of the Meteoritical Society, Meteoritics 26:402.

Vaniman, D.T., Bish, D.L., Ming, D.W., Bristow, T.F., Morris, R.V., Blake, D.F., Chipera, S.J., Morrison, S.M., Treiman, A.H., Rampe, E.B., Rice, M., Achilles, C.N., Grotzinger, J., McLennan, S.M., Williams, J., Bell, J., III, Newsom, H., Downs, R.T., Maurice, S., Sarrazin, P., Yen, A.S., Morookian, J.M., Farmer, J.D., Stack, K., Milliken, R.E., Ehlmann, B., Sumner, D.Y., Berger, G., Crisp, J.A., Hurowitz, J.A., Anderson, R., Des Marais, D., Stolper, E.M., Edgett, K.S., Gupta, S., Spanovich, N., and the MSL Science Team. (2014) Mineralogy of a mudstone at Yellowknife Bay, Gale Crater, Mars. Science 343, doi:10.1126/science.1243480.

Varnes, E.S., Jakosky, B.M., and McCollom, T.M. (2003) Biological potential of martian hydrothermal systems. Astrobiology 3:407-414.

Velde, B. (1985) Clay Minerals. A Physico-Chemical Explanation of Their Occurrence, Developments in Sedimentology Vol. 40, Elsevier, Amsterdam.

Vengosh, A., Starinsky, A., Kolodny, Y., and Chivas, A.R. (1991) Boron isotope geochemistry as a tracer for the evolution of brines and associated hot springs from the Dead Sea, Israel. Geochim Cosmochim Acta 55:1689-1695.

Vernon, R.H. (2004) A Practical Guide to Rock Microstructure, Cambridge University Press, Cambridge, UK.

Walton, A.W. (2008) Microtubules in basalt glass from Hawaii Scientific Drilling Project \#2 phase 1 core and Hilina slope, Hawaii: evidence of the occurrence and behavior of endolithic microorganisms. Geobiology 6:351-364.

Walton, A.W. and Schiffman, P. (2003) Alteration of hyaloclastites in the HSDP 2 Phase 1 Drill Core 1. Description and paragenesis. Geochemistry, Geophysics, Geosystems 4:1-31.

Wang, A., Jolliff, B.L., and Haskin, L.A. (1999) Raman spectroscopic characterization of a martian SNC meteorite: Zagami. J Geophys Res 104:8509-8519.

Warren, P.H., Huber, H., and Ulff-Møller, F. (2006) Alkalifeldspathic material entrained in $\mathrm{Fe}, \mathrm{S}$-rich veins in a monomict ureilite. Meteorit Planet Sci 41:797-813.

Weaver, C.E. and Pollard, L.D. (1973) The Chemistry of Clay Minerals, Developments in Sedimentology Vol. 15, Elsevier, Amsterdam.

Webster, C.R., Mahaffy, P.R., Atreya, S.K., Flesch, G.J., Farley, K.A., and the MSL Science Team. (2013) Low upper limit to methane abundance on Mars. Science 342: $355-357$. 
Wentworth, S.J. and Gooding, J.L. (1990) Pre-terrestrial origin of "rust" in the Nakhla meteorite. In Scientific Results of the NASA-Sponsored Study Project on Mars: Evolution of Volcanism, Tectonics, and Volatiles, Lunar and Planetary Institute, Houston, pp 298-299.

Westall, F., Foucher, F., Cavalazzi, B., de Vries S.T., Nijman, W., Pearson, V., Watson, J., Verchovsky, A., Wright, I., Rouzaud, J.-N., Marchesini, D., and Anne, S. (2011) Volcaniclastic habitats for early life on Earth and Mars: a case study from $\sim 3.5 \mathrm{Ga}$-old rocks from the Pilbara, Australia. Planet Space Sci 59:1093-1106.

Westall, F., Loizeau, D., Foucher, F., Bost, N., Betrand, M., Vago, J., and Kminek, G. (2013) Habitability on Mars from a microbiological point of view. Astrobiology 13:887-897.

White, S.N. (2009) Laser Raman spectroscopy as a technique for identification of seafloor hydrothermal and cold seep minerals. Chem Geol 259:240-252.

Williams, R.M.E., Grotzinger, J.P., Dietrich, W.E., Gupta, S., Sumner, D.Y., Wiens, R.C., Mangold, N., Malin, M.C., Edgett, K.S., Maurice, S., Forni, O., Gasnault, O., Ollila, A., Newsom, H.E., Dromart, G., Palucis, M.C., Yingst, R.A., Anderson, R.B., Herkenhoff, K.E., Le Mouélic, S., Goetz, W., Madsen, M.B., Koefoed, A., Jensen, J.K., Bridges, J.C., Schwenzer, S.P., Lewis, K.W., Stack, K.M., Rubin, D., Kah, L.C., Bell, J.F., III, Farmer, J.D., Sullivan, R., Van Beek, T., Blaney, D.L., Pariser, O., Deen, R.G., and the MSL Science Team. (2013) Martian fluvial conglomerates at Gale Crater. Science 340:1068-1072.

Wolff-Boenisch, D., Gislason, S.R., Oelkers, E.H., and Putnis, C.V. (2004) The dissolution rates of natural glasses as a function of their composition at $\mathrm{pH} 4$ and 10.6, and temperatures from 25 to $74^{\circ} \mathrm{C}$. Geochim Cosmochim Acta $68: 4843-4858$.
Wray, J.J., Dobrea, E.Z.N., Arvidson, R.E., Wiseman, S.M., Squyres, S.W., McEwen, A.S., Mustard, J.F., and Murchie, S.L. (2009a) Phyllosilicates and sulfates at Endeavour Crater, Meridiani Planum, Mars. Geophys Res Lett 36:L21201.

Wray, J.J., Murchie, S.L., Squyres, S.W., Seelos, F.P., and Tornabene, L.L. (2009b) Diverse aqueous environments on ancient Mars revealed in the southern highlands. Geology 37:1043-1046.

Zahnle, K., Freedman, R.S., and Catling, D.C. (2011) Is there methane on Mars? Icarus 212:493-503.

Zhang, G., Dong, H., Kim, J., and Eberl, D.D. (2007) Microbial reduction of structured $\mathrm{Fe}^{3+}$ in the nontronite by a thermophilic bacterium and its role in promoting the smectite to illite reaction. Am Mineral 92:1411-1419.

Zhou, Z. and Fyfe, W.S. (1989) Palagonitization of basaltic glass from DSDP Site 335, Leg 37: textures, chemical composition, and mechanism of formation. Am Mineral 74:1045-1053.

Zhou, Z., Fyfe, W.S., Tazaki, K., and Van Der Gasst, S.J. (1992) The structural characteristics of palagonite from DSDP SITE 335. Can Mineral 30:75-81.

Address correspondence to: Elias Chatzitheodoridis

9 Heroon Polytechneiou str. GR-15780 Zografou Athens

Greece

E-mail: eliasch@metal.ntua.gr

Submitted 13 July 2013 Accepted 19 May 2014

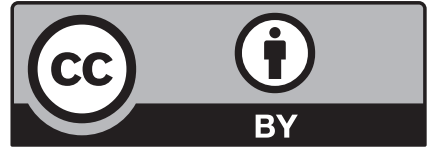

This work is licensed under a Creative Commons Attribution 3.0 United States License. You are free to copy, distribute, transmit and adapt this work, but you must attribute this work as "Astrobiology. Copyright 2014 Mary Ann Liebert, Inc. http://liebertpub.com/ast, used under a Creative Commons Attribution License: http:// creativecommons.org/licenses/by/3.0/us/" 